\title{
Squad-Level Soldier-Robot Dynamics: Exploring Future Concepts Involving Intelligent Autonomous Robots
}

\author{
by Clifford C Swiecicki, Linda R Elliott, and Robert Wooldridge
}

ARL-TR-7215

February 2015 


\section{NOTICES}

\section{Disclaimers}

The findings in this report are not to be construed as an official Department of the Army position unless so designated by other authorized documents.

Citation of manufacturer's or trade names does not constitute an official endorsement or approval of the use thereof.

Destroy this report when it is no longer needed. Do not return it to the originator. 


\title{
Army Research Laboratory
}

Aberdeen Proving Ground, MD 21005-5425

\section{Squad-Level Soldier-Robot Dynamics: Exploring Future Concepts Involving Intelligent Autonomous Robots}

\author{
Clifford C Swiecicki, Linda R Elliott, and Robert Wooldridge
} Human Research and Engineering Directorate, ARL 


\section{REPORT DOCUMENTATION PAGE}

Form Approved OMB No. 0704-0188

Public reporting burden for this collection of information is estimated to average 1 hour per response, including the time for reviewing instructions, searching existing data sources, gathering and maintaining the data needed, and completing and reviewing the collection information. Send comments regarding this burden estimate or any other aspect of this collection of information, including suggestions for reducing the burden, to Department of Defense, Washington Headquarters Services, Directorate for Information Operations and Reports (0704-0188), 1215 Jefferson Davis Highway, Suite 1204, Arlington, VA 22202-4302. Respondents should be aware that notwithstanding any other provision of law, no person shall be subject to any penalty for failing to comply with a collection of information if it does not display a currently valid OMB control number.

PLEASE DO NOT RETURN YOUR FORM TO THE ABOVE ADDRESS.

\begin{tabular}{|l|l|l|l}
\hline 1. REPORT DATE (DD-MM-YYYY) & 2. REPORT TYPE & 3. DATES COVERED (From - To)
\end{tabular}

\begin{tabular}{l|l} 
February 2015 & Final
\end{tabular}

4. TITLE AND SUBTITLE

Squad-Level Soldier-Robot Dynamics: Exploring Future Concepts Involving

Intelligent Autonomous Robots

September 2013-September 2014

5a. CONTRACT NUMBER

5b. GRANT NUMBER

5c. PROGRAM ELEMENT NUMBER

6. AUTHOR(S)

Clifford C Swiecicki, Linda R Elliott, and Robert Wooldridge

5d. PROJECT NUMBER

5e. TASK NUMBER

5f. WORK UNIT NUMBER

7. PERFORMING ORGANIZATION NAME(S) AND ADDRESS(ES)

8. PERFORMING ORGANIZATION

REPORT NUMBER

US Army Research Laboratory

ATTN: RDRL-HRM-DJ

ARL-TR-7215

Aberdeen Proving Ground, MD 21005-5425

9. SPONSORING/MONITORING AGENCY NAME(S) AND ADDRESS(ES)

10. SPONSOR/MONITOR'S ACRONYM(S)

11. SPONSOR/MONITOR'S REPORT

NUMBER(S)

\section{DISTRIBUTION/AVAILABILITY STATEMENT}

Approved for public release; distribution is unlimited

\section{SUPPLEMENTARY NOTES}

\section{ABSTRACT}

This report describes the development, application, and results obtained from scenario-based structured interview items designed to support the concept development of autonomous and intelligent robot capabilities with a Soldier squad. Results will be used to validate and inform scenario development within a simulation platform. Eighteen Soldiers participated in these interviews and provided detailed feedback with regard to information and capability requirements, priorities of use, and recommendations for robot roles and responsibilities. The results are summarized in the report and detailed in appendixes sorted by topic area and Soldier group.

\section{SUBJECT TERMS}

Soldier-robot concepts, cognitive task interviews, autonomous squad member, Army ground robotics, future Army robotics

\begin{tabular}{|l|l|l|c|c|l|}
\hline \multicolumn{2}{|l|}{ 16. SECURITY CLASSIFICATION OF: } & $\begin{array}{c}\text { 17. LIMITATION } \\
\text { OF ABSTRACT }\end{array}$ & $\begin{array}{l}\text { 18. NUMBER } \\
\text { OF PAGES }\end{array}$ & $\begin{array}{l}\text { 19a. NAME OF RESPONSIBLE PERSON } \\
\text { Linda R Elliott }\end{array}$ \\
\cline { 1 - 1 } $\begin{array}{l}\text { a. REPORT } \\
\text { Unclassified }\end{array}$ & $\begin{array}{l}\text { b. ABSTRACT } \\
\text { Unclassified }\end{array}$ & $\begin{array}{l}\text { c. THIS PAGE } \\
\text { Unclassified }\end{array}$ & UU & 152 & $\begin{array}{l}\text { 19b. TELEPHONE NUMBER (Include area code) } \\
706-545-5493\end{array}$ \\
\hline
\end{tabular}




\section{Contents}

List of Tables $\quad$ v

Acknowledgments $\quad$ vi

$\begin{array}{lr}\text { 1. Introduction } & 1\end{array}$

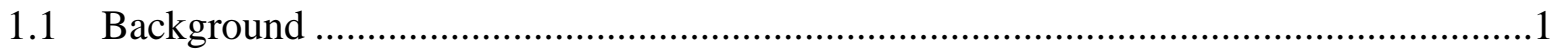

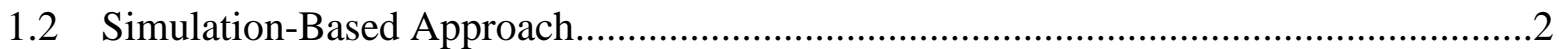

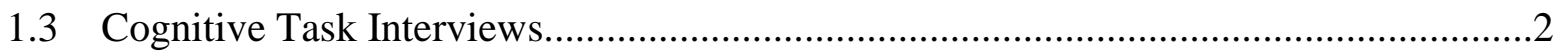

2. Method 4

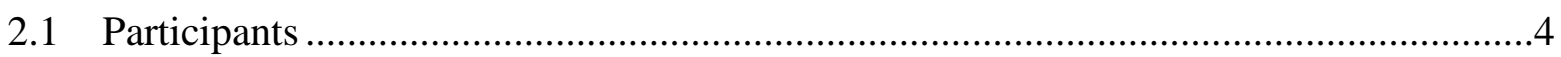

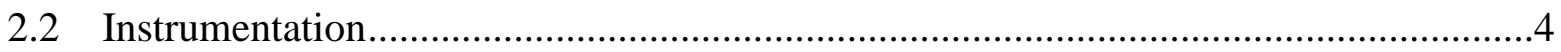

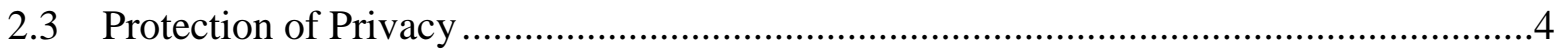

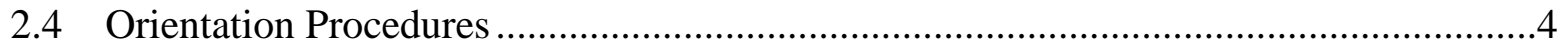

2.5 Structured Focus Interviews ...............................................................................

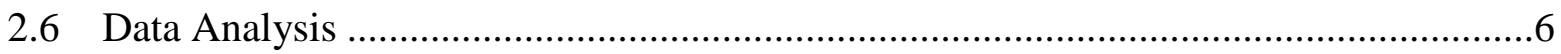

3. Results $\quad 6$

P.1 Phase I: Junior Enlisted Soldiers ..................................................................6

3.1.1 Demographics Questionnaire ...............................................................6

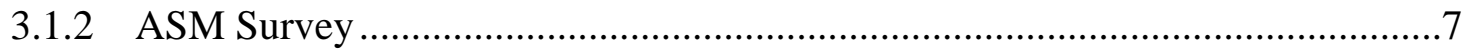

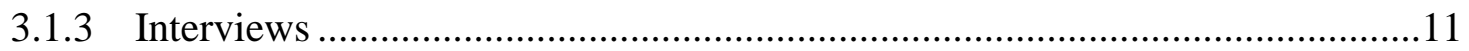

3.2 Phase II: Senior Enlisted Soldiers ...............................................................16

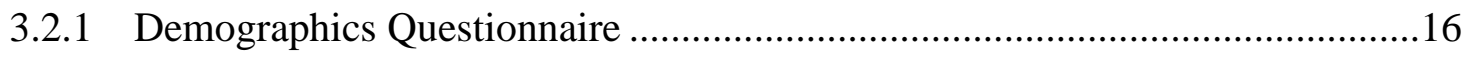

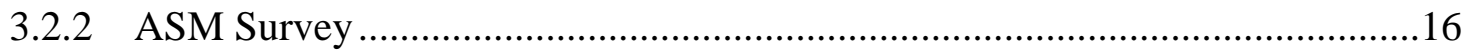

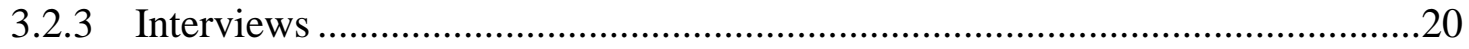

4. Conclusions and Recommendations 25

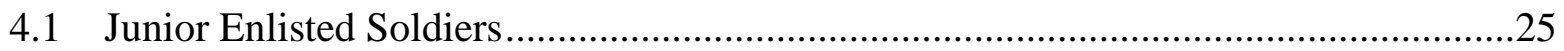

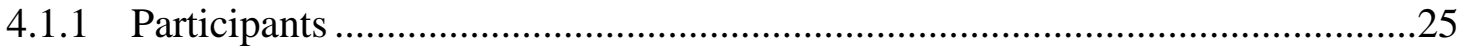

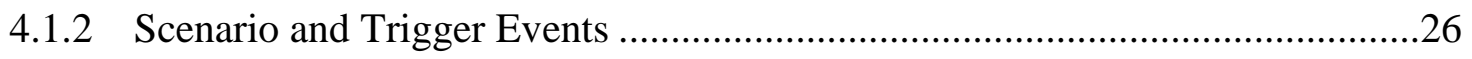

4.1.3 ASM Concept, Design, and Capabilities......................................................26 


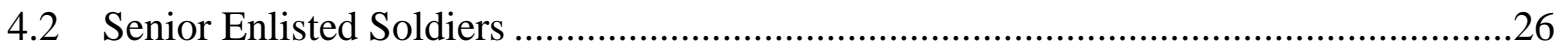

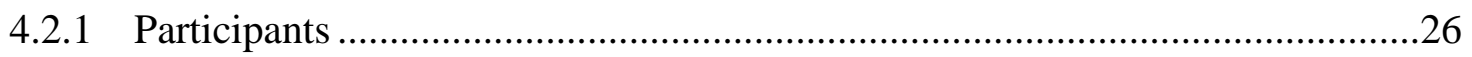

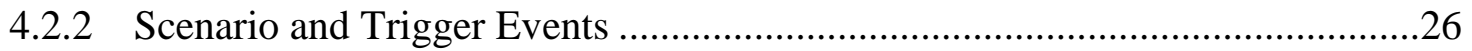

4.2.3 ASM Concept, Design, and Capabilities.................................................27

4.3 Overall Comments and Observations...................................................................27

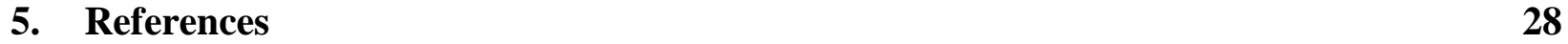

$\begin{array}{ll}\text { Appendix A. Informed Consent Form } & 31\end{array}$

Appendix B. Demographics: Junior Enlisted Soldiers 37

Appendix C. Survey Results: Junior Enlisted Soldiers 43

$\begin{array}{ll}\text { Appendix D. Interview Results: Junior Enlisted Soldiers } & 79\end{array}$

Appendix E. Demographics: Senior Noncommissioned Officers 99

Appendix F. Survey Results: Senior Noncommissioned Officers 103

Appendix G. Interview Results: Senior Noncommissioned Officers 125

$\begin{array}{ll}\text { List of Symbols, Abbreviations, and Acronyms } & 141\end{array}$

$\begin{array}{ll}\text { Distribution List } & 142\end{array}$ 


\section{List of Tables}

Table 1 Trigger event 1: mortar attack, junior enlisted .....................................................8

Table 2 Trigger event 2: receive sniper fire, junior enlisted .................................................8

Table 3 Trigger event 3: encounter an obstacle and maneuver around it, junior enlisted ............8

Table 4 Trigger event 4: detect an IED, junior enlisted......................................................9

Table 5 Trigger event 5: ambush, junior enlisted ................................................................9

Table 6 Trigger event 6: civilian vehicle or personnel approach position, junior enlisted............9

Table 7 Trigger event 7: loss of forward line of sight, junior enlisted ...................................10

Table 8 Necessary and nice-to-have priorities, junior enlisted.............................................11

Table 9 Mission-oriented and task-related items, junior enlisted ............................................15

Table 10 Trigger event 1: mortar attack, senior NCOs........................................................17

Table 11 Trigger event 2: receive sniper fire, senior NCOs .................................................18

Table 12 Trigger event 3: encounter an obstacle and maneuver around it, senior NCOs ...........18

Table 13 Trigger event 4: detect an IED, senior NCOs ........................................................18

Table 14 Trigger event 5: ambush, senior NCOs ..............................................................19

Table 15 Trigger event 6: civilian vehicle or personnel approach position, senior NCOs ..........19

Table 16 Trigger event 7: loss of forward line of sight, senior NCOs.....................................19

Table 17 Necessary and nice-to-have priorities, senior NCOs ...............................................21

Table 18 Mission-oriented and task-related items, senior NCOs ...........................................24 


\section{Acknowledgments}

The authors would like to thank and acknowledge the contributions of the project managers supporting the effort described in this report: Jessie Chen (US Army Research Laboratory/Human Research and Engineering Directorate), and Mary Ann Fields (US Army Research Laboratory/Vehicle Technology Directorate) with reference to multiyear investigations of human-robot interaction. We are particularly indebted to the Soldiers who participated readily and steadily throughout this event. Their expert perspective provides great insight about how to best integrate and possibly design an intelligent autonomous robot for augmentation of the squad as discussed in this report 


\section{Introduction}

\subsection{Background}

The US Army has had rapid acquisition and successful incorporation of robots into its ranks (Axe 2008). The contribution of robots to Army operations is evidenced by their widespread use, with many thousands of assets deployed for diverse combat missions—such as collecting reconnaissance information, supporting logistics (e.g., carrying materiel), executing combat operations, protecting personnel, and retrieving the combat wounded (Axe 2008; Doare et al. 2014). The variety of ground robotic platforms used for military missions is diverse, ranging from the size of a remote control bulldozer (e.g., Armored Combat Engineer Robot), to platforms that can be held and thrown (Price 2013). Their effectiveness has made robotic assets ubiquitous and even more diverse. Their contributions in the context of explosive ordnance disposal missions have saved the lives of numerous soldiers (Singer 2009). There is no doubt that robotics use in general, and the military in particular, will become nearly ubiquitous, allowing Soldiers to easily see, hear, touch, and/or manipulate objects from a distance.

While the future is full of promise, the widespread prevalence and increasing variety of these robotic assets create a major challenge to robot operators, who must learn to manage a spectrum of assets. There is a corresponding challenge to human factors specialists to design human-robot interactions that are simpler and easy to use (National Research Council 2005; Barnes and Jentsch 2010). This is particularly crucial to the Warfighters who must use these systems while maintaining awareness of their surroundings (Barnes and Evans 2010). Progress has been made with regard to more intuitive displays and controls for robot telepresence (Elliott et al. 2012) and increasing levels of autonomy to lower operator workload (Pettitt et al. 2012; Chen and Barnes 2013).

While progress has been made with regard to current human-robot interactions, robotic assets are evolving to become more autonomous and intelligent. For example, much progress has been made with regard to mobility (e.g., robot can follow user-supplied waypoints without effortful teleoperation) (Pettitt et al. 2012). As another example, iRobot has developed a larger (250 lb) version of the Packbot for military use that is capable of running a 4-min mile for $5 \mathrm{~h}$ while carrying $100 \mathrm{lb}$, able to fit through a doorway and climb stairs, and has USB ports to accommodate advanced sensors and intelligent software (Singe 2009). Given these increases in complexity and capabilities, designers, more than ever, must strive to understand how Warfighters think and their potential reactions to the new robotic technology, especially when decisions are many and must be made quickly (Redden et al. 2013). 
Thus, robots are steadily evolving from tools to more intelligent entities. Future concepts include the transition from robots as tools to robots that can play a more intelligent and autonomous role within a squad. This includes cognitive concepts such that the robot would be, to some degree, be better able to "see” (e.g., scan and recognize objects), "think” (e.g., recognize implications and decide on a best course of action), and consequently, “act” (Barnes et al. 2014). Ultimately, the goal is to develop robots that can be expected to interact with Soldiers, executing tactical actions as planned, yet able to act autonomously, or suggest changes in plans, when the situation requires it. The Joint Forces Command, in its 2025 plans, envisioned forces that were largely robotic, such that a detachment might include 150 Soldiers and as many as 2,000 robots (Singer 2009). Robots will be considered in conjunction with their partners, much as military working dogs are considered as a working unit with their handlers. Indeed, current and future scenarios include dyads and triads that integrate military working dogs, robotic assets, and human "handlers" (Ackerman 2014).

At this time, developers need to consider not only capabilities per se but also the usability from the operator point of view. While usability is often assumed to be ease of use, much more information is needed to develop capabilities that are operationally relevant. In this report, we describe and execute an approach to support the concept development of future robotic assets.

\subsection{Simulation-Based Approach}

Given these future capabilities, how can we predict which capabilities are most useful to the squad? Questions arise with regard to what the future robot would do, what events and tasks would be most operationally relevant, and what would be the appropriate level of robot autonomy within a command structure. In addition, we need to explore and identify potential problems early in the development process.

While these advanced robotic concepts (e.g., ability to see, interpret, and make decisions) do not currently exist, they can be modeled within simulation-based scenarios. Consequently, simulation-based scenarios are being developed to explore issues of Soldier-robot dynamics. However, the effectiveness of these simulations depends heavily on the degree to which simulation scenarios reflect realistic events, such that scenario events, procedures, and tactics are consistent with actual combat situations. Our approach to validation of simulation scenario events and elicitation of Soldier feedback (e.g., identification of issues, concerns, information requirements) is described in the following sections.

\subsection{Cognitive Task Interviews}

This report describes the development of structured interview and questionnaire items designed to explore these issues, inform scenario development, and validate scenario events with regard to operational tactics. Cognitive task analysis techniques are commonly used to investigate and improve behavior and decision making in the workplace (Schraagen et al. 2009). There are many interview-based approaches to cognitive task analysis (Crandall et al. 2006; Hoffman 2007; 
Hoffman and Militello 2009), and while specific approaches and strategies differ, the underlying goal is understanding of work in context - that is, the investigation of work demands and expertise through the lens of the experienced operator.

Knowledge elicitation techniques are a proven means to incorporate expert-based judgments early in the development and design of emerging technology (Hoffman 2008). These techniques were applied to identify how best to design and use wearable flexible displays in military operations (Hoffman and Elliott 2010). In that effort, experienced Army captains, recently back from Iraq, participated in in-depth $(1.5 \mathrm{~h})$ scenario-based interviews. First, a tactical scenario involving cordon and search (a typical tactical operation) was developed and validated through subject matter experts. The scenario comprised many single events, where information may be processed, decisions made, and/or actions taken. At each event, the Soldier would be asked to comment about the event, with regard to operational relevance, information requirements, tactical options, and/or decisions. The resulting data, organized by event and by issue, served to inform developers how to tailor the display to user requirements and concerns.

In this effort, we started with a scenario that was already developed to investigate events of particular interest to developers of advanced robotic capabilities. These events were initially refined to reflect current military tactics, techniques and procedures. Interview questions were developed, using the scenario-based approach, to gain detailed feedback from Soldiers with regard to operational relevance, information requirements, tactical options, and decision processes - particularly with regard to how the Soldier would use an advanced robotic platform during each event. This serves to not only validate and refine the scenario of interest but also to inform the developers of robotic cognition and decision making with regard to formulation of a semantic understanding of a tactical situation. This approach to knowledge elicitation has overlapping goals similar to heuristic (e.g., usability) evaluations performed by a set of "users" with regard to an interface. However, with the scenario-based envisioning approach, the experts are not using a device per se, to look for usability problems. Instead, they are asked to consider in detail, mission events as they unfold, in order to capture experience-based feedback with regard to questions such as "what information would you need now", "what is likely to go wrong”, "what would you do next”, etc.

Developers of the simulation and artificial intelligence programs were also part of this process. First, they were asked to communicate particular issues they would like to include as interview topics. After items were drafted, they were distributed to developers and other project stakeholders to ensure their concerns were included. This resulted in the final content of the questionnaires and interview items. 


\section{Method}

\subsection{Participants}

The voluntary, fully informed consent of the participants was obtained. All participants read and signed an Informed Consent Form. Participants did not receive any compensation for participating in this investigation. The investigation was conducted in 2 phases. In Phase I, 12 junior enlisted Soldiers were recruited for the experimentally based assessment. In Phase II, 6 senior noncommissioned officers (NCOs) were recruited for the assessment.

\subsection{Instrumentation}

Instrumentation consisted of 2 questionnaires (demographics and mission tasks) and items developed for a structured interview.

\subsection{Protection of Privacy}

Each participant was assigned a roster number for data collection purposes. The roster number was used on all questionnaires to ensure privacy, in lieu of names or other personal identifying information. The roster number was only associated with the participant name on the informed consent document. The informed consent documents were the only documents with privacy act information and accordingly, are secured in a locked file cabinet for at least 3 years. Data obtained during the questionnaire and interview periods are stored separate from documents containing personal information. All data and information obtained was considered privileged and held in confidence. Any photographic or video images taken of the participants during the study did not identify any of their personal information (name, rank, or status).

\subsection{Orientation Procedures}

Each volunteer was briefed on the purpose of the investigation, the procedures to be followed to ensure privacy of information during data collection, and any risks involved in their participation. The investigator communicated the experiment goals, procedures, risks, and issues explicated in the consent form. Soldiers were given an opportunity to review the experiment objectives, have any of their questions answered by the investigators, and asked to sign the consent form indicating their informed voluntary consent to participate. The form also requested their permission to have photos or video taken, which participants could decline.

The participants were informed that if they choose not to participate, they could convey that choice privately to the experimenter. An opportunity was provided to convey their choice privately. All Soldiers decided to participate, completed the information on the last page of the form, and signed it. A sample of the informed consent form is included in Appendix A. 
Once roster numbers were assigned and explained, a demographic questionnaire was administered to the participant to obtain pertinent information on the Soldier's background and military experience.

\subsection{Structured Focus Interviews}

After each Soldier group completed the informed consent and demographics form, they were given a detailed description of a route reconnaissance scenario with a written specification of key events, and were asked to complete a detailed questionnaire relating to an autonomous squad member (ASM). After each group completed the questionnaire, they participated in a structured interview to determine the key capabilities and tasks the ASM needs to support a successful mission.

Because the initial group of 12 Soldiers ranged in rank from E-1 to E-5, 6 additional Soldiers were recruited from senior enlisted ranks. This allowed us to explore additional perspectives from a leadership point of view. Methodology and procedures apply to both groups of Soldiers. Data from these interviews were analyzed separately to identify similarity and differences corresponding to leadership and experience.

For each interview session, the interviewer began with an explanation of the research goals, as explained in the informed consent. He then administered a scenario-based questionnaire. He explained each scenario event, probed for feedback with regard to that event pertaining to realism and likelihood, the typical reaction of squad members if faced with the scenario event, the type of information they would likely need or seek out, and the possible contributions of an ASM to that event. The interviewer encouraged discussion and captured Soldier comments with regard to refining, informing, or augmenting scenario content; and ASM capabilities and design considerations.

The questionnaire items were structured to poll the Soldiers on their opinions on the concept of employment for the ASM to include the following: location during the mission; actions by the squad leader, squad members, and the ASM during each of the trigger events; understanding of common military hand and arm signals and verbal commands by the ASM; and the level of trust, from none to complete trust, in the ASM being able to perform mission-related tasks. These questions also served as a precursor to the interview questions by establishing a foundation on which to base the ASM capabilities and employment considerations.

The interview questions were structured to poll the Soldiers on their opinions for key ASM capabilities and task performance to include the following:

- Top 3 capabilities for successful mission accomplishment

- Top 3 capabilities or functions that would be nice to have for an ASM

- General concept of an ASM 
- Command and control of an ASM

- Mission status, and general and specific capabilities, sensors, and mission tasks that should be considered for future ASM design and employment.

\subsection{Data Analysis}

Information from the questionnaires and interviews was captured through written questionnaire responses and interviewer notes. Data were documented through descriptive summaries and tables regarding topics of discussion.

\section{Results}

\subsection{Phase I: Junior Enlisted Soldiers}

\subsubsection{Demographics Questionnaire}

Twelve Soldiers were recruited for the experimentally based assessment. The Soldiers completed a demographics questionnaire initially to determine their military background and experience. They had an average age of 25 years with an average time in service of 4 years. They ranged in rank from E-1 through E-5 and had one of the following military occupational specialties (MOSs): 11B, 11C, 13F, 19K, 91C, or 91H.

Three of the 12 Soldiers had been deployed to Afghanistan with one of those also having deployments to Iraq and Kuwait. Two of the 3 deployed Soldiers had experience with robots during their deployments in Afghanistan, one in an Infantry unit and one in an Armor unit. These robots were used to detonate improved explosive devices (IEDs) and for surveillance, respectfully. These 2 Soldiers thought the following capabilities of the robots were contributing factors to the robot's successful mission accomplishment: maneuverability, speed of traversing the route, sensor packages, capability to negotiate any type of terrain, load carrying capability, weight/transportability, and their size.

All Soldiers were asked, assuming a robot had all the capabilities they would like it to have, what missions could it be best designed to complete. The majority felt that surveillance or reconnaissance were the best missions for the robots. Four of the 12 felt that the robot would also be good for dismounted patrols. Two of the 12 felt that it could be used to clear buildings and trenches. The Soldiers expressed that a camera (day and night) package, IED detection, nuclear, biological, and chemical (NBC) detection, load carrying, and a weapon system were key capabilities or tasks that were needed. Soldiers were almost equally split on the best way to control the robot: teleoperated (5), autonomous (4), and a combination of teleoperated and autonomous (3).

A detailed summary of the demographics questionnaire is located in Appendix B. 


\subsubsection{ASM Survey}

\subsubsection{Premission Checks}

Soldiers were given options with regard to how they would prefer to be notified regarding ASM status. They were equally divided (red/amber/green lights (4), text message (3), and item-by-item checklist display (4)) as to their preference for being notified or assessing that the ASM was operational. There was a consensus that ammunition, weapons, casualty aids and litter, rations and water, and rucksacks should be transported or carried by an ASM to reduce Soldier load.

\subsubsection{Mission Execution}

Most Soldiers (5) stated they preferred to position the ASM in front of the squad. The remaining Soldiers were divided as to where to position the ASM or who to "tie" it to for operational control. Upon reaching the starting point (SP), Soldiers wanted the ASM to begin surveillance of what was ahead, looking for enemy or IEDs and providing an alert if any danger to the squad was present. Two Soldiers preferred the ASM to provide for rear security of the squad. During subsequent movement for the mission, Soldiers wanted the ASM to scout forward and scan for any danger including enemy, IEDs, or targets.

\subsubsection{Trigger Events}

Soldiers were asked a series of questions pertaining to what actions the squad leader (SL), the squad, and the ASM would take when a specific event occurred during the conduct of the mission. Follow-up questions were then asked on what actions were necessary to reorient the squad and the ASM to continue the mission. Detailed responses by individual Soldier are found in Appendix C.

Appendix C keeps the responses separated by Soldier so that they may be maintained in context to the trigger event and their relationship to the other responses by the same Soldier.

Demographic data pertinent to the experience and background of each Soldier are also furnished for the reader's use as appropriate. The reader can then grasp the "tactical context" to each Soldier's responses by trigger event.

Summary tables for each trigger event, with the consensus of opinion, are provided in Tables 1-7. 
Table 1 Trigger event 1: mortar attack, junior enlisted

\begin{tabular}{|c|c|}
\hline Position & $\begin{array}{l}\text { Summary of Tasks or Actions to Be Taken } \\
\text { (Consensus of Participants/General Conclusions) }\end{array}$ \\
\hline Squad Leader & $\begin{array}{l}\text { Yell incoming. Move self and squad out of impact area as quickly and safely as } \\
\text { possible. }\end{array}$ \\
\hline Squad & React to SL commands and move out of impact area in direction given by SL. \\
\hline ASM & $\begin{array}{l}\text { Follow squad. Try to identify direction of mortars. Scan area for safe route and } \\
\text { alert squad. }\end{array}$ \\
\hline $\begin{array}{l}\text { SL actions to reorient } \\
\text { squad }\end{array}$ & $\begin{array}{l}\text { Regroup in covered position. Check or verify status of personnel and } \\
\text { equipment. }\end{array}$ \\
\hline Reorient ASM & Scan area for enemy. Determine alternate route to continue with the mission. \\
\hline $\begin{array}{l}\text { ASM relocation } \\
\text { choice }\end{array}$ & $\begin{array}{l}\text { Equally split between not moving it to another position in the squad to moving } \\
\text { it based on the situation and what task it is to perform. }\end{array}$ \\
\hline
\end{tabular}

Table 2 Trigger event 2: receive sniper fire, junior enlisted

\begin{tabular}{|c|c|}
\hline Position & $\begin{array}{c}\text { Summary of Tasks or Actions to Be Taken } \\
\text { (Consensus of Participants/General Conclusions) }\end{array}$ \\
\hline Squad Leader & $\begin{array}{l}\text { Give order to take cover (move out of kill zone if necessary). Try to determine } \\
\text { where sniper fire originated from. }\end{array}$ \\
\hline Squad & $\begin{array}{l}\text { Take cover. Determine where sniper fire is coming from. Provide suppressive fire } \\
\text { on sniper's location. }\end{array}$ \\
\hline ASM & Scan area and detect sniper's location. \\
\hline $\begin{array}{l}\text { SL actions to reorient } \\
\text { squad }\end{array}$ & $\begin{array}{l}\text { Eliminate sniper if tactically feasible. Continue mission on planned or alternate } \\
\text { route as necessary. }\end{array}$ \\
\hline Reorient ASM & $\begin{array}{l}\text { Determine route to engage sniper or to continue mission. Notify higher echelon } \\
\text { of situation. Continue to scan for enemy threats. }\end{array}$ \\
\hline $\begin{array}{l}\text { ASM relocation } \\
\text { choice }\end{array}$ & $\begin{array}{l}\text { ASM should move out of danger area to protect itself. Could be used as cover for } \\
\text { squad if necessary. }\end{array}$ \\
\hline
\end{tabular}

Table 3 Trigger event 3: encounter an obstacle and maneuver around it, junior enlisted

\begin{tabular}{|c|c|}
\hline Position & $\begin{array}{l}\text { Summary of Tasks or Actions to Be Taken } \\
\text { (Consensus of Participants/General Conclusions) }\end{array}$ \\
\hline Squad Leader & $\begin{array}{l}\text { Halt the squad. Set up security. Determine the best and safest route around } \\
\text { obstacle. }\end{array}$ \\
\hline Squad & Pull security. Bound from one side of the obstacle to the other. \\
\hline ASM & Determine best route around obstacle. Lead the squad around the obstacle. \\
\hline $\begin{array}{l}\text { SL actions to reorient } \\
\text { squad }\end{array}$ & Regroup, maintain security, and continue with the mission. \\
\hline Reorient ASM & Lead squad around obstacle on new route. \\
\hline $\begin{array}{l}\text { ASM relocation } \\
\text { choice }\end{array}$ & Change location to lead squad around the obstacle on new route. \\
\hline
\end{tabular}


Table 4 Trigger event 4: detect an IED, junior enlisted

\begin{tabular}{|c|c|}
\hline Position & $\begin{array}{l}\text { Summary of Tasks or Actions to Be Taken } \\
\text { (Consensus of Participants/General Conclusions) }\end{array}$ \\
\hline Squad Leader & $\begin{array}{l}\text { Halt squad. Cordon off area around IED and establish } 360^{\circ} \text { security. Scan for } \\
\text { other IEDs. Call up EOD. }\end{array}$ \\
\hline Squad & $\begin{array}{l}\text { Pull security. Prevent others from entering area. Scan for other IEDs and any } \\
\text { trigger man. }\end{array}$ \\
\hline ASM & $\begin{array}{l}\text { Move forward and confirm that object is an IED. Scan area for other IEDs and } \\
\text { hostile personnel in area. }\end{array}$ \\
\hline $\begin{array}{l}\text { SL actions to reorient } \\
\text { squad }\end{array}$ & Once IED has been disposed of, continue with mission. \\
\hline Reorient ASM & $\begin{array}{l}\text { Scan area for other IEDs and enemy. Continue with mission after IED has been } \\
\text { disposed of. }\end{array}$ \\
\hline $\begin{array}{l}\text { ASM relocation } \\
\text { choice }\end{array}$ & $\begin{array}{l}\text { ASM verifies accuracy of IED detection. Moves to a good scanning position to } \\
\text { scan area for other IEDs and enemy personnel. }\end{array}$ \\
\hline
\end{tabular}

Table 5 Trigger event 5: ambush, junior enlisted

\begin{tabular}{|c|c|}
\hline Position & \begin{tabular}{|c}
$\begin{array}{c}\text { Summary of Tasks or Actions to Be Taken } \\
\text { (Consensus of Participants/General Conclusions) }\end{array}$ \\
\end{tabular} \\
\hline Squad Leader & $\begin{array}{l}\text { Determine whether to assault through the ambush or conduct a flanking } \\
\text { maneuver around enemy force. Have squad suppress enemy. Contact higher and } \\
\text { provide report. }\end{array}$ \\
\hline Squad & Teams conduct fire and maneuver to gain fire superiority over the enemy. \\
\hline ASM & $\begin{array}{l}\text { Report situation to higher. Identify where the enemy is. Drop off supplies to } \\
\text { squad members as needed. }\end{array}$ \\
\hline $\begin{array}{l}\text { SL actions to reorient } \\
\text { squad }\end{array}$ & $\begin{array}{l}\text { Once enemy is defeated, check status of equipment and personnel. Provide } \\
\text { casualty aid. }\end{array}$ \\
\hline Reorient ASM & $\begin{array}{l}\text { Continue scanning area for enemy threats. Assist in searches. Determine route to } \\
\text { continue the mission. }\end{array}$ \\
\hline $\begin{array}{l}\text { ASM relocation } \\
\text { choice }\end{array}$ & $\begin{array}{l}\text { ASM remains in position except to distribute supplies to squad members who } \\
\text { need them. }\end{array}$ \\
\hline
\end{tabular}

Table 6 Trigger event 6: civilian vehicle or personnel approach position, junior enlisted

\begin{tabular}{|l|l|}
\hline \multicolumn{1}{|c|}{ Position } & \multicolumn{1}{c|}{$\begin{array}{c}\text { Summary of Tasks or Actions to Be Taken } \\
\text { (Consensus of Participants/General Conclusions) }\end{array}$} \\
\hline Squad Leader & $\begin{array}{l}\text { Stop squad and the vehicle or personnel. Make an assessment of whether they are } \\
\text { hostile (weapons, explosives) or friendly. }\end{array}$ \\
\hline Squad & Establish security. Conduct vehicle and personnel searches. \\
\hline ASM & $\begin{array}{l}\text { Maintain surveillance of the vehicle. Scan for weapons and explosives. Search } \\
\text { the vehicle. }\end{array}$ \\
\hline $\begin{array}{l}\text { SL actions to reorient } \\
\text { squad }\end{array}$ & Detain or release personnel encountered and then continue the mission. \\
\hline Reorient ASM & Establish route to next waypoint. Send reports to higher. \\
\hline $\begin{array}{l}\text { ASM relocation } \\
\text { choice }\end{array}$ & ASM maintains its current position. \\
\hline
\end{tabular}


Table 7 Trigger event 7: loss of forward line of sight, junior enlisted

\begin{tabular}{|l|l|}
\hline \multicolumn{1}{|c|}{ Position } & \multicolumn{1}{c|}{$\begin{array}{c}\text { Summary of Tasks or Actions to Be Taken } \\
\text { (Consensus of Participants/General Conclusions) }\end{array}$} \\
\hline Squad Leader & $\begin{array}{l}\text { Slow down or halt the squad. Establish security. Move forward or have ASM } \\
\text { move forward to location where forward area can be observed. }\end{array}$ \\
\hline Squad & Pull security while scanning area around squad. \\
\hline ASM & Move forward while scanning area to determine what is ahead out of sight. \\
\hline $\begin{array}{l}\text { SL actions to reorient } \\
\text { squad }\end{array}$ & Move to ASM's location while maintaining formation and continue mission. \\
\hline Reorient ASM & Wait for squad to reach it and then continue on with the mission. \\
\hline $\begin{array}{l}\text { ASM relocation } \\
\text { choice }\end{array}$ & $\begin{array}{l}\text { Move ahead of squad and then continue in the squad formation once the squad } \\
\text { reaches it and continue mission. }\end{array}$ \\
\hline
\end{tabular}

\subsubsection{Hand and Arm Signals}

Soldiers felt that the ASM should know and understand all of the basic hand and arm signals used. Double time, vee, and disperse were signals where Soldiers were equally divided as to whether the ASM should know and understand these signals. The hand and arm signals surveyed and the individual Soldier responses are tabulated in Appendix C.

\subsubsection{Verbal Commands}

Soldiers thought that the ASM should know and understand all of the basic verbal commands surveyed. They were not as unanimous for the run and duck commands as other commands commonly used. The verbal commands surveyed, as well as other suggested verbal commands that should be known, and the individual Soldier responses are tabulated in Appendix C.

\subsubsection{Postmission Checks}

Soldiers did not change their opinions on how they would prefer to be notified about the ASM's status when reporting postmission checks. They retained their preferences as for the premission checks. Soldiers were equally divided (red/amber/green lights (4), text message (3), and item-byitem checklist display (4)) as to their preference for being notified or assessing that the ASM was still functioning properly.

\subsubsection{Trust in ASM to Conduct Tasks}

Soldiers were asked to identify what tasks they had complete trust, some trust, and no trust in for the ASM to conduct. Soldiers had complete trust in the ASM to scout or check routes, check for IEDs, and know its location via GPS. Soldiers had some trust in the ASM to evacuate casualties. Soldiers had no trust in the ASM to engage the enemy if the ASM had a weapon system, without human intervention. The complete lists of responses to the areas of trust are tabulated in Appendix C with many single responses for most tasks identified without a general consensus among Soldiers. 


\subsubsection{Interviews}

The following paragraphs summarize questions asked of the Soldiers during the interview process by identifying the most frequent responses, and in some cases not the consensus of the whole group. Detailed summaries are tabulated in Appendix D.

\subsubsection{Demographics and Mission Questionnaire Follow-Up}

Soldiers expressed many different reasons for positioning the ASM within the squad. These ranged from being less of a distraction to repositioning it as the mission dictates. One Soldier expressed a lack of trust in the ASM and said it should prove that it is trustworthy first.

\subsubsection{Capabilities and Functions of the ASM}

Soldiers were asked to prioritize the top 3 capabilities or functions that the ASM should have (necessary) to ensure mission success and also the top 3 "nice-to-have" capabilities or functions. Table 8 summarizes the most common responses, although, not the consensus of the group as a whole.

Table 8 Necessary and nice-to-have priorities, junior enlisted

\begin{tabular}{|c|l|l|}
\hline Priority & \multicolumn{1}{|c|}{ Necessary } & \multicolumn{1}{c|}{ Nice to Have } \\
\hline 1 & Navigation of terrain. & $\begin{array}{l}\text { 1. Capability to transport supplies and } \\
\text { equipment. } \\
\text { 2. Weapon system. }\end{array}$ \\
\hline 2 & $\begin{array}{l}\text { 1. Identification of targets and scanning for } \\
\text { enemy. } \\
\text { 2. Night vision/thermal instrumentation. }\end{array}$ & $\begin{array}{l}\text { Carry first aid supplies and evacuate } \\
\text { casualties. }\end{array}$ \\
\hline 3 & Load carrying ability. & $\begin{array}{l}1 \text { Transport litters and casualty evacuation } \\
\text { aid. } \\
\text { 2. External power source for recharging } \\
\text { batteries. }\end{array}$ \\
\hline
\end{tabular}

\subsubsection{Modifications Necessary for Missions Other than Route Reconnaissance}

Six of the 12 Soldiers indicated that nothing would have to be changed on the ASM to conduct other types of missions.

\subsubsection{Modifications Necessary for Night Missions}

Soldiers indicated an infrared (IR) or thermal camera would be necessary. Soldiers also indicated that it should have night vision capability with a display. 


\subsubsection{ASM Concept}

Eleven of the 12 Soldiers felt that the ASM was a good idea. The one Soldier who said it was not based his response on the lack of trust he had in it to complete tasks and that he was not big on technology. Soldiers liked the idea of reducing the Soldier load by offloading it to the ASM. Providing additional security was also indicated as an asset.

\subsubsection{ASM Command and Control}

Seven of the 12 Soldiers indicated that the ASM should understand verbal commands as the primary means of maintaining command and control of it. Three Soldiers thought that it should have a dedicated operator.

\subsubsection{ASM Acknowledgement of Receipt of Command}

Soldiers were evenly split on the best way that the ASM should acknowledge that it received a command. Their choices included verbal (3), visual (3), text message (4), and no acknowledgement by just executing the command (2). Text messages were identified as being easy to interpret, maintain noise and light discipline, and useful as a backup for verbal acknowledgment. One Soldier recommended an earpiece be used when noise and light discipline protocols are being followed.

\subsubsection{ASM Preprogrammed Skills or Knowledge}

Soldiers expressed many different ideas about what capabilities the ASM should have "out of the box" to perform required tasks. Soldiers indicated that the ASM should know how to navigate and make the best use of the terrain as well as know how to seek and find cover. Additionally, it should have a basic understanding of battle drills and how to stay out of the way if a firefight occurs.

\subsubsection{Soldier Skills}

The majority of Soldiers developed their personal skills through a combination of unit training and schools. A third of the Soldiers identified that schools were their primary source for their skills.

\subsubsection{ASM Reminder of Next Mission Objective}

Soldiers were nearly unanimous (11 of 12) that the ASM should provide a reminder of the next mission objective after an interruption of the mission occurred. Soldiers felt that this could be helpful to the squad leader who has many tasks. One Soldier did not trust it because of security reasons - the enemy may gain knowledge of operation if ASM is captured. 
3.1.3.11 ASM Reporting Status of Phase Lines, Lines of Departure, Objective, etc.

Again, Soldiers were nearly unanimous (11 of 12) that the ASM would be an aid if it informed the squad of reaching phase lines, lines of departure, etc. on time. This would act as confirmation that the mission was proceeding on schedule and the squad was in the right location. One Soldier expressed a lack of trust in the ASM due to security reasons.

\subsubsection{Mission Interruption and Subsequent Actions and Consequences}

Five Soldiers indicated that they have had potentially bad consequences occur during the conduct of a mission. Their responses are summarized in Appendix D.

\subsubsection{Weapons Platform}

Nine of the 12 Soldiers indicated that they would like the ASM to have a weapons platform mounted on it. Seven of those Soldiers indicated that they preferred another Soldier to be "in the loop” for conducting the actual engagements with the weapon system. Eight of the Soldiers preferred a remote device for weapon system control, primarily to prevent a Soldier from being exposed. Soldiers did not trust the decision making of the ASM to provide autonomous engagements for fear of fratricide, out-of-range engagements, and safety. One Soldier expressed that even it were autonomous that the ASM should wait for confirmation before conducting an engagement. Responses pertaining to the caliber and basic load for the weapon system are found in Appendix D.

\subsubsection{Casualty Evacuation}

Soldiers were nearly unanimous (11 of 12) that the ASM should be configured for casualty evacuation. Eight of the 11 Soldiers indicated that the ASM should not evacuate the casualties autonomously to the casualty collection point because a human would be necessary to accompany the ASM to return fire to protect the casualty. Soldiers felt that the time to configure the ASM for casualty evacuation, if not embedded, should be kept to the bare minimum with 6 indicating as soon as possible and 2 indicating less than $5 \mathrm{~min}$. Ten of the 11 Soldiers indicated that the ASM should be capable of evacuating 1 or 2 casualties.

\subsubsection{Smoke Screen}

Eight of the 12 Soldiers felt that the ASM should have a smoke-producing capability with 7 of those preferring a dispenser to a generator-based capability. Seven Soldiers also identified the need for wind-sensing capability to produce an effective smoke screen in the right direction and right area.

\subsubsection{Chemical Detection or Alarms}

Soldiers were unanimous that the ASM should have a chemical detection or alarm system. They saw it as being able to provide real-time warnings and reporting since Soldiers do not continuously monitor for chemical threats. 


\subsubsection{Target Detection Capability}

Soldiers were nearly unanimous (11 of 12) that the ASM should have a target detection capability. It should identify both human and vehicular targets and provide an azimuth and distance to the target. Nine of the 11 Soldiers also indicated that the ASM should track the target once it detected it.

\subsubsection{Shot Detection Capability}

Soldiers were unanimous that the ASM should have a shot detection capability that provides the location, distance, azimuth to the shooter and caliber of weapon fired. Two Soldiers indicated that it should do the same for indirect fire.

\subsubsection{Extendable Mast for Camera Sensor}

Soldiers were nearly unanimous (11 of 12) that the ASM camera sensor should be mounted on an extendable/collapsible mast for day and night operations. Seven of the 11 Soldiers indicated a needed height capability of 8-10 ft to look over walls. One Soldier indicated that the ASM should be able to elevate itself instead of using a mast.

\subsubsection{Loading/Retrieval Arm}

The majority of Soldiers did not feel that the ASM needed a mechanical arm for loading or retrieving equipment or casualties. They felt that Soldiers could better load and protect another wounded Soldier and that equipment could be loaded by Soldiers because it is not that heavy or time consuming.

\subsubsection{Conveying Mission to ASM}

Soldiers would prefer a map with graphics capability or a computer keyboard for conveying the mission to the ASM. Soldiers also expressed a concern about having the mission completely downloaded because of potential security compromises if the ASM was captured.

\subsubsection{Other Mission-Oriented or Task-Related Items Needed}

Soldiers identified many items needed. Security was mentioned with the ASM needing the capability to have the memory wiped out to prevent compromise of the mission or friendly forces. Radios and radio mounts should be provided to lessen the Soldier load burden. Independent wheel suspension and fording capability of 3-5 ft are needed for terrain navigation.

\subsubsection{Other Potential ASM Considerations}

Table 9 summarizes the other mission-oriented or task-related items Soldiers were asked if the ASM should have. Detailed comments about each are found in Appendix D. 
Table 9 Mission-oriented and task-related items, junior enlisted

\begin{tabular}{|l|c|c|}
\hline Mission-Oriented or Task-Related Item & Yes & No \\
\hline Manual backup for command and control & 12 & 0 \\
\hline Battery charger & 12 & 0 \\
\hline Run-flat tires & 12 & 0 \\
\hline Map display & 11 & 1 \\
\hline Air-transportable & 11 & 1 \\
\hline Run-silent mode of operation & 12 & 0 \\
\hline Voice recognition & 9 & 3 \\
\hline Multilingual voice recognition & 5 & 7 \\
\hline
\end{tabular}

A manual backup is considered necessary to overcome any malfunctions. One Soldier indicated that no robot should have total control of itself.

A battery charger was identified as being useful for charging radio batteries primarily. Five Soldiers indicated that it should charge all the batteries used by the squad and needed the appropriate adapters if necessary.

Run-flat tires are necessary for the ASM to be able to continue the mission and not have to be abandoned or retrieved. Soldiers felt that if it cannot continue the mission then it becomes useless as an asset.

A map display was seen as an aid for command and control as well as maintaining situational awareness.

The ASM should be air-transportable if it is intended to be used by and considered an asset of the squad. It should be able to be transported with the squad for their use and be available on all missions.

A run silent mode of operation is necessary to maintain noise and light discipline when the mission dictates and to maintain an element of surprise.

Five of the 9 Soldiers identifying the need for the ASM to have voice recognition would prefer for it to recognize all the voices of the entire squad whereas the other 4 identified that selected personnel typically the chain of command, should be the only ones.

Bilingual voice recognition raised concerns about the enemy being able to command and control the ASM and for security during conversations with indigenous personnel. 


\subsection{Phase II: Senior Enlisted Soldiers}

\subsubsection{Demographics Questionnaire}

Six senior enlisted Soldiers were recruited for this phase of the experimentally based assessment. The Soldiers completed a demographics questionnaire initially to determine their military background and experience. They had an average age of 29 years with an average time in service of 9.5 years. There was 1 E-5 promotable and 5 E-6s and all were MOS 11B.

All of the senior enlisted Soldiers had at least 1 deployment (3 to Afghanistan, 4 to Iraq, and 4 to Kuwait). Four of the 6 deployed Soldiers had experience with robots during their deployments (3 in Afghanistan and 1 in Iraq) in an Infantry unit. These robots were used to explore and detonate IEDs and for surveillance or reconnaissance missions. These senior enlisted Soldiers thought the following capabilities of the robots were contributing factors to the robot's successful mission accomplishment: ability to lift objects, sensor packages, terrain negotiation, maneuverability, and providing another set of eyes.

All Soldiers were asked, assuming a robot had all the capabilities they would like it to have, what missions could it be best designed to complete. The majority, 4 of the 6 , felt that surveillance or reconnaissance were the best missions for the robots. Other missions suggested included: transportation, weapons employment, medevac, route clearing, patrols, and checking mined or booby-trapped areas. The Soldiers expressed that a camera (day and night) package, IED detection, load carrying, and maneuverability in terrain were some of the key capabilities or features that were needed. Five of the 6 senior enlisted Soldiers felt that the best way to control the robot was teleoperation with the sixth Soldier preferring autonomous operation.

A detailed summary of the demographics questionnaire is located in Appendix E.

\subsubsection{ASM Survey}

\subsubsection{Premission Checks}

Soldiers were given options with regard to how they would prefer to be notified regarding ASM status. Two preferred red/amber/green lights, 2 preferred a text message, 1 preferred an item-byitem checklist display, and the last Soldier preferred a combination of lights with a short and long version of an item-by-item checklist as to their preference for being notified or assessing that the ASM was operational. There was a consensus that ammunition and weapons should be carried by the ASM to increase the lethality of the squad and reduce the Soldier load. Meals, water, and grenades were other items identified to be carried by the ASM to reduce the Soldier load. 


\subsubsection{Mission Execution}

Soldiers were divided as to where the ASM should be located for the start of the mission: 3 preferred at the rear of the formation, 2 preferred it at the front, and 1 preferred it tied to the squad leader. Upon reaching the SP, Soldiers wanted the ASM to begin conducting status checks and to conduct surveillance of what was ahead of the squad. During subsequent movement for the mission, Soldiers wanted the ASM to scout forward and scan for any danger.

\subsubsection{Trigger Events}

Soldiers were asked a series of questions pertaining to what actions the SL, the squad, and the ASM would take when a specific event occurred during the conduct of the mission. Follow-up questions were then asked on what actions were necessary to reorient the squad and the ASM to continue the mission. Detailed responses by individual Soldier are found in Appendix F.

Appendix F keeps the responses separated by Soldier so that they may be maintained in context to the trigger event and their relationship to the other responses by the same Soldier.

Demographic data pertinent to the experience and background of each Soldier are also furnished for the reader's use as appropriate. The reader can then grasp the "tactical context" to each Soldier's responses by trigger event.

Summary tables for each trigger event, with the consensus of opinion, are provided in Tables 10-16.

Table 10 Trigger event 1: mortar attack, senior NCOs

\begin{tabular}{|c|c|}
\hline Position & $\begin{array}{c}\begin{array}{c}\text { Summary of Tasks or Actions to Be Taken } \\
\text { (Consensus of Participants/General Conclusions) }\end{array} \\
\end{array}$ \\
\hline Squad Leader & $\begin{array}{l}\text { Determine new course. Provide squad with a distance and direction to move. } \\
\text { Continually assess the situation. }\end{array}$ \\
\hline Squad & $\begin{array}{l}\text { Move to rally point given by the squad leader (distance and direction of } \\
\text { movement). Maintain security during movement. }\end{array}$ \\
\hline ASM & $\begin{array}{l}\text { Try to identify direction of mortars. Scan area for safe route and move with the } \\
\text { squad. }\end{array}$ \\
\hline $\begin{array}{l}\text { SL actions to reorient } \\
\text { squad }\end{array}$ & $\begin{array}{l}\text { Regroup in covered position. Check with team leaders. Reorganize and } \\
\text { consolidate as required. }\end{array}$ \\
\hline Reorient ASM & Follow directions of squad leader and continue movement with the squad. \\
\hline $\begin{array}{l}\text { ASM relocation } \\
\text { choice }\end{array}$ & $\begin{array}{l}\text { Four of the } 6 \text { favored moving it to another position based on the situation and } \\
\text { what just happened on the mission. }\end{array}$ \\
\hline
\end{tabular}


Table 11 Trigger event 2: receive sniper fire, senior NCOs

\begin{tabular}{|l|l|}
\hline \multicolumn{1}{|c|}{ Position } & \multicolumn{1}{c|}{$\begin{array}{c}\text { Summary of Tasks or Actions to Be Taken } \\
\text { (Consensus of Participants/General Conclusions) }\end{array}$} \\
\hline Squad Leader & $\begin{array}{l}\text { Take cover. Try to determine where sniper fire originated from. Report situation } \\
\text { to higher. }\end{array}$ \\
\hline Squad & Take cover. Determine where sniper fire is coming from. Maintain security. \\
\hline ASM & Determine sniper's location. \\
\hline $\begin{array}{l}\text { SL actions to reorient } \\
\text { squad }\end{array}$ & $\begin{array}{l}\text { Eliminate sniper if tactically feasible via fire and maneuver. Continue mission on } \\
\text { planned or alternate route as necessary. }\end{array}$ \\
\hline Reorient ASM & Continue to scan for enemy threats. Move to appropriate position. \\
\hline $\begin{array}{l}\text { ASM relocation } \\
\text { choice }\end{array}$ & $\begin{array}{l}\text { Four of the } 6 \text { felt that the ASM should move out of danger area to protect itself } \\
\text { and then scan for potential targets. }\end{array}$ \\
\hline
\end{tabular}

Table 12 Trigger event 3: encounter an obstacle and maneuver around it, senior NCOs

\begin{tabular}{|l|l|}
\hline \multicolumn{1}{|c|}{ Position } & \multicolumn{1}{c|}{$\begin{array}{c}\text { Summary of Tasks or Actions to Be Taken } \\
\text { (Consensus of Participants/General Conclusions) }\end{array}$} \\
\hline Squad Leader & Move around the obstacle after determining the best route around obstacle. \\
\hline Squad & Pull security during movement. \\
\hline ASM & Recon route around the obstacle. \\
\hline $\begin{array}{l}\text { SL actions to reorient } \\
\text { squad }\end{array}$ & Lead team leader leads squad around obstacle. \\
\hline Reorient ASM & Follow the squad. \\
\hline $\begin{array}{l}\text { ASM relocation } \\
\text { choice }\end{array}$ & $\begin{array}{l}\text { Majority of senior enlisted did not see any reason for ASM to change its location } \\
\text { except to move to rear. }\end{array}$ \\
\hline
\end{tabular}

Table 13 Trigger event 4: detect an IED, senior NCOs

\begin{tabular}{|c|c|}
\hline Position & $\begin{array}{c}\begin{array}{c}\text { Summary of Tasks or Actions to Be Taken } \\
\text { (Consensus of Participants/General Conclusions) }\end{array} \\
\end{array}$ \\
\hline Squad Leader & $\begin{array}{l}\text { Halt squad. Cordon off area around IED. Confirm presence of IED. Notify } \\
\text { higher. }\end{array}$ \\
\hline Squad & Pull security. \\
\hline ASM & Move forward and confirm that object is an IED. \\
\hline $\begin{array}{l}\text { SL actions to reorient } \\
\text { squad }\end{array}$ & Conduct equipment and personnel status checks and continue mission. \\
\hline Reorient ASM & $\begin{array}{l}\text { Exploit IED and confirm it. Continue with mission after IED has been disposed } \\
\text { of. }\end{array}$ \\
\hline $\begin{array}{l}\text { ASM relocation } \\
\text { choice }\end{array}$ & $\begin{array}{l}\text { Near unanimous decision that IED should not change its position within the } \\
\text { formation after actions are complete. }\end{array}$ \\
\hline
\end{tabular}


Table 14 Trigger event 5: ambush, senior NCOs

\begin{tabular}{|c|c|}
\hline Position & $\begin{array}{l}\text { Summary of Tasks or Actions to Be Taken } \\
\text { (Consensus of Participants/General Conclusions) }\end{array}$ \\
\hline Squad Leader & Return fire. Maneuver squad to move against and defeat the enemy. \\
\hline Squad & Teams conduct fire and maneuver against enemy position to destroy enemy. \\
\hline ASM & Report situation to higher. Drop off supplies to squad members as needed. \\
\hline $\begin{array}{l}\text { SL actions to reorient } \\
\text { squad }\end{array}$ & Reconsolidate and reorganize \\
\hline Reorient ASM & Resume movement with the squad. \\
\hline $\begin{array}{l}\text { ASM relocation } \\
\text { choice }\end{array}$ & $\begin{array}{l}\text { Near unanimous decision that IED should not change its position within the } \\
\text { formation after actions are complete. }\end{array}$ \\
\hline
\end{tabular}

Table 15 Trigger event 6: civilian vehicle or personnel approach position, senior NCOs

\begin{tabular}{|c|c|}
\hline Position & $\begin{array}{c}\text { Summary of Tasks or Actions to Be Taken } \\
\text { (Consensus of Participants/General Conclusions) }\end{array}$ \\
\hline Squad Leader & Stop squad and the vehicle or personnel. Maintain security. \\
\hline Squad & Establish security. Conduct vehicle and personnel searches. \\
\hline ASM & Maintain surveillance and security. \\
\hline $\begin{array}{l}\text { SL actions to reorient } \\
\text { squad }\end{array}$ & Maintain security. \\
\hline Reorient ASM & Nothing. \\
\hline $\begin{array}{l}\text { ASM relocation } \\
\text { choice }\end{array}$ & $\begin{array}{l}\text { Near unanimous decision that IED should not change its position within the } \\
\text { formation after actions are complete. }\end{array}$ \\
\hline
\end{tabular}

Table 16 Trigger event 7: loss of forward line of sight, senior NCOs

\begin{tabular}{|l|l|}
\hline \multicolumn{1}{|c|}{ Position } & \multicolumn{1}{c|}{$\begin{array}{c}\text { Summary of Tasks or Actions to Be Taken } \\
\text { (Consensus of Participants/General Conclusions) }\end{array}$} \\
\hline Squad Leader & Send out reconnaissance element. \\
\hline Squad & Conduct a short halt and pull security. \\
\hline ASM & Move forward as or with the reconnaissance element. \\
\hline $\begin{array}{l}\text { SL actions to reorient } \\
\text { squad }\end{array}$ & Regroup and continue mission. \\
\hline Reorient ASM & Continue in the squad formation. \\
\hline $\begin{array}{l}\text { ASM relocation } \\
\text { choice }\end{array}$ & $\begin{array}{l}\text { Near unanimous decision that IED should not change its position within the } \\
\text { formation after actions are complete. }\end{array}$ \\
\hline
\end{tabular}




\subsubsection{Hand and Arm Signals}

Soldiers felt that the ASM should know and understand the majority of the basic hand and arm signals used (move out, double time, enemy in sight, wedge, vee, column, staggered column, NBC, danger area, and freeze). Echelon left, echelon right, contact left, and contact right were signals where Soldiers were equally divided as to whether the ASM should know and understand these signals. The majority of senior enlisted Soldiers did not feel that the ASM needed to know and understand the following signals: take cover, disperse, and assemble. The hand and arm signals surveyed and the individual Soldier responses are tabulated in Appendix F.

\subsubsection{Verbal Commands}

Soldiers were equally divided as to whether the ASM should know and understand the following

basic verbal commands: halt, move, and run. They did not feel that the ASM needed to know and understand the following verbal commands: stop, and duck. Additional verbal commands suggested were shut down, follow, destroy, status, and move out. The verbal commands surveyed and the individual Soldier responses are tabulated in Appendix F.

\subsubsection{Postmission Checks}

Soldiers did not change their opinions on how they would prefer to be notified about the ASM's status when reporting postmission checks. They retained their preferences as for the premission checks. Two preferred red/amber/green lights, 2 preferred a text message, 1 preferred an itemby-item checklist display, and the last Soldier preferred a combination of lights with a short and long version of an item-by-item checklist as to their preference for being notified or assessing that the ASM was operational.

\subsubsection{Trust in ASM to Conduct Tasks}

Soldiers were asked to identify what tasks they had complete trust, some trust, and no trust in for the ASM to conduct. There was no consensus in any of these areas and the most common responses are cited as follows. Soldiers had complete trust in the ASM to carry the gear and evacuate casualties. Soldiers had some trust in the ASM to conduct reconnaissance and send some reports. Soldiers had no trust in the ASM to engage the enemy if the ASM had a weapon system, without human interface and to completely move and think on its own. The complete lists of responses to the areas of trust are tabulated in Appendix F with many single responses for most tasks identified without a general consensus among Soldiers.

\subsubsection{Interviews}

The following paragraphs summarize questions asked of the senior enlisted Soldiers during the interview process by identifying the most frequent responses, and in some cases not the consensus of the whole group. Detailed summaries are tabulated in Appendix G. 


\subsubsection{Demographics and Mission Questionnaire Follow-Up}

Soldiers were nearly equally divided on where to position the ASM ranging from the front, rear, and tied to the squad leader. All Soldiers expressed a lack of trust in the ASM. Soldiers felt it was expendable and could be used for cover in order to save a human.

\subsubsection{Capabilities and Functions of the ASM}

Soldiers were asked to prioritize the top 3 capabilities or functions that the ASM should have (necessary) to ensure mission success and also the top 3 nice-to-have capabilities or functions. Table 17 summarizes the most common responses, although not the consensus of the group as a whole.

Table 17 Necessary and nice-to-have priorities, senior NCOs

\begin{tabular}{|c|c|c|}
\hline Priority & Necessary & Nice to Have \\
\hline 1 & $\begin{array}{l}\text { Mobility and maneuverability to keep load with } \\
\text { the squad. }\end{array}$ & $\begin{array}{l}\text { Digital communication capability tied in with } \\
\text { FBCB2. }\end{array}$ \\
\hline 2 & $\begin{array}{l}\text { Durability and reliability to stay in the mission to } \\
\text { its end. }\end{array}$ & Tracking device and GPS. \\
\hline 3 & $\begin{array}{l}\text { Provide location and distance to an identified } \\
\text { target as part of counter-fire sensors. }\end{array}$ & $\begin{array}{l}\text { Sustained power with possible alternate } \\
\text { power source. }\end{array}$ \\
\hline
\end{tabular}

\subsubsection{Modifications Necessary for Missions Other than Route Reconnaissance}

Three of the 6 Soldiers indicated that nothing would have to be changed on the ASM to conduct other types of missions. The other 3 individually indicated a need for a weapon system, intelligence for navigation, and thermal sensors.

\subsubsection{Modifications Necessary for Night Missions}

Soldiers indicated an IR sensor with a visual display would be necessary. One Soldier indicated that it should also have IR floodlights.

\subsubsection{ASM Concept}

Five of the 6 senior Soldiers felt that the ASM was not a good idea. These Soldiers tied their responses to their lack of trust and independent operation of the ASM. The one Soldier who said it was a good idea indicated that it was an “OK” idea.

\subsubsection{ASM Command and Control}

All 6 of the senior NCOs identified using a dedicated operator as the primary means of maintaining command and control of the ASM. Five identified the dedicated operator alone and the sixth NCO recommended using a dedicated operator with the ASM understanding verbal commands. 


\subsubsection{ASM Acknowledgement of Receipt of Command}

Soldiers were evenly split among 3 ways that the ASM should acknowledge that it received a command. Their choices included: text message (2), entirely mission dependent (verbal or display) (2), and no acknowledgement by just executing the command (2). The 2 NCOs who identified that it was strictly mission dependent also identified that night operations may require different techniques to maintain noise and light discipline requirements of the mission.

\subsubsection{ASM Preprogrammed Skills or Knowledge}

Soldiers indicated that the ASM should know basic team and squad formations and what distances to maintain between Soldiers and itself. Additionally, the ASM needs to know battle drills and expected responses and basic soldiering skills.

\subsubsection{Soldier Skills}

Half of the senior Soldiers attributed their personal skills through on-the-job training (OJT). One Soldier identified that his skills were a product of the combination of OJT and schools. The remaining 2 Soldiers identified schools and combat respectfully as their sources of personal knowledge.

\subsubsection{ASM Reminder of Next Mission Objective}

Four of the 6 senior Soldiers preferred the ASM to provide a reminder of the next mission objective after an interruption of the mission occurred. They based this on enemy contact and how everything can change in the heat of the battle.

3.2.3.11 ASM Reporting Status of Phase Lines, Lines of Departure, Objective, etc.

The senior NCOs were unanimous that the ASM would be an aid if it informed the squad of reaching phase lines, lines of departure, etc. on time. One Soldier felt that reaching the objective was not required of the ASM to notify the squad but that the other notifications were alright.

\subsubsection{Mission Interruption and Subsequent Actions and Consequences}

Two of the 6 Soldiers indicated that they have had potentially bad consequences occur during the conduct of a mission. They attributed their situations to being in a firefight and civilians on the battlefield. Their responses are summarized in Appendix G.

\subsubsection{Weapons Platform}

The senior NCOs were nearly unanimous with 5 of the 6 indicating that they would like the ASM to have a weapons platform mounted on it. Four of those 5 NCOs indicated that they preferred another Soldier to be in the loop for conducting the actual engagements with the weapon system. They were evenly split on whether the weapon system should have a remote 
control device or manned with a Soldier in the loop. Soldiers did not trust the decision making of the ASM to provide autonomous engagements. Responses pertaining to the caliber and basic load for the weapon system are found in Appendix G.

\subsubsection{Casualty Evacuation}

The senior Soldiers were unanimous that the ASM should be configured for casualty evacuation. They were evenly split on whether the ASM should evacuate the casualties autonomously or be escorted to the casualty collection point. The majority of these Soldiers felt that the time to configure the ASM for casualty evacuation, if not embedded, should be less than $90 \mathrm{~s}$. The majority of Soldiers also indicated that the ASM should be capable of evacuating 1 or 2 casualties.

\subsubsection{Smoke Screen}

All 6 of the senior Soldiers felt that the ASM should have a smoke-producing capability with 2 of those preferring a dispenser and the remaining 4 preferring a generator-based capability. Four of the 6 Soldiers also identified the need for wind-sensing capability to produce an effective smoke screen in the right direction and right area. Four of the 6 identified a need to be able to produce a smoke screen out to $50 \mathrm{~m}$ with the other 2 indicating a requirement out to $35 \mathrm{~m}$.

\subsubsection{Chemical Detection or Alarms}

Soldiers were nearly unanimous with 5 of the 6 preferring the ASM to have a chemical detection or alarm system. They saw it as being able to provide real-time warnings and reporting and reducing Soldier tasks.

\subsubsection{Target Detection Capability}

Soldiers were nearly unanimous (5 of 6) that the ASM should have a target detection capability. It should identify both human and vehicular targets, provide an azimuth and distance to the target, and track the target once it detected it. The Soldiers identified ranges from 800 to 2,000 m for these requirements.

\subsubsection{Shot Detection Capability}

Soldiers were unanimous that the ASM should have a shot detection capability that provided the location, distance, azimuth to the shooter, and caliber of weapon fired. One Soldier indicated that it had to be very reliable and another indicated that it should have an option to conduct an engagement of what was detected. 


\subsubsection{Extendable Mast for Camera Sensor}

Soldiers were nearly unanimous (5 of 6) that the ASM camera sensor should be mounted on an extendable/collapsible mast for day and night operations. They indicated a needed height of 6-20 ft. One Soldier indicated that the ASM should have facial recognition and another suggested it needed a less-than-lethal capability, for example, a dazzler.

\subsubsection{Loading/Retrieval Arm}

The Soldiers were nearly unanimous (5 of 6) that the ASM did not need a mechanical arm for loading or retrieving equipment or casualties. The one Soldier indicated that it would be good for equipment but not needed for casualty evacuation tasks. They felt that Soldiers could better load and protect another wounded Soldier. They also indicated that this would be a time-consuming task for the ASM and also a problem on how to control the ASM conducting the tasks.

\subsubsection{Conveying Mission to ASM}

The majority of the Soldiers would prefer a Blue Force Tracker system with a computer keyboard for conveying the mission to the ASM. One Soldier said the operator should be able to verbally tell the ASM the mission or send it a text message. Another indicated a premission checklist in tablet form with different mission sets preloaded.

\subsubsection{Other Mission-Oriented or Task-Related Items Needed}

Soldiers identified many other items that are needed. Some of these included a water purification system, both a wheeled and tracked capability, 4-5 ft fording capability, ladders, and the need to be $100 \%$ reliable. The complete list of all suggestions can be found in Appendix G.

\subsubsection{Other Potential ASM Considerations}

Table 18 summarizes the other mission-oriented or task-related items Soldiers were asked if the ASM should have. Detailed comments about each are found in Appendix G.

Table 18 Mission-oriented and task-related items, senior NCOs

\begin{tabular}{|l|c|c|}
\hline Mission-Oriented or Task-Related Item & Yes & No \\
\hline Manual backup for command and control & 6 & 0 \\
\hline Battery charger & 6 & 0 \\
\hline Run-flat tires & 6 & 0 \\
\hline Map display & 5 & 1 \\
\hline Air-transportable & 6 & 0 \\
\hline Run-silent mode of operation & 6 & 0 \\
\hline Voice recognition & 4 & 2 \\
\hline Multilingual voice recognition & 2 & 4 \\
\hline
\end{tabular}


A manual backup is considered necessary to overcome any malfunctions. Two Soldiers said it should be fail-safe. Others indicated that anything needs a backup and the ASM could break.

A battery charger was identified as being useful for charging all squad batteries. One Soldier indicated that it should be a universal battery charger.

Run-flat tires are necessary for the ASM to be able to continue the mission and not have to be recovered. One Soldier recommended a pressurization/depressurization system.

A map display was seen as an aid for communicating tasks to the ASM.

The ASM should be air-transportable if it is intended to be used by and considered an asset of the squad. It should be as portable as the squad. The ASM should be able to be transported with the squad for their use and be available on all missions. One Soldier recommended that it should also provide recovery options by a helicopter.

A run-silent mode of operation is necessary to maintain noise and light discipline when the mission dictates. One Soldier suggested that a silent mode of operation should be the only operational mode of the ASM.

Four of the 6 Soldiers identified the need for the ASM to have voice recognition for selected personnel. The squad leader and selected personnel should be recognized by the ASM. One Soldier said that it would be needed for reconnaissance but not for command and control because it should be able to detect the enemy by hearing and understanding their language. One Soldier was against voice recognition based on it possibly being a security issue.

The majority of senior NCOs felt that bilingual voice recognition raised concerns about the enemy being able to command and control the ASM and for security during conversations with indigenous personnel. One of the 2 Soldiers who said it should have this capability indicated that it could provide intelligence on what the locals were conversing about.

\section{Conclusions and Recommendations}

\subsection{Junior Enlisted Soldiers}

\subsubsection{Participants}

With only 2 of the 12 Soldiers having any experience with robots either directly or indirectly, coupled with the time in service, rank, and duty position of most, Soldier responses regarding squad and ASM actions during trigger events should be cautiously analyzed on a case-by-case basis. However, Soldier insights and recommendations in general are consistent with sound military judgment, and it should be noted that these Soldiers of this rank and experience will be the ultimate users. 


\subsubsection{Scenario and Trigger Events}

Soldiers did not express any concerns with the trigger events as not being realistic or plausible. The lack of leadership experience within the subject group for squad-related missions may have prevented a general consensus of opinion for SL, squad, and ASM actions on the different trigger events. The result was a typical "textbook" solution versus a real-life experience solution and not knowing how to employ an ASM to the full advantage of what it could provide. Soldiers may not have realized what an ASM sensor package could fully do or provide and this prevented them from employing it in the most useful position in relation to the squad.

\subsubsection{ASM Concept, Design, and Capabilities}

Soldiers were very positive in their support for an ASM to augment the squad and saw the potential to reduce the Soldier load, increase lethality, and provide location and route information. Some also perceived the potential for the ASM to provide automated reporting and status updates to higher echelons to reduce the leader's tasks. For the ASM to be considered helpful and not a burden to the squad, it must demonstrate reliability, navigational capability, and be available at all times to conduct a mission from start to finish. Additionally, the Soldiers' comments about operational security and prevention of compromised mission information is a real-world and legitimate design concern. ASM operation and sensor packages must conform to noise and light disciplines encountered by forces operating in all geographic terrain and mission contingencies.

\subsection{Senior Enlisted Soldiers}

\subsubsection{Participants}

Four of the 6 senior Soldiers had experience with robots either directly or indirectly. Two used the robot for IED-related tasks and the other used the robot for surveillance or reconnaissance. For both groups, the sensor packages on the robot were the most important for mission success. They were nearly unanimous (5 of 6) in preferring the ASM to be teleoperated versus autonomous. This was clearly based on their general lack of trust for the ASM to act independently and not be "supervised" or controlled in some manner.

\subsubsection{Scenario and Trigger Events}

Like the junior enlisted Soldiers, the senior enlisted Soldiers also did not express any concerns with the trigger events as not being realistic or plausible. The variety of leadership experience and personal experiences with robots within the subject group prevented a general consensus of opinion for SL, squad, and ASM actions on the different trigger events. Again, their amount of trust in the ASM was also a contributing factor. Soldiers may not have trusted what an ASM could do in theory and therefore their decisions prevented them from employing it in the most useful position in relation to the squad or to be more helpful during missions with specific tasks to be performed. 


\subsubsection{ASM Concept, Design, and Capabilities}

Unlike the junior enlisted Soldiers, the senior Soldiers were less positive in their support for an ASM to augment the squad and did not see the potential to reduce the Soldier load, increase lethality, and provide location and route information without committing a dedicated operator for command and control of the ASM. The senior enlisted Soldiers shared similar opinions with the junior enlisted Soldiers that for the ASM to be considered helpful and not a burden to the squad, it must demonstrate reliability, navigational capability, and be available at all times to conduct a mission from start to finish. Similarly, the 2 groups of Soldiers agreed that the ASM operation and sensor packages must conform to noise and light disciplines encountered by forces operating in all geographic terrain and mission contingencies.

\subsection{Overall Comments and Observations}

- Based on the lack of trust, especially with the senior enlisted Soldiers who will be the decision makers within the squad, new equipment training could be used to increase the trust in the ASM. The training will have to be thorough, put the ASM through its paces, and demonstrate the ASM's full range of capabilities for the Soldiers to accept it as "an additional squad member” and use it in an autonomous role or mode to its full capacity.

- The ASM must be dependable and reliable to accompany the squad on any mission for it to be totally accepted as a squad asset by all squad members. Otherwise, there will be a tendency to leave it in the rear.

- The ASM should be modular in design and capabilities with sensor packages and accessories being able to be mounted and removed quickly without special tools to make it adaptable and efficient for any mission.

- Actions of the leaders, squad members, and ASM for each of the trigger events and interview results identified in the body of the report should be useful as insights for the computer programmers to define squad actions for those and similar trigger events.

- The Soldier recommendations and the other potential ASM considerations identified in the body of the report should be useful to the combat developers in developing the requirements for an ASM system. 


\section{References}

Ackerman E. Emergency response teams combine mobile robots, drones, and dogs. New York (NY): IEEE Spectrum. 2014 May 6. http://spectrum.ieee.org/automaton/robotics/military -robots/emergency-response-teams-combine-mobile-robots-drones-and-dogs.

Axe D. War bots: how U.S. military robots are transforming war in Iraq, Afghanistan, and the future. Ann Arbor (MI): Nimble Books LLC; 2008.

Barnes M, Chen J, Jentsch F, Oron-Gilad T, Redden E, Elliott L, Evans A. Designing for humans in autonomous systems: military applications. Aberdeen Proving Ground (MD): Army Research Laboratory (US); 2014. Report No.: ARL-TR-6782. Also available at http://www.arl.army.mil/www/default.cfm?technical_report=6985.

Barnes M, Evans A. Soldier-robot teams in future battlefields: an overview. In: Barnes M, Jentsch F, editors. Human-robot interactions in future military operations. Farnham, Surrey (UK): Ashgate Publishing Limited; 2010.

Barnes M, Jentsch F, editors. Human-robot interactions in future military operations. Farnham, Surrey (UK): Ashgate Publishing Limited; 2010.

Chen JY, Barnes MJ. Human-agent teaming for multi-robot control: a literature review. Aberdeen Proving Ground (MD): Army Research Laboratory (US); Army Research Laboratory (US); 2013. Report No.: ARL-TR-6328. Also available at http://www.arl.army.mil/www/default.cfm?technical_report=6707.

Crandall B., Klein G, Hoffman R. Working minds: a practitioner's guide to cognitive task analysis. Cambridge (MA): MIT Press; 2006.

Doare R, Danet D, Hanon J, Boisboissel G. Robots on the battlefield: contemporary issues and implications for the future. Fort Leavenworth (KS): Combat Studies Institute Press; 2014.

Elliott LR, Jansen C, Redden E, Pettitt R. Robotic telepresence: perception, performance, and user experience. Aberdeen Proving Ground (MD): Army Research Laboratory (US); 2012. Report No.: ARL-TR-5928. Also available at http://www.arl.army.mil/www/default.cfm?technical_report=6405.

Hoffman, R. Expertise out of context: proceedings of the sixth international conference on naturalistic decision making. New York (NY): Lawrence Erlbaum Associates; 2007.

Hoffman RR. Human factors contributions to knowledge elicitation. Human Factors. 2008;50:(3)481-488. 
Hoffman RR, Elliott LR. Using scenario-based envisioning to explore wearable flexible displays. Ergonomics in Design. 2010;18-4:4-8.

Hoffman R, Militello L. Perspectives on cognitive task analysis: historical origins and modern communities of practice. New York: Psychology Press, Taylor and Francis Group; 2009.

National Research Council. Interfaces for ground and air military robots: workshop summary, Washington (DC): National Academies Press; 2005.

Pettitt RA, Redden ES, Carstens CB, Hooper D. Scalability of robotic controllers: effects of progressive autonomy on intelligence, surveillance, and reconnaissance robotic tasks. Aberdeen Proving Ground (MD): Army Research Laboratory (US); 2012. Report No.: ARL-TR-6182. Also available at http://www.arl.army.mil/www/default.cfm?technical_report=6759.

Price S. Amazing military robots. North Mankato (MN): Capstone Press; 2013.

Redden E, Elliott L, Barnes M. Robots: the new teammates. In: Coovert M, Thompson L, editors. The psychology of workplace technology. Society of Industrial Organizational Psychology Frontiers Series. New York (NY): Routledge Press; 2013.

Schraagen J, Chipman S, Shalin V. Cognitive task analysis. Mahwah (NJ): Lawrence Erlbaum Associates; 2009.

Singer PW. Wired for war: the robotics revolution and conflict in the twenty-first century. New York (NY): Penguin Press; 2009. 
INTENTIONALLY LEFT BLANK. 


\section{Appendix A. Informed Consent Form}

This appendix appears in its original form, without editorial change. 


\section{Informed Consent Form}

Army Research Laboratory, Human Research \& Engineering

Directorate, Aberdeen Proving Ground, MD

Title of Project: Soldier-Based Refinement of Simulation-based Scenarios: Squad-level Utilization of Autonomous Squad Member Robotic Assets

Project Number: ARL-

Sponsor: Army Research Laboratory

Principal Investigators:

Name: Linda R. Elliott

Division: Human Factors Integration Division

Branch: Weapons Branch

Team: Field Element at Maneuver Center of Excellence, Fort Benning, GA.

Phone Number: 7065459145

Email: Linda.r.elliott@us.army.mil

Name: Clifford Swiecicki

Division: Human Factors Integration Division

Branch: Weapons Branch

Team: Field Element at Maneuver Center of Excellence, Fort Benning, GA.

Phone Number: 7065459140

Email: clifford.c.swiecicki.civ@mail.mil

You are being asked to join a research study. This consent form explains the research study and your part in it. Please read this form carefully before you decide to take part. You can take as much time as you need. Please ask the research staff any questions at any time about anything you do not understand. You are a volunteer. If you join the study, you can change your mind later. You can decide not to take part now or you can quit at any time later on.

\section{Purpose of the Study}

The purpose of this study is to gain information from Soldiers in order to develop and more fully refine a route reconnaissance scenario at the squad level. Once refined, the scenario will be used to explore squad-level performance, particularly in a situation where the squad has a more "intelligent" robotic asset. We would like for you to review scenario events and discuss aspects of the scenario with the other Soldiers in your group. Your critical feedback and suggestions 
will help to develop more realistic scenario events, alternate courses of action, and ways in which a more autonomous robot could contribute in such a situation.

\section{Procedures to be Followed}

If you agree to participate in this study and sign this consent form, we will ask you to fill out a demographics questionnaire that asks you about your experience and background. You will be briefed further on the purpose and procedures of this focus group. The focus group meeting is expected to be about 60-90 minutes.

\section{Discomforts and Risks}

The risks associated with this experiment are considered minimal. The risks that will be encountered during this investigation are typical of the risks encountered by Soldiers performing indoor classroom training. Please inform investigators if you experience any discomfort or problems during the session.

\section{Benefits}

There are no personal benefits for you for taking part in this study. however, your participation will provide valuable information about Soldier performance that will assist in the design of future Army systems.

\section{Duration}

It will take less than 2 hours for you to take part in this study.

\section{Confidentiality}

Your participation in this research is confidential. Paper-based data will be stored and secured in a locked file cabinet. Computer-based data, without any identifying information, will be stored on a password-protected computer. This consent form will be securely retained for a minimum of three years.

If the results of the experiment are published or presented to anyone, no personally identifiable information will be shared. Publication of the results of this study in a journal or technical report, or presentation at a meeting, will not reveal personally identifiable information. The research staff will protect you data from disclosure to people not connected with the study. However, complete confidentiality cannot be guaranteed because officials of the U. S. Army human Research Protections Office and the Army Research Laboratory's Institutional Review board are permitted by law to inspect the records obtained in this study to insure compliance with laws and regulations covering experiments using human subjects.

We would like your permission to take pictures/video during the experimental session. The pictures will be printed in technical reports and shown during presentations when we describe the results of the study. To protect your identity, we will ask you to remove your name badge and 
we will pixelate the image to obscure your face. You can still be in the study if you prefer not to be photographed/videotaped. Please indicate below if you will agree to allow us to take pictures of you.

I give consent to be photographed/video during this study: Yes _ No please initial:

\section{Contact Information for Additional Questions}

You have the right to obtain answers to any questions you might have about this research both while you take part in the study and after you leave the research site. Please contact anyone listed at the top of the first page of this consent form for more information about this study. You may also contact the chairperson of the human Research \& Engineering directorate, Institution Review board, at (410) 278-5992 with questions, complaints, or concerns about this research, or if you feel this study has harmed you. The chairperson can also answer questions about your rights as a research participant. You may also call the chairperson's number if you cannot reach the research team or wish to talk to someone else.

\section{Voluntary Participation}

Your decision to be in this research is voluntary. You can stop at any time. You do not have to answer any questions you do not want to answer. Refusal to take part in or withdrawing from this study will involve no penalty or loss of benefits you would receive by staying in it.

Military personnel cannot be punished under the Uniform code of Military Justice for choosing not to take part in or withdrawing from this study, and cannot receive administrative sanctions for choosing not to participate.

Civilian employees or contractors cannot receive administrative sanctions for choosing not to participate in or withdrawing from this study.

You must be 18 years of age or older to take part in this research study. If you agree to take part in this research study based on the information outlined above, please sign your name and the date below.

You will be given a copy of this consent form for your records. 
Participant NAME

Participant Signature

date

Person Obtaining consent

date 
INTENTIONALLY LEFT BLANK. 


\section{Appendix B. Demographics: Junior Enlisted Soldiers}

This appendix appears in its original form, without editorial change. 


\section{AUTONOMOUS SQUAD MEMBER DEMOGRAPHICS}

$$
\mathrm{N}=12
$$

1. Age: 25 Years

2. Sex: 11 male, 1 female

3. Rank:

\begin{tabular}{|c|c|}
\hline RANK & QUANTITY \\
\hline E-1 & 1 \\
\hline E-2 & 1 \\
\hline E-3 & 1 \\
\hline E-4 & 2 \\
\hline E-5 & 7 \\
\hline
\end{tabular}

4. MOS:

\begin{tabular}{|c|c|}
\hline MOS & QUANTITY \\
\hline $11 \mathrm{~B}$ & 4 \\
\hline $11 \mathrm{C}$ & 1 \\
\hline $13 \mathrm{~F}$ & 1 \\
\hline $19 \mathrm{~K}$ & 4 \\
\hline $91 \mathrm{C}$ & 1 \\
\hline $91 \mathrm{H}$ & 1 \\
\hline
\end{tabular}

5. Years in service: 4 years

6. Deployments: Have you been deployed? 3 Yes, 9 No

If yes, where and how many times to each location.

\begin{tabular}{|l|c|}
\hline \multicolumn{1}{|c|}{ LOCATION } & NUMBER \\
\hline Afghanistan & 3 \\
\hline Iraq & 1 \\
\hline Kuwait & 1 \\
\hline
\end{tabular}


7. Present duty position:

\begin{tabular}{|l|c|}
\hline DUTY POSITION & NUMBER \\
\hline Squad leader & 2 \\
\hline Team leader & 1 \\
\hline M240 gunner & 2 \\
\hline Squad member & 1 \\
\hline Tank commander & 1 \\
\hline Tank driver & 2 \\
\hline Tank gunner & 1 \\
\hline Forward observer & 1 \\
\hline NCOIC & 1 \\
\hline
\end{tabular}

8. Have you had experience with robots during tactical operations, either directly (operation) or indirectly (in support and aware of what the robot did)?

$\underline{2}$ Yes (If yes, answer all the following)

- 2 Afghanistan Iraq

10 No (If No, go to question 12)

- Type of unit assigned: $\underline{1}$ Infantry, $\underline{1}$ Armor

9. What was the robot used for?

- Detonate IEDs

- Surveillance

10. Which of the following contributed to successful robot missions (check all that apply):

- $\_$_ Maneuverability

- $\quad 2$ _ Speed of traversing route

- __ Ability to lift objects

- $\quad 2$ _ Sensors (cameras, acoustic, etc.)

- _ 2 _ Ability to negotiate any type of terrain

- $\quad 2$ _ Load carrying capability

- _ 2 _ Weight/transportability

- $\quad 1$ Size

11. What missions are robots best suited for:

- Mission: dismounted patrol, counter-IED, surveillance

- Distance to control robot: 6,000 meters (surveillance) 
12. If the robot had all the capabilities you would like it to have, then what missions would it be best designed for?

- Missions:

\begin{tabular}{|l|c|}
\hline \multicolumn{1}{|c|}{ MISSION } & NUMBER \\
\hline Dismounted patrol & 4 \\
\hline Surveillance/reconnaissance & 8 \\
\hline Clearing buildings and trenches & 2 \\
\hline Scanning streets & 1 \\
\hline Route clearing & 1 \\
\hline Carrying equipment & 1 \\
\hline Guard & 1 \\
\hline Provide cover & 1 \\
\hline Infiltrate & 1 \\
\hline Target identification & 1 \\
\hline Maintenance on equipment & 1 \\
\hline Rounding troops back up & 1 \\
\hline
\end{tabular}

- Capabilities:

\begin{tabular}{|l|c|}
\hline \multicolumn{1}{|c|}{ CAPABILITY } & NUMBER \\
\hline Camera (day and night, zoom) & 5 \\
\hline IED detection & 2 \\
\hline NBC detection & 2 \\
\hline Indirect fire detection & 1 \\
\hline Enemy detection & 1 \\
\hline Load carrying & 3 \\
\hline Terrain negotiation & 1 \\
\hline Lasing device & 1 \\
\hline Weapon system & 2 \\
\hline Monitor ammunition available & 1 \\
\hline Determine safe rally point & 1 \\
\hline Fix generator & 1 \\
\hline Evaluate injured Soldier & 1 \\
\hline Provide cover & 1 \\
\hline Provide situational awareness & 1 \\
\hline Pushed out to behind enemy lines & 1 \\
\hline Track friendly Soldier locations & 1 \\
\hline
\end{tabular}


- Concept of employment:

\begin{tabular}{|l|c|}
\hline \multicolumn{1}{|c|}{ EMPLOYMENT } & NUMBER \\
\hline Forward of unit, early threat identification & 2 \\
\hline Point man & 2 \\
\hline Long range surveillance and enemy detection & 2 \\
\hline Carry extra equipment & 2 \\
\hline Move with unit & 2 \\
\hline Behind enemy lines & 1 \\
\hline Lase targets and generate targeting information & 1 \\
\hline
\end{tabular}

13. For future operations, what would be the best method of controlling the robot?

\begin{tabular}{|l|c|}
\hline \multicolumn{1}{|c|}{ CONTROL METHOD } & NUMBER \\
\hline Tele-operated (operator control via joystick, screen, or voice) & 5 \\
\hline $\begin{array}{l}\text { Autonomous (artificial intelligence and robot acts similar to a } \\
\text { squad member) }\end{array}$ & 4 \\
\hline Tele-operated and autonomous & 3 \\
\hline
\end{tabular}


INTENTIONALLY LEFT BLANK. 
Appendix C. Survey Results: Junior Enlisted Soldiers

This appendix appears in its original form, without editorial change. 


\section{AUTONOMOUS SQUAD MEMBER SURVEY INSTRUCTIONS}

You have been identified as the squad leader within a platoon. That platoon has been given a mission to conduct a dismounted route reconnaissance. Your squad has been designated as the lead or point squad for the mission. Your squad has been ordered to conduct a route reconnaissance along a section of road to be used for military movement. The area of operations has evidence of friendly and enemy events. There has been enemy activity in the area and your mission is to ensure that the route is clear for vehicular travel and any IEDs are reported and disposed of. You have been given photographs of certain high value targets (HVT) known to be in the area in the past 96 hours and are supposed to identify and detain these persons if encountered.

The Area of Operations (AO) is a lightly forested undulating patch of countryside with a couple of buildings and at least one paved road with occasional vehicular or pedestrian traffic.

The platoon leader has given you a company asset to aid in your mission - an autonomous squad member (ASM) (see concept and equipment photos below). The ASM has artificial intelligence, acts as a member of the squad, and conducts tasks and movement on its own based on the actions of the other squad members and its own observations from its sensor suite. The ASM is an all terrain vehicle that can navigate most terrain except for steep slopes but travels primarily on roads. It has obstacle avoidance technologies that allow it to maneuver around obstacles and non-negotiable terrain features. The ASM is equipped with multiple cameras, acoustic sensors, and lasers. It has a cargo carrying capability for squad equipment and other technologies that you will define based on the mission.

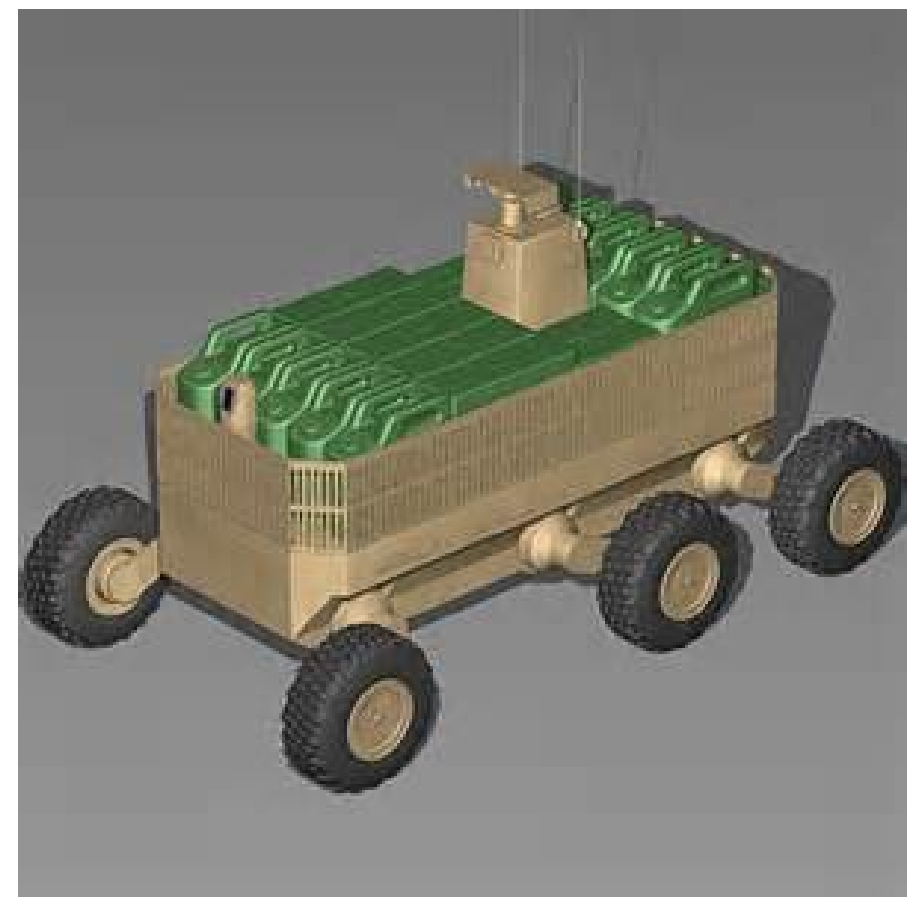




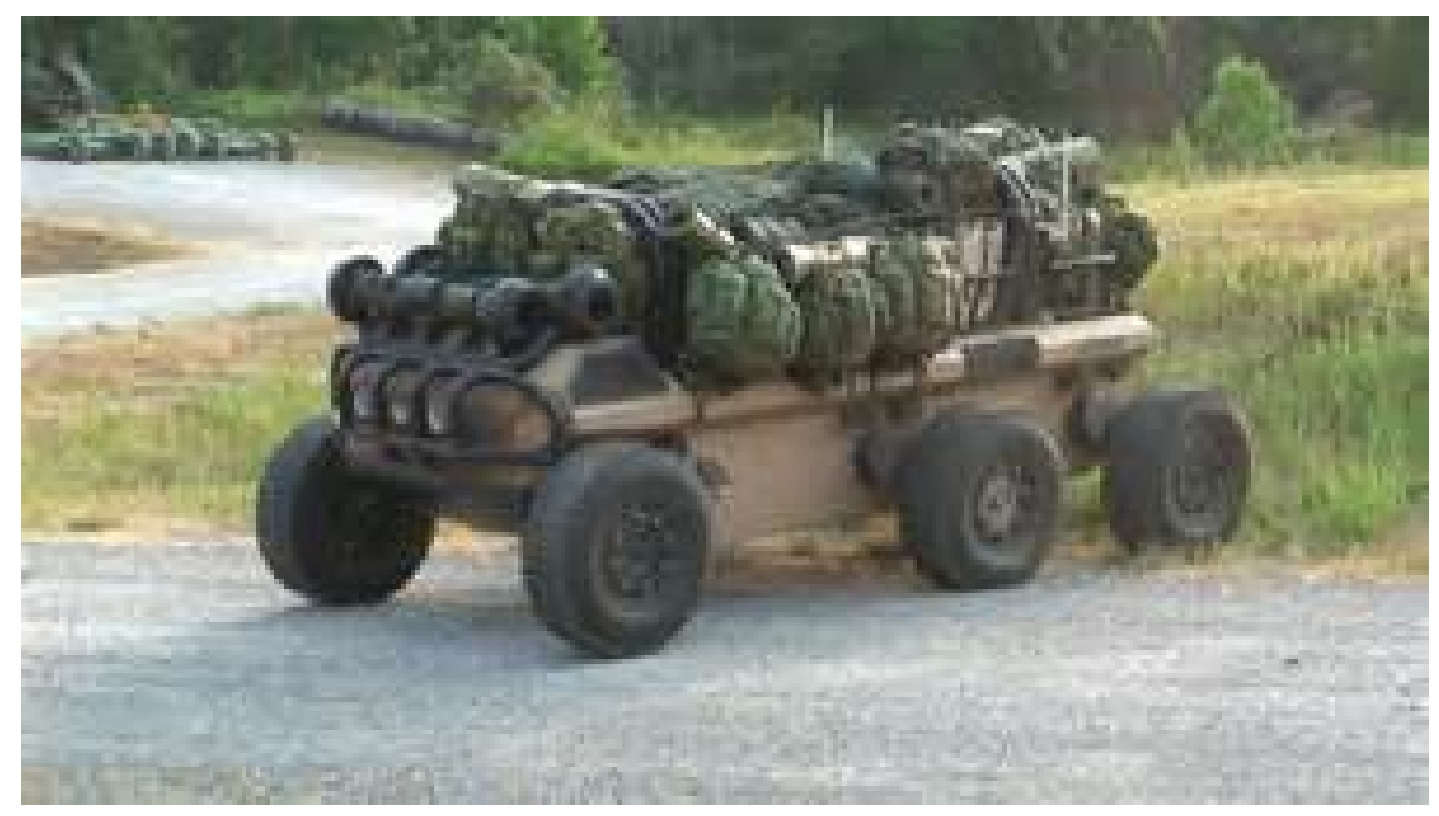

You will be asked a series of questions related to the mission and key events during it about your actions, your squad members' actions, and the actions of the ASM. These are constructed to help you determine the best ways to use and equip the ASM for successful mission performance. After completing the questionnaire, you will be interviewed.

During the mission, your squad will encounter events that will trigger some action or decisions. Your responses will aid computer modelers to develop the simulation and incorporate the actions of the squad and the ASM to determine various outcomes.

Please ask questions about anything you do not understand on the survey. 


\section{AUTONOMOUS SQUAD MEMBER SCENARIO SURVEY RESULTS}

\section{$\mathbf{N}=12$}

\section{Pre-mission checks:}

What is the preferred method for the ASM to indicate that all systems (power, drive train, tires, etc. and sensors) are operational?

\begin{tabular}{|l|c|}
\hline \multicolumn{1}{|c|}{ PREFERRED METHOD } & NUMBER \\
\hline red/amber/green lights & 4 \\
\hline text message to operator/SL & 3 \\
\hline item by item checklist display & 4 \\
\hline alert signal & 0 \\
\hline $\begin{array}{l}\text { other: (describe) Something to hook up to like the check engine light in } \\
\text { a car to know the exact error. }\end{array}$ & 1 \\
\hline
\end{tabular}

What equipment, weapons, ammunition etc. would you want to be able to load on the ASM initially that would be available to the squad during the mission?

\begin{tabular}{|l|c|}
\hline \multicolumn{1}{|c|}{ ITEMS TO BE LOADED } & NUMBER \\
\hline Weapons (small arms or heavy weapons) & 5 \\
\hline Spare weapon barrels & 1 \\
\hline Tripods & 1 \\
\hline Ammunition & 11 \\
\hline Camera & 1 \\
\hline Casualty aid and litter & 6 \\
\hline Detainee equipment & 1 \\
\hline Meals ready to eat (MRE) & 5 \\
\hline Water & 4 \\
\hline Radio & 3 \\
\hline Rucksacks & 5 \\
\hline Power source & 1 \\
\hline Land navigation tracking system & 1 \\
\hline Grenades & 1 \\
\hline Flares & 1 \\
\hline
\end{tabular}

\section{Execution of mission:}

Where in the formation do you want the ASM located?

\begin{tabular}{|l|c|}
\hline \multicolumn{1}{|c|}{ ASM LOCATION } & NUMBER \\
\hline Front & 5 \\
\hline Rear & 1 \\
\hline Middle & 2 \\
\hline Tied to SL & 2 \\
\hline Tied to squad member & 2 \\
\hline
\end{tabular}


What actions and/or tasks do you want the ASM to conduct upon reaching the SP?

\begin{tabular}{|l|c|}
\hline \multicolumn{1}{|c|}{ ACTIONS AND/OR TASKS } & NUMBER \\
\hline Reconnaissance. & 5 \\
\hline Begin movement once instructed. Alert of any danger. & 3 \\
\hline $\begin{array}{l}\text { Item by item systems check and text message to squad leader when fully } \\
\text { operational. }\end{array}$ & 2 \\
\hline Some type of system's check. & 1 \\
\hline Look for enemy and IEDs. & 4 \\
\hline Download equipment at different locations depending on the equipment. & 1 \\
\hline Send up reports to higher via message. & 1 \\
\hline Follow formation. & 1 \\
\hline Conduct rear security. & 2 \\
\hline Distributing supplies. & 1 \\
\hline Provide feedback on area about to be entered. & 1 \\
\hline
\end{tabular}

During subsequent movement, what actions and/or tasks do you want the ASM to conduct?

\begin{tabular}{|l|c|}
\hline \multicolumn{1}{|c|}{ ACTIONS AND/OR TASKS } & NUMBER \\
\hline Scouting forward. & 4 \\
\hline Scanning for danger. & 5 \\
\hline Navigation. & 1 \\
\hline Prepare signal jamming. & 1 \\
\hline Send front line trace to squad leaders by use of satellite GPS. & 1 \\
\hline Look for IEDs. & 2 \\
\hline Battery or fuel alerts. & 1 \\
\hline Serve as radio telephone operator for squad leader & 1 \\
\hline Keep communication up. & 1 \\
\hline Search for targets. & 2 \\
\hline Carry extra equipment. & 1 \\
\hline Return enemy fire. & 1 \\
\hline I don't know & 1 \\
\hline
\end{tabular}


3. During the mission, you come under a mortar attack.

Roster Number 3: E-4, MOS 11B, M240 Gunner, 2.5 years in service

As the squad leader, what actions or tasks do you do? Take cover and move squad in appropriate direction to move out of range.

What actions or tasks do the rest of the squad conduct (not the ASM)? Take cover and try to identify the direction of fire.

What actions or tasks do you want the ASM conduct? Identify the direction of fire. What actions or tasks do you take to reorient the squad and continue the mission? Move out of range, regroup, and pick best route to objective.

What actions or tasks do you want the ASM to take to reorient and continue the mission? Scout out a better route for the squad to move.

Do you want the ASM to change its location in reference to its initial position? No

Roster Number 5: E-4, MOS 11B, M240 Gunner, 3 years in service

As the squad leader, what actions or tasks do you do? Get squad out of the area quickly. Alert leadership.

What actions or tasks do the rest of the squad conduct (not the ASM)? Get out of the area.

What actions or tasks do you want the ASM conduct? Move with squad.

What actions or tasks do you take to reorient the squad and continue the mission?

Once to safety, find out where the squad is and where we need to be.

What actions or tasks do you want the ASM to take to reorient and continue the mission? Using GPS, find out where we are.

Do you want the ASM to change its location in reference to its initial position? No.

\section{Roster Number 9: E-5, MOS 11B, Team Leader, 4 years in service}

As the squad leader, what actions or tasks do you do? Call out incoming and direct squad to go into the prone position. Call out distance and direction of incoming fires. What actions or tasks do the rest of the squad conduct (not the ASM)? Echoes the distance and direction and moves away from the kill zone.

What actions or tasks do you want the ASM conduct? Break contact by audio directions from the squad leader. Calculate the safest course of action.

What actions or tasks do you take to reorient the squad and continue the mission? Find bearings and take alternate route to the objective.

What actions or tasks do you want the ASM to take to reorient and continue the mission? Calculate the best route to take to continue the mission.

Do you want the ASM to change its location in reference to its initial position? No.

\section{Roster Number 10: E-1, MOS 11B, Squad Member, 1 year in service}

As the squad leader, what actions or tasks do you do? Drop down, yell incoming, and identify where we're being attacked so my squad can know. Find cover and return fire.

What actions or tasks do the rest of the squad conduct (not the ASM)? They repeat after me and yell incoming. Drop down and identify where the attack is at. Find cover and return fire. 
What actions or tasks do you want the ASM conduct? I would want the ASM to stay close to me and find cover and scan the area for enemies or any type of incoming attack. What actions or tasks do you take to reorient the squad and continue the mission? I would have my team leaders check on their team to see if they have all their equipment or if anyone has been hit. Then they would pick up and continue the mission. My team leaders would give their teams sectors of fire.

What actions or tasks do you want the ASM to take to reorient and continue the mission? I would have the ASM continue scanning the area while my team leaders are going around doing their checks.

Do you want the ASM to change its location in reference to its initial position? Yes, if there's a wounded Soldier or a soldier low on ammunition then the ASM should change its location and head to them.

Roster Number 15: E-5, MOS 19K, Tank gunner, 4 years in service As the squad leader, what actions or tasks do you do? Move out of the blast zone and maneuver around the blast zone along with my squad. Also announce incoming when indirect fire is being conducted.

What actions or tasks do the rest of the squad conduct (not the ASM)? The primary action would be to move away from the danger zone.

What actions or tasks do you want the ASM conduct? There is not really too many options during indirect fire, but the ASM could possibly alert the squad "incoming" and direct the squad into the fastest way out of the danger zone.

What actions or tasks do you take to reorient the squad and continue the mission? Direct the squad into the direction and distance you want them to take.

What actions or tasks do you want the ASM to take to reorient and continue the mission? Maybe use a sensor to detect which direction the squad took and move along with them.

Do you want the ASM to change its location in reference to its initial position? Yes, I would want it to move to my location to help prevent the damage of any equipment or to the ASM.

Roster Number 17: E-2, MOS 19K, Tank driver, 1 year in service

As the squad leader, what actions or tasks do you do? Get down and execute a low silhouette. Would give a direction and distance to run.

What actions or tasks do the rest of the squad conduct (not the ASM)? Get down and listen for commands.

What actions or tasks do you want the ASM conduct? Follow the squad.

What actions or tasks do you take to reorient the squad and continue the mission? Regroup in a safe area and find a way around.

What actions or tasks do you want the ASM to take to reorient and continue the mission? A check to see if it's fully functional.

Do you want the ASM to change its location in reference to its initial position? No. 
Roster Number 20: E-5, MOS 19K, Tank commander, 10 years in service As the squad leader, what actions or tasks do you do? Get down. Assemble my squad at different pre-set location. Conduct LACE (liquid, ammo, casualties, equipment) report. Call higher with situation report (SITREP).

What actions or tasks do the rest of the squad conduct (not the ASM)? Team leaders conduct LACE report to me. Soldiers conduct MEDEVAC if needed and pull security.

What actions or tasks do you want the ASM conduct? Let higher know. What actions or tasks do you take to reorient the squad and continue the mission? Reorganize and consolidate equipment.

What actions or tasks do you want the ASM to take to reorient and continue the mission? Pull up map on FBCB2 and let higher know of where we are moving to.

Do you want the ASM to change its location in reference to its initial position? Yes, so it doesn't get blown up following the squad.

Roster Number 21: E-3, MOS 19K, Tank driver, .5 years in service

As the squad leader, what actions or tasks do you do? Ensure 100 percent functionality of squad and provide leadership and direction to travel.

What actions or tasks do the rest of the squad conduct (not the ASM)? Conduct react to mortar attack "indirect fire" drill.

What actions or tasks do you want the ASM conduct? Follow squad and report contact with general location of contact to higher up.

What actions or tasks do you take to reorient the squad and continue the mission? Check azimuth. Move and scan while following robot.

What actions or tasks do you want the ASM to take to reorient and continue the mission? Gather GPS data. Conduct normal actions and try to stay out of mortar range. Do you want the ASM to change its location in reference to its initial position? Yes, needs to be able o change course if needed.

\section{Roster Number 27: E-5, MOS 11C, squad leader, 7 years in service}

As the squad leader, what actions or tasks do you do? Get down. Wait 3-5 seconds. Find cover and run to it. Make sure $100 \%$ of personnel are OK.

What actions or tasks do the rest of the squad conduct (not the ASM)? Try to find the mortar point.

What actions or tasks do you want the ASM conduct? To work as a radar to track where the mortar rounds came from.

What actions or tasks do you take to reorient the squad and continue the mission? Ensure all personnel are OK. Call it up to higher. Make sure that there are no enemy scouts in the area.

What actions or tasks do you want the ASM to take to reorient and continue the mission? Do a 360 degree scan to ensure that there are no enemy in the area.

Do you want the ASM to change its location in reference to its initial position? No. 


\section{Roster Number 29: E-5, MOS 13F, Forward Observer, 4 years in service}

As the squad leader, what actions or tasks do you do? Call direction of fire. Place squad members and communicate with other squad leaders for movement.

What actions or tasks do the rest of the squad conduct (not the ASM)? Observe area and provide security.

What actions or tasks do you want the ASM conduct? Crater analysis.

What actions or tasks do you take to reorient the squad and continue the mission?

Pull security. Find direction and distance or have ASM lase grid to target. Call in a fire mission to mortars. Continue mission.

What actions or tasks do you want the ASM to take to reorient and continue the mission? Pull security. Find direction and distance or have ASM lase grid to target. Call in a fire mission to mortars. Continue mission.

Do you want the ASM to change its location in reference to its initial position? No.

\section{Roster Number 32: E-5, MOS 91C, NCOIC, 7 years in service}

As the squad leader, what actions or tasks do you do? Fire back. Get my Soldiers to cover while still firing. Check everyone for status while firing. Check to see if we can handle it or need to fall back. Report up saying which status and if I can handle it. Wait on reply back.

What actions or tasks do the rest of the squad conduct (not the ASM)? Fire back and take cover. Give status. Await following orders (fall back or push forward).

What actions or tasks do you want the ASM conduct? Fire back and give status. Survey the area to see if we can take it. Move forward to allow Soldiers to fall back if the word is given not to move forward.

What actions or tasks do you take to reorient the squad and continue the mission? Alert them to reply back with a quick status of themselves and equipment. Alert them to a rally point to get hands on status and 360 degree security.

What actions or tasks do you want the ASM to take to reorient and continue the mission? Send reports to higher without someone having to talk on a radio and walk around with one all the time.

Do you want the ASM to change its location in reference to its initial position? Both, just in case the signal is tapped it should be able to change its location and send out a warning.

\section{Roster Number 33: E-5, MOS 91H, Squad leader, 3.5 years in service}

As the squad leader, what actions or tasks do you do? Get squad to a good cover area safely.

What actions or tasks do the rest of the squad conduct (not the ASM)? Cover each other as they move to a cover area.

What actions or tasks do you want the ASM conduct? Scan for safe area to move towards and identify where mortar attack is coming from. Send information to all Soldiers.

What actions or tasks do you take to reorient the squad and continue the mission? If it has all the footprints of all Soldiers in the squad then we will be able to track each other and if the squad leaders touch screen can be touched, drawing lines and sent to other Soldiers in the squad on where to meet up. 
What actions or tasks do you want the ASM to take to reorient and continue the mission? Continue scanning area. Once all Soldiers are together it should then continue to next point.

Do you want the ASM to change its location in reference to its initial position? Yes, once all Soldiers are together again, then it should update its position and proceed from there.

4. During the mission, you receive sniper fire.

Roster Number 3: E-4, MOS 11B, M240 Gunner, 2.5 years in service

As the squad leader, what actions or tasks do you do? Take cover and maneuver to better position to conduct react to fire tasks.

What actions or tasks do the rest of the squad conduct (not the ASM)? Take cover and identify sniper and suppress in order to move to a better location.

What actions or tasks do you want the ASM conduct? Try to identify sniper position so the squad can maneuver on the target quicker and easier.

What actions or tasks do you take to reorient the squad and continue the mission? Find better route to objective or to target.

What actions or tasks do you want the ASM to take to reorient and continue the mission? Identify the sniper and find best route to maneuver on the target.

Do you want the ASM to change its location in reference to its initial position? No.

\section{Roster Number 5: E-4, MOS 11B, M240 Gunner, 3 years in service}

As the squad leader, what actions or tasks do you do? Make sure squad members are behind cover.

What actions or tasks do the rest of the squad conduct (not the ASM)? Get behind cover. Try to identify where fire is coming from.

What actions or tasks do you want the ASM conduct? Scan with camera to relay position of the sniper.

What actions or tasks do you take to reorient the squad and continue the mission? Find out if we will be able to eliminate the target and continue or go on a different route. What actions or tasks do you want the ASM to take to reorient and continue the mission? Help by showing where we are and avenues to enemy or out of area.

Do you want the ASM to change its location in reference to its initial position? Yes, tied to squad leader.

Roster Number 9: E-5, MOS 11B, Team Leader, 4 years in service

As the squad leader, what actions or tasks do you do? Alert squad of sniper fire and direct squad to take cover.

What actions or tasks do the rest of the squad conduct (not the ASM)? Take cover and locate where the sniper fire is coming from.

What actions or tasks do you want the ASM conduct? Identify where the sniper is located and calculate the best route to engage and destroy the enemy.

What actions or tasks do you take to reorient the squad and continue the mission?

Once sniper is destroyed, continue on the original route. 
What actions or tasks do you want the ASM to take to reorient and continue the mission? Continue movement with the squad.

Do you want the ASM to change its location in reference to its initial position? No.

\section{Roster Number 10: E-1, MOS 11B, Squad Member, 1 year in service}

As the squad leader, what actions or tasks do you do? Yell contact. Drop down and find cover. By not moving, checking by asking or yelling to see if anyone has been hit. What actions or tasks do the rest of the squad conduct (not the ASM)? I want my squad to yell contact, drop down, and find cover. They should try to see where the shooting is coming from without moving from their covered and concealed position. What actions or tasks do you want the ASM conduct? I would want the ASM to find cover and scan for any wounded Soldiers, scan for enemy sniper or for any enemy forces.

What actions or tasks do you take to reorient the squad and continue the mission? I would try to get my entire squad out of the area the sniper is aiming at and then have my team leaders do their checks on the Soldiers. Then they would continue the mission.

What actions or tasks do you want the ASM to take to reorient and continue the mission? I would want the ASM to continue on scanning for any snipers. As squad members move out, have the ASM scan buildings.

Do you want the ASM to change its location in reference to its initial position? No.

\section{Roster Number 15: E-5, MOS 19K, Tank gunner, 4 years in service}

As the squad leader, what actions or tasks do you do? Direct my squad into cover and out of fire of the sniper.

What actions or tasks do the rest of the squad conduct (not the ASM)? Move into cover, then possibly scan and detect the sniper.

What actions or tasks do you want the ASM conduct? Try and detect which direction the fire "shot" came from. Or even act as cover if the terrain does not offer any.

What actions or tasks do you take to reorient the squad and continue the mission? Try to eliminate the target first. If it seems fatal then I would break contact and move out of the danger zone.

What actions or tasks do you want the ASM to take to reorient and continue the mission? If the squad decides to break contact, then the ASM would simply maneuver out with the squad.

Do you want the ASM to change its location in reference to its initial position? Yes, out of contact to help prevent any damage to equipment or the ASM.

\section{Roster Number 17: E-2, MOS 19K, Tank driver, 1 year in service}

As the squad leader, what actions or tasks do you do? Order to cover and seek to eliminate hostile.

What actions or tasks do the rest of the squad conduct (not the ASM)? Find cover and engage hostile.

What actions or tasks do you want the ASM conduct? Act as cover and figure out the direction of where the rounds came from and position itself between us and the sniper.

What actions or tasks do you take to reorient the squad and continue the mission? Treat wounded and report status. 
What actions or tasks do you want the ASM to take to reorient and continue the mission? If there's time, do a functions check.

Do you want the ASM to change its location in reference to its initial position? Yes, I would like it to move to the center so it could be used as cover.

Roster Number 20: E-5, MOS 19K, Tank commander, 10 years in service As the squad leader, what actions or tasks do you do? Take cover and get out of area. What actions or tasks do the rest of the squad conduct (not the ASM)? Once out of area, team leaders LACE. Soldiers conduct 360 degree security.

What actions or tasks do you want the ASM conduct? Send message to higher on SITREP.

What actions or tasks do you take to reorient the squad and continue the mission? Let higher know and reorganize and reconstitute equipment.

What actions or tasks do you want the ASM to take to reorient and continue the mission? Pull up map on FBCB2.

Do you want the ASM to change its location in reference to its initial position? Yes, so it doesn't get shot following the squad.

Roster Number 21: E-3, MOS 19K, Tank driver, .5 years in service As the squad leader, what actions or tasks do you do? Lead the squad. What actions or tasks do the rest of the squad conduct (not the ASM)? Conduct react to sniper fire drill.

What actions or tasks do you want the ASM conduct? Suppress with machine gun. What actions or tasks do you take to reorient the squad and continue the mission? Ensure squad readiness and follow robot.

What actions or tasks do you want the ASM to take to reorient and continue the mission? Ensure sniper is either dead or suppressed. Provide cover while rest of squad moves tactically to cover and continues mission.

Do you want the ASM to change its location in reference to its initial position? No, needs to remain in good spot to cover squad if need be or move to kill sniper.

\section{Roster Number 27: E-5, MOS 11C, squad leader, 7 years in service}

As the squad leader, what actions or tasks do you do? Get behind cover and try to find where the sniper is shooting from.

What actions or tasks do the rest of the squad conduct (not the ASM)? Get behind cover and try to find where the sniper is shooting from.

What actions or tasks do you want the ASM conduct? To scan using thermal technology 360 degrees to find the sniper. To shoot back at the sniper with crew served weapons.

What actions or tasks do you take to reorient the squad and continue the mission? Take out target. Call it up to higher and continue the mission.

What actions or tasks do you want the ASM to take to reorient and continue the mission? Call up to higher via text message.

Do you want the ASM to change its location in reference to its initial position? Yes, to watch as a tracker so the squad leader can put his attention on the rest of the squad. 


\section{Roster Number 29: E-5, MOS 13F, Forward Observer, 4 years in service}

As the squad leader, what actions or tasks do you do? Find direction of shooter and orient squad.

What actions or tasks do the rest of the squad conduct (not the ASM)? Orient towards shooter, lay down suppressive fires, and continue battle drill.

What actions or tasks do you want the ASM conduct? Pick up heat signatures and provide grid to said heat signatures.

What actions or tasks do you take to reorient the squad and continue the mission?

Tactically bound to eliminate threat or conduct call for fire.

What actions or tasks do you want the ASM to take to reorient and continue the mission? Pick up heat signatures and provide grid to that location.

Do you want the ASM to change its location in reference to its initial position? No.

\section{Roster Number 32: E-5, MOS 91C, NCOIC, 7 years in service}

As the squad leader, what actions or tasks do you do? Give order to take cover, survey the land, give direction of sniper. Make decision on taking sniper out. Report this to higher and wait on answer to take sniper out.

What actions or tasks do the rest of the squad conduct (not the ASM)? Take good cover. Survey land to help seek out sniper. Await orders to kill or move out.

What actions or tasks do you want the ASM conduct? Survey land faster and provide target information. Give best direction to target. Report everything.

What actions or tasks do you take to reorient the squad and continue the mission? Alert them to provide quick status of personnel and supplies. Alert them to a rally point to get a hands on status and 360 degree security.

What actions or tasks do you want the ASM to take to reorient and continue the mission? Send reports to higher without someone having to talk on a radio and walk around with one all the time.

Do you want the ASM to change its location in reference to its initial position? Yes, if needed to move.

\section{Roster Number 33: E-5, MOS 91H, Squad leader, 3.5 years in service}

As the squad leader, what actions or tasks do you do? Identify where the fire is coming from. Place soldiers accordingly and cover them as they move.

What actions or tasks do the rest of the squad conduct (not the ASM)? Move to where they are in a safe position to return fire and cover battles as they move.

What actions or tasks do you want the ASM conduct? Keeping track of Soldiers' footprints and scanning area. Identify additional threats. Find a safe route to the next point and relay route back to Soldiers. Alert squad leader of any fallen Soldiers.

What actions or tasks do you take to reorient the squad and continue the mission? Use drawing on the screen to communicate with Soldiers or via an effective ear piece to communicate with everyone.

What actions or tasks do you want the ASM to take to reorient and continue the mission? Dictate a safe rally point out of readings it gets from enemy scans.

Do you want the ASM to change its location in reference to its initial position? Yes, it should always change when Soldiers are back together. 
5. During the mission, you encounter an obstacle that requires movement around it.

\section{Roster Number 3: E-4, MOS 11B, M240 Gunner, 2.5 years in service}

As the squad leader, what actions or tasks do you do? Halt the squad and pull security.

What actions or tasks do the rest of the squad conduct (not the ASM)? Pull security while best route is determined.

What actions or tasks do you want the ASM conduct? Move forward to find the best route around obstacle.

What actions or tasks do you take to reorient the squad and continue the mission? Pull security until the best route is determined and then pick up and move out.

What actions or tasks do you want the ASM to take to reorient and continue the mission? Look for potential hostile activity while it finds an alternate route.

Do you want the ASM to change its location in reference to its initial position? Yes.

Move around the object or obstacle to find a good route.

\section{Roster Number 5: E-4, MOS 11B, M240 Gunner, 3 years in service}

As the squad leader, what actions or tasks do you do? Determine best way around obstacle.

What actions or tasks do the rest of the squad conduct (not the ASM)? Pull security and be prepared to move on command.

What actions or tasks do you want the ASM conduct? Using GPS, show best way around obstacle.

What actions or tasks do you take to reorient the squad and continue the mission? After determining best route and likely avenue of approach, put my guys where I need them and move out.

What actions or tasks do you want the ASM to take to reorient and continue the mission? Same as squad.

Do you want the ASM to change its location in reference to its initial position? No.

Roster Number 9: E-5, MOS 11B, Team Leader, 4 years in service

As the squad leader, what actions or tasks do you do? Halt the squad and determine the best route to go around the obstacle.

What actions or tasks do the rest of the squad conduct (not the ASM)? Take a knee and scan their sectors of fire.

What actions or tasks do you want the ASM conduct? Assist in determining the best route.

What actions or tasks do you take to reorient the squad and continue the mission? Determine the best route and continue the mission.

What actions or tasks do you want the ASM to take to reorient and continue the mission? Continue mission using the alternate route.

Do you want the ASM to change its location in reference to its initial position? No. 
Roster Number 10: E-1, MOS 11B, Squad Member, 1 year in service

As the squad leader, what actions or tasks do you do? I would halt the entire squad.

I will identify the obstacle and come up with a way around it. Then have my first team go through while the second team is pulling guard. Then my second team would follow. What actions or tasks do the rest of the squad conduct (not the ASM)? I would have my first team go through while my second team is pulling guard. Once my first team goes through, then the second team picks up and follows through.

What actions or tasks do you want the ASM conduct? I would want the ASM to stay back with the second team and pull guard. Then move out with the second team once the first team is through.

What actions or tasks do you take to reorient the squad and continue the mission? Have both team leaders do their normal checks on each Soldier in their team. Check equipment and water and see if anyone was wounded.

What actions or tasks do you want the ASM to take to reorient and continue the mission? I would have the ASM continue scanning and if needed have the ASM move to any Soldier that is missing equipment or low on water or is wounded.

Do you want the ASM to change its location in reference to its initial position? No.

Roster Number 15: E-5, MOS 19K, Tank gunner, 4 years in service

As the squad leader, what actions or tasks do you do? Find the area that is best concealed or offers no potential threat and move around it.

What actions or tasks do the rest of the squad conduct (not the ASM)? Bound from one side of the obstacle to the other and pull far side security to allow the rest of the squad to bound to their position.

What actions or tasks do you want the ASM conduct? In this case, go ahead of the squad to ensure there is no potential threat in the area. Also to make sure the enemy is not using the obstacle as a choke point to lead the squad into that direction.

What actions or tasks do you take to reorient the squad and continue the mission? I would rally my squad on the far side of the obstacle and continue mission from that position.

What actions or tasks do you want the ASM to take to reorient and continue the mission? At this point, I would like for the ASM to get my squad back in the appropriate direction.

Do you want the ASM to change its location in reference to its initial position? Yes, to the far side of the obstacle to ensure there is no threat before the squad maneuvers around the obstacle.

Roster Number 17: E-2, MOS 19K, Tank driver, 1 year in service

As the squad leader, what actions or tasks do you do? Evaluate the obstacle and call it in. Let others know to search for the best possible way around.

What actions or tasks do the rest of the squad conduct (not the ASM)? Pull security. What actions or tasks do you want the ASM conduct? Get down as low as possible to hide itself.

What actions or tasks do you take to reorient the squad and continue the mission? Regroup and continue the mission.

What actions or tasks do you want the ASM to take to reorient and continue the mission? Follow the group.

Do you want the ASM to change its location in reference to its initial position? No. 
Roster Number 20: E-5, MOS 19K, Tank commander, 10 years in service

As the squad leader, what actions or tasks do you do? Push out security and call higher.

What actions or tasks do the rest of the squad conduct (not the ASM)? Pull security. What actions or tasks do you want the ASM conduct? Contact higher.

What actions or tasks do you take to reorient the squad and continue the mission? Find out what higher wants.

What actions or tasks do you want the ASM to take to reorient and continue the mission? Depends on what higher directs.

Do you want the ASM to change its location in reference to its initial position? Yes, we as a squad will move once higher decides, follows squad.

Roster Number 21: E-3, MOS 19K, Tank driver, .5 years in service As the squad leader, what actions or tasks do you do? Guide squad around. What actions or tasks do the rest of the squad conduct (not the ASM)? Follow me. What actions or tasks do you want the ASM conduct? Lead squad leader. What actions or tasks do you take to reorient the squad and continue the mission? Follow robot.

What actions or tasks do you want the ASM to take to reorient and continue the mission? Re-orient and follow new route.

Do you want the ASM to change its location in reference to its initial position? Yes, to navigate around obstacle.

Roster Number 27: E-5, MOS 11C, squad leader, 7 years in service As the squad leader, what actions or tasks do you do? See if there is a way to move around the obstacle.

What actions or tasks do the rest of the squad conduct (not the ASM)? Move around obstacle.

What actions or tasks do you want the ASM conduct? To be able to move with the rest of the squad and not get stuck. Find paths while still keeping the squad on course.

What actions or tasks do you take to reorient the squad and continue the mission? Call up to higher.

What actions or tasks do you want the ASM to take to reorient and continue the mission? Call up to higher via text.

Do you want the ASM to change its location in reference to its initial position? Yes, track location. 
Roster Number 29: E-5, MOS 13F, Forward Observer, 4 years in service As the squad leader, what actions or tasks do you do? Assess obstacle and go around. What actions or tasks do the rest of the squad conduct (not the ASM)? Have situational awareness (SA) and scan area.

What actions or tasks do you want the ASM conduct? Send up location of change in route.

What actions or tasks do you take to reorient the squad and continue the mission? Call short halt. Guide around obstacle.

What actions or tasks do you want the ASM to take to reorient and continue the mission? Nothing.

Do you want the ASM to change its location in reference to its initial position? No.

Roster Number 32: E-5, MOS 91C, NCOIC, 7 years in service

As the squad leader, what actions or tasks do you do? Stop and get 360 degree security. Send out two scouts in different directions. Await scouts' reports. Move to scout's location that is better and safe. Report to higher of first stop, the move around, and then movement out.

What actions or tasks do the rest of the squad conduct (not the ASM)? Get 360 degree security. Two will scout out and report back. Await orders on best direction for travel.

What actions or tasks do you want the ASM conduct? Survey land so that we do not run into objects that will stop us. Handle all reporting to higher.

What actions or tasks do you take to reorient the squad and continue the mission? Alert them of the path and move out.

What actions or tasks do you want the ASM to take to reorient and continue the mission? Send out the direction of travel to higher and have them report back.

Do you want the ASM to change its location in reference to its initial position? No, if just doing land navigation there is no need to change location.

\section{Roster Number 33: E-5, MOS 91H, Squad leader, 3.5 years in service}

As the squad leader, what actions or tasks do you do? Move squad accordingly. Alert them of what is going on.

What actions or tasks do the rest of the squad conduct (not the ASM)? Follow and move accordingly. If something comes up, alert the squad leader.

What actions or tasks do you want the ASM conduct? Scan the area and provide scan of new route to squad.

What actions or tasks do you take to reorient the squad and continue the mission? Make sure all Soldiers are up and intact. Review ASM scan and continue mission. What actions or tasks do you want the ASM to take to reorient and continue the mission? Alert Soldiers of route to be taken. ASM stays in place until all Soldiers arrive and then continues mission.

Do you want the ASM to change its location in reference to its initial position? Yes, to current position because that will have been the last safe point. 
6. During the mission, you detect an IED location.

\section{Roster Number 3: E-4, MOS 11B, M240 Gunner, 2.5 years in service}

As the squad leader, what actions or tasks do you do? Cordon off area and perform checks for other possible IEDs or hostiles.

What actions or tasks do the rest of the squad conduct (not the ASM)? Pull security and cordon off area.

What actions or tasks do you want the ASM conduct? Scan area for hostile personnel and other possible IEDs.

What actions or tasks do you take to reorient the squad and continue the mission? Cordon area off. Call EOD and wait or move on after marking location.

What actions or tasks do you want the ASM to take to reorient and continue the mission? Mark IED for EOD or other units to know it is there.

Do you want the ASM to change its location in reference to its initial position? Yes, move to good scanning location.

\section{Roster Number 5: E-4, MOS 11B, M240 Gunner, 3 years in service}

As the squad leader, what actions or tasks do you do? Stop movement. Check for secondary IEDs. Confirm that it is an IED. Cordon off the area. Notify leadership. What actions or tasks do the rest of the squad conduct (not the ASM)? Make sure no one comes into the area.

What actions or tasks do you want the ASM conduct? Check for more IEDs.

What actions or tasks do you take to reorient the squad and continue the mission? Once clear, determine which way to move out.

What actions or tasks do you want the ASM to take to reorient and continue the mission? Same as squad.

Do you want the ASM to change its location in reference to its initial position? Yes, scanning for more IEDs.

Roster Number 9: E-5, MOS 11B, Team Leader, 4 years in service

As the squad leader, what actions or tasks do you do? Halt the squad and cordon off the IED. Call for EOD to come and detonate the IED.

What actions or tasks do the rest of the squad conduct (not the ASM)? Set up a perimeter around the IED and scan for secondary IEDs.

What actions or tasks do you want the ASM conduct? Move to the IED to get a better look at what kind of IEDs there are.

What actions or tasks do you take to reorient the squad and continue the mission? Once IED is destroyed, continue the mission.

What actions or tasks do you want the ASM to take to reorient and continue the mission? Continue scanning for secondary IEDs and continue the mission.

Do you want the ASM to change its location in reference to its initial position? No. 
Roster Number 10: E-1, MOS 11B, Squad Member, 1 year in service

As the squad leader, what actions or tasks do you do? Once I detect an IED, I will immediately halt my entire squad, back up if we're too close, and find cover. I would have my squad pull security.

What actions or tasks do the rest of the squad conduct (not the ASM)? Have my squad find cover and pull security.

What actions or tasks do you want the ASM conduct? I will have the ASM continue to move forward scanning while moving and have it designate the IED.

What actions or tasks do you take to reorient the squad and continue the mission? Once the IED is taken care of, I will have my team leaders do their normal checks on their teams.

What actions or tasks do you want the ASM to take to reorient and continue the mission? I would have the ASM come back after it takes care of the IED and continue to scan the area.

Do you want the ASM to change its location in reference to its initial position? Yes, the ASM needs to come back to the squad once it's done with the IED.

\section{Roster Number 15: E-5, MOS 19K, Tank gunner, 4 years in service} As the squad leader, what actions or tasks do you do? Announce "IED”. From there we conduct 5's and 25's. Basically to ensure there isn't a chain of IEDs. Then you perform 360 degree security around the IED itself until the proper EOD team can come in and properly handle the explosive.

What actions or tasks do the rest of the squad conduct (not the ASM)? They help pull 360 degree security.

What actions or tasks do you want the ASM conduct? Approach the IED at a closer distance to confirm that it is an IED.

What actions or tasks do you take to reorient the squad and continue the mission? Direct them to pull outer 360 degree security on the IED until it is properly disposed of. What actions or tasks do you want the ASM to take to reorient and continue the mission? Possibly confirm if it is an IED.

Do you want the ASM to change its location in reference to its initial position? Move closer to the explosive to confirm if it is an IED or just "garbage".

\section{Roster Number 17: E-2, MOS 19K, Tank driver, 1 year in service}

As the squad leader, what actions or tasks do you do? After sighted, I would order a blockade to keep civilians out of the possible blast radius and at the same time call it in to command and provide location of the bomb so bomb squad could get sent in.

What actions or tasks do the rest of the squad conduct (not the ASM)? Clear the area cautiously - don't want to alert the trigger man or scare the public.

What actions or tasks do you want the ASM conduct? Stick with the specific part of the group and keep whatever gear it's holding away from the bomb. It could defuse the bomb if possible or give an alert to command of our location and status.

What actions or tasks do you take to reorient the squad and continue the mission? After the bomb is defused, we would get a status report and continue.

What actions or tasks do you want the ASM to take to reorient and continue the mission? Come back to the group and alert us if it has taken critical damage that could decrease its performance.

Do you want the ASM to change its location in reference to its initial position? No. 
Roster Number 20: E-5, MOS 19K, Tank commander, 10 years in service

As the squad leader, what actions or tasks do you do? Pull back, set security, and call higher.

What actions or tasks do the rest of the squad conduct (not the ASM)? Pull back, set security, and look for overwatchers.

What actions or tasks do you want the ASM conduct? Pull back, contact higher.

What actions or tasks do you take to reorient the squad and continue the mission?

Depends on what higher decides.

What actions or tasks do you want the ASM to take to reorient and continue the mission? Contact higher and let me know what they say.

Do you want the ASM to change its location in reference to its initial position? Yes, so it doesn't get blown up. Follows the squad.

\section{Roster Number 21: E-3, MOS 19K, Tank driver, .5 years in service}

As the squad leader, what actions or tasks do you do? Get away from it and navigate around it.

What actions or tasks do the rest of the squad conduct (not the ASM)? Get away from it and navigate around it.

What actions or tasks do you want the ASM conduct? Stay back and wait for orders. What actions or tasks do you take to reorient the squad and continue the mission? Tell robot to shoot at it to blow it up.

What actions or tasks do you want the ASM to take to reorient and continue the mission? Blow up IED.

Do you want the ASM to change its location in reference to its initial position? No.

Roster Number 27: E-5, MOS 11C, squad leader, 7 years in service

As the squad leader, what actions or tasks do you do? Call it up to the platoon leader. Get positive identification and call up EOD.

What actions or tasks do the rest of the squad conduct (not the ASM)? Look out for trigger man. Look for secondary IEDs. Look for trip wire.

What actions or tasks do you want the ASM conduct? Alert the squad leader before reaching the IED.

What actions or tasks do you take to reorient the squad and continue the mission? Blow up the IED in place and continue mission.

What actions or tasks do you want the ASM to take to reorient and continue the mission? Call up to higher. Mark as a known point for IED. Continue mission.

Do you want the ASM to change its location in reference to its initial position? Yes, to track location and to upload grid so commander can track that location if more IEDs were to placed there. 
Roster Number 29: E-5, MOS 13F, Forward Observer, 4 years in service As the squad leader, what actions or tasks do you do? Short halt. 360 degree security 100 meters around IED. Send up through communications channels.

What actions or tasks do the rest of the squad conduct (not the ASM)? 360 degree security 100 meters around IED.

What actions or tasks do you want the ASM conduct? If capable of disarming IED, disarm it. If not, scan area for trigger via heat signature.

What actions or tasks do you take to reorient the squad and continue the mission? Once IED is neutralized, continue mission.

What actions or tasks do you want the ASM to take to reorient and continue the mission? Once IED is neutralized, continue mission.

Do you want the ASM to change its location in reference to its initial position? No.

\section{Roster Number 32: E-5, MOS 91C, NCOIC, 7 years in service}

As the squad leader, what actions or tasks do you do? Alert everyone to back off 30 meters. Get 360 degree security around IED. Report to higher. Don't let anyone in area. Await EOD.

What actions or tasks do the rest of the squad conduct (not the ASM)? Back off 30 meters.. Pull 360 degree security. Don't let anyone in.

What actions or tasks do you want the ASM conduct? Alert everyone in the area of IED. Check IED and disarm if possible. Send reports to higher.

What actions or tasks do you take to reorient the squad and continue the mission? Maintain 360 degree perimeter until further orders are given.

What actions or tasks do you want the ASM to take to reorient and continue the mission? Alert everyone faster of what is happening and when we can move out. Send all reports.

Do you want the ASM to change its location in reference to its initial position? Yes, change location so the enemy will think we are lost or gone.

\section{Roster Number 33: E-5, MOS 91H, Squad leader, 3.5 years in service}

As the squad leader, what actions or tasks do you do? Notify Soldiers as soon as seen. Call EOD. Stay a safe distance away and set up 360 degree scan of area.

What actions or tasks do the rest of the squad conduct (not the ASM)? Conduct 360 degree scan of area but at a good distance away from IED.

What actions or tasks do you want the ASM conduct? It should be able to do the job of EOD.

What actions or tasks do you take to reorient the squad and continue the mission? Once the IED is taken care of, move to safe spot and set up guard until ASM has a safe route to take to next point.

What actions or tasks do you want the ASM to take to reorient and continue the mission? Continue to travel and scan to next point on a safe route. Once it's about two miles out, stop and wait while stills canning area and notify squad leader of any changes.

Do you want the ASM to change its location in reference to its initial position? Yes, as mission and route dictates. Forward to scan new route and safe points. 
7. During the mission, you are ambushed.

Roster Number 3: E-4, MOS 11B, M240 Gunner, 2.5 years in service

As the squad leader, what actions or tasks do you do? Conduct react to ambush tasks. What actions or tasks do the rest of the squad conduct (not the ASM)? Conduct react to ambush tasks.

What actions or tasks do you want the ASM conduct? Halt and drop supplies to squad leader or those who need them.

What actions or tasks do you take to reorient the squad and continue the mission?

Destroy objective and perform ACE report. Kick out special teams.

What actions or tasks do you want the ASM to take to reorient and continue the mission? Search hostiles or move ammunition and gear to those who need them.

Do you want the ASM to change its location in reference to its initial position? Yes, move along the line of the squad to assist with spreading out equipment and ammunition as needed.

Roster Number 5: E-4, MOS 11B, M240 Gunner, 3 years in service As the squad leader, what actions or tasks do you do? Determine whether to assault through ambush or flank.

What actions or tasks do the rest of the squad conduct (not the ASM)? Return fire, seek cover, and call in distance, direction, and description.

What actions or tasks do you want the ASM conduct? Using camera, identify where the enemy is.

What actions or tasks do you take to reorient the squad and continue the mission? After it is clear, check guys for equipment, find out where we need to be and move out. What actions or tasks do you want the ASM to take to reorient and continue the mission? Using GPS, show the way.

Do you want the ASM to change its location in reference to its initial position? Yes, tied to squad leader.

\section{Roster Number 9: E-5, MOS 11B, Team Leader, 4 years in service}

As the squad leader, what actions or tasks do you do? Call for the squad to get online and assault through the ambush.

What actions or tasks do the rest of the squad conduct (not the ASM)? Get online and gain fire superiority while assaulting through the ambush.

What actions or tasks do you want the ASM conduct? Halt and wait to be called forward once the enemy has been destroyed.

What actions or tasks do you take to reorient the squad and continue the mission? Conduct aid and litter searches, detainee searches, consolidate and continue the mission. What actions or tasks do you want the ASM to take to reorient and continue the mission? Move forward and assist in searches.

Do you want the ASM to change its location in reference to its initial position? No. 


\section{Roster Number 10: E-1, MOS 11B, Squad Member, 1 year in service}

As the squad leader, what actions or tasks do you do? Yell contact, drop down, and identify how many enemies, their direction and distance.

What actions or tasks do the rest of the squad conduct (not the ASM)? I would want my squad to yell out the same thing as me. The teams get on line with each other as the second comes around to one side to make an L-shaped ambush.

What actions or tasks do you want the ASM conduct? I want the ASM to stick with me and continue to scan.

What actions or tasks do you take to reorient the squad and continue the mission? I will have my team leaders do their normal checks on each member in their team.

What actions or tasks do you want the ASM to take to reorient and continue the mission? I want the ASM to continue to stick with me and scan the area. Do you want the ASM to change its location in reference to its initial position? No.

\section{Roster Number 15: E-5, MOS 19K, Tank gunner, 4 years in service}

As the squad leader, what actions or tasks do you do? Call up contact and return fire to the enemy.

What actions or tasks do the rest of the squad conduct (not the ASM)? Return fire to the enemy.

What actions or tasks do you want the ASM conduct? Act as concealment or possibly be close to squad so the squad can replenish its ammunition if needed.

What actions or tasks do you take to reorient the squad and continue the mission? After contact is broken or the target is eliminated, we conduct checks to make sure no one is hurt and everyone's ammunition, water, equipment, etc., is good.

What actions or tasks do you want the ASM to take to reorient and continue the mission? Simply stay close by and move along with the squad.

Do you want the ASM to change its location in reference to its initial position? No.

\section{Roster Number 17: E-2, MOS 19K, Tank driver, 1 year in service}

As the squad leader, what actions or tasks do you do? Call out contact, find cover or get down, and give distance and direction. Provide description of enemy. Get on line and return fire. Determine the appropriate action (flank, break contact, etc.).

What actions or tasks do the rest of the squad conduct (not the ASM)? Get down, find cover, return fire and wait for orders.

What actions or tasks do you want the ASM conduct? If durable, it could provide cover by being cover and be moving cover for the flanking team.

What actions or tasks do you take to reorient the squad and continue the mission? Get status report (ammunition, wounded, water, etc.).

What actions or tasks do you want the ASM to take to reorient and continue the mission? Get a diagnostic of its systems and damage - but quickly because it needs to get moving.

Do you want the ASM to change its location in reference to its initial position? Yes, middle or front to provide cover if none is available. 
Roster Number 20: E-5, MOS 19K, Tank commander, 10 years in service

As the squad leader, what actions or tasks do you do? Assess the threat and location. Seek cover. Engage the enemy. Move Soldiers to either flank to destroy or pull back. Call for fire. Conduct MEDEVAC.

What actions or tasks do the rest of the squad conduct (not the ASM)? Engage enemy.

What actions or tasks do you want the ASM conduct? Contact higher and provide SITREP.

What actions or tasks do you take to reorient the squad and continue the mission? Destroy enemy. Pull back and conduct MEDEVAC.

What actions or tasks do you want the ASM to take to reorient and continue the mission? Contact higher.

Do you want the ASM to change its location in reference to its initial position? Yes, to bring gear and then follow the squad.

Roster Number 21: E-3, MOS 19K, Tank driver, .5 years in service As the squad leader, what actions or tasks do you do? React to contact.

What actions or tasks do the rest of the squad conduct (not the ASM)? React to contact.

What actions or tasks do you want the ASM conduct? Charge in and shoot everything disrupting their ambush so squad can move.

What actions or tasks do you take to reorient the squad and continue the mission? Move in to robot location.

What actions or tasks do you want the ASM to take to reorient and continue the mission? Stay where it's at and scan 360 degrees for enemy.

Do you want the ASM to change its location in reference to its initial position? No.

\section{Roster Number 27: E-5, MOS 11C, squad leader, 7 years in service}

As the squad leader, what actions or tasks do you do? Get down behind cover and return fire.

What actions or tasks do the rest of the squad conduct (not the ASM)? Gain fire superiority. Bound up to the objective.

What actions or tasks do you want the ASM conduct? Send message via text.

What actions or tasks do you take to reorient the squad and continue the mission? Call up to higher.

What actions or tasks do you want the ASM to take to reorient and continue the mission? Nothing.

Do you want the ASM to change its location in reference to its initial position? No. 


\section{Roster Number 29: E-5, MOS 13F, Forward Observer, 4 years in service}

As the squad leader, what actions or tasks do you do? Call out and to higher. Lay down suppressive fire.

What actions or tasks do the rest of the squad conduct (not the ASM)? Return fire. What actions or tasks do you want the ASM conduct? Send up report of unexpected halt.

What actions or tasks do you take to reorient the squad and continue the mission? Eliminate ambush and continue the mission.

What actions or tasks do you want the ASM to take to reorient and continue the mission? Send report of activity.

Do you want the ASM to change its location in reference to its initial position? No.

Roster Number 32: E-5, MOS 91C, NCOIC, 7 years in service

As the squad leader, what actions or tasks do you do? Fire. Give order to fall back to safe location. Report up for back up (air support, tanks, etc.).

What actions or tasks do the rest of the squad conduct (not the ASM)? Fire and fall back.

What actions or tasks do you want the ASM conduct? Send reports - give location for fire attack. Return fire.

What actions or tasks do you take to reorient the squad and continue the mission? Get to safe point that was briefed by mission. Return fire. Give self reports.

What actions or tasks do you want the ASM to take to reorient and continue the mission? Remind everyone of safe point. Alert them to send a self report. Alert them of rally point or safe point if not safe. Send all reports.

Do you want the ASM to change its location in reference to its initial position? Yes, as needed by mission and events.

\section{Roster Number 33: E-5, MOS 91H, Squad leader, 3.5 years in service}

As the squad leader, what actions or tasks do you do? Take action as seen fit. Call Soldiers to do battlefield exercises necessary.

What actions or tasks do the rest of the squad conduct (not the ASM)? Follow battlefield actions, cover battle buddies.

What actions or tasks do you want the ASM conduct? Since it would be tracking ammunition usage for each soldier and knows each location, move to them to provide ammunition. Report any fallen Soldier and return fire.

What actions or tasks do you take to reorient the squad and continue the mission? After ambush is over, look at smart phone tracking device and push forward after reporting ammunition and casualty status.

What actions or tasks do you want the ASM to take to reorient and continue the mission? Communicate route information, known enemy locations, and safest route. Do you want the ASM to change its location in reference to its initial position? No. 
8. During the mission a civilian vehicle approaches or personnel are approaching.

Roster Number 3: E-4, MOS 11B, M240 Gunner, 2.5 years in service

As the squad leader, what actions or tasks do you do? Stop the vehicle or personnel and do proper checks.

What actions or tasks do the rest of the squad conduct (not the ASM)? Pull security and perform proper checks.

What actions or tasks do you want the ASM conduct? Search vehicle for possible threats. Identify personnel if possible.

What actions or tasks do you take to reorient the squad and continue the mission? Check personnel or vehicle if needed and detain if necessary. Push on.

What actions or tasks do you want the ASM to take to reorient and continue the mission? Check area and push on in alternate route if needed.

Do you want the ASM to change its location in reference to its initial position? Yes, in vicinity of personnel or vehicle.

\section{Roster Number 5: E-4, MOS 11B, M240 Gunner, 3 years in service}

As the squad leader, what actions or tasks do you do? Order them to stop and determine if they are friendly or not.

What actions or tasks do the rest of the squad conduct (not the ASM)? Pull security and search vehicle if appropriate.

What actions or tasks do you want the ASM conduct? Keep camera on vehicle or personnel.

What actions or tasks do you take to reorient the squad and continue the mission? Make sure everyone is safe and ready to move out and then move out.

What actions or tasks do you want the ASM to take to reorient and continue the mission? Show route using GPS.

Do you want the ASM to change its location in reference to its initial position? Yes, tied to squad leader.

Roster Number 9: E-5, MOS 11B, Team Leader, 4 years in service

As the squad leader, what actions or tasks do you do? Alert squad to halt and find cover and concealment.

What actions or tasks do the rest of the squad conduct (not the ASM)? Gets into the prone position and remains silent.

What actions or tasks do you want the ASM conduct? Gets directed where to go by the squad leader and shuts down.

What actions or tasks do you take to reorient the squad and continue the mission? Once the threat has passed, continue the mission.

What actions or tasks do you want the ASM to take to reorient and continue the mission? Continue the mission.

Do you want the ASM to change its location in reference to its initial position? No. 
Roster Number 10: E-1, MOS 11B, Squad Member, 1 year in service

As the squad leader, what actions or tasks do you do? Have a traffic control point (TCP) set up and notify my squad there's a vehicle or personnel approaching.

What actions or tasks do the rest of the squad conduct (not the ASM)? I would have my squad conduct a proper TCP.

What actions or tasks do you want the ASM conduct? I will have the ASM scan vehicles only looking for and bombs or weapons.

What actions or tasks do you take to reorient the squad and continue the mission? After searching the vehicle or personnel are checked, have them continue to watch on the TCP until properly relieved.

What actions or tasks do you want the ASM to take to reorient and continue the mission? Continue helping on the TCP.

Do you want the ASM to change its location in reference to its initial position? No.

\section{Roster Number 15: E-5, MOS 19K, Tank gunner, 4 years in service}

As the squad leader, what actions or tasks do you do? Command them to "stop" or "get back" then carry on with the mission. If the vehicle continues to approach, then use a little more of an aggressive command, without having to treat them as a threat.

What actions or tasks do the rest of the squad conduct (not the ASM)? Command them to "stop" or "get back" as well. Trying not to allow the civilians to touch them or grab their gear.

What actions or tasks do you want the ASM conduct? Announce the command over a loud speaker.

What actions or tasks do you take to reorient the squad and continue the mission? Everyone stays close and continues forward on the mission.

What actions or tasks do you want the ASM to take to reorient and continue the mission? Continue to follow along with the squad.

Do you want the ASM to change its location in reference to its initial position? No.

\section{Roster Number 17: E-2, MOS 19K, Tank driver, 1 year in service}

As the squad leader, what actions or tasks do you do? Get them to stop at a distance. Figure out what is going on.

What actions or tasks do the rest of the squad conduct (not the ASM)? Provide security if needed.

What actions or tasks do you want the ASM conduct? Report situation to command. What actions or tasks do you take to reorient the squad and continue the mission? Regroup and carry on.

What actions or tasks do you want the ASM to take to reorient and continue the mission? Fall in where it was previously assigned.

Do you want the ASM to change its location in reference to its initial position? No. 
Roster Number 20: E-5, MOS 19K, Tank commander, 10 years in service As the squad leader, what actions or tasks do you do? See if they are threat by visual means.

What actions or tasks do the rest of the squad conduct (not the ASM)? See if they are threat by visual means.

What actions or tasks do you want the ASM conduct? Nothing.

What actions or tasks do you take to reorient the squad and continue the mission?

Nothing.

What actions or tasks do you want the ASM to take to reorient and continue the mission? Nothing.

Do you want the ASM to change its location in reference to its initial position? No.

Roster Number 21: E-3, MOS 19K, Tank driver, .5 years in service As the squad leader, what actions or tasks do you do? Halt squad. What actions or tasks do the rest of the squad conduct (not the ASM)? Halt. What actions or tasks do you want the ASM conduct? Pull in front of vehicle or personnel acting as a road block or cover.

What actions or tasks do you take to reorient the squad and continue the mission? Investigate vehicle or personnel.

What actions or tasks do you want the ASM to take to reorient and continue the mission? Be ready to kill the target at a moment's notice.

Do you want the ASM to change its location in reference to its initial position? No.

Roster Number 27: E-5, MOS 11C, squad leader, 7 years in service As the squad leader, what actions or tasks do you do? Stop the ca. Make them turn off the car. Search the car.

What actions or tasks do the rest of the squad conduct (not the ASM)? Vehicle and personnel searches.

What actions or tasks do you want the ASM conduct? Work as a scanner for faster time on and off the objective.

What actions or tasks do you take to reorient the squad and continue the mission? Call up to higher.

What actions or tasks do you want the ASM to take to reorient and continue the mission? Call up to higher via text.

Do you want the ASM to change its location in reference to its initial position? Yes, track location. 
Roster Number 29: E-5, MOS 13F, Forward Observer, 4 years in service

As the squad leader, what actions or tasks do you do? Call halt.

What actions or tasks do the rest of the squad conduct (not the ASM)? 360 degree security. Inspect vehicle/personnel.

What actions or tasks do you want the ASM conduct? Take images, send to brigade or higher for recognition of possible high value target (HVT).

What actions or tasks do you take to reorient the squad and continue the mission?

Detain or release personnel and then continue mission.

What actions or tasks do you want the ASM to take to reorient and continue the mission? Nothing.

Do you want the ASM to change its location in reference to its initial position? No.

Roster Number 32: E-5, MOS 91C, NCOIC, 7 years in service

As the squad leader, what actions or tasks do you do? Follow company and battalion standing operating procedures (SOP).

What actions or tasks do the rest of the squad conduct (not the ASM)? Follow the orders of the NCOIC.

What actions or tasks do you want the ASM conduct? The ASM should know the SOP prior.

What actions or tasks do you take to reorient the squad and continue the mission? Stand by and await guidance.

What actions or tasks do you want the ASM to take to reorient and continue the mission? Send reports.

Do you want the ASM to change its location in reference to its initial position? No.

\section{Roster Number 33: E-5, MOS 91H, Squad leader, 3.5 years in service}

As the squad leader, what actions or tasks do you do? As soon as they are spotted, try to identify whether or not they have weapons. (If they are a priority enemy or a threat.)

What actions or tasks do the rest of the squad conduct (not the ASM)? Be ready to react in case there is a threat.

What actions or tasks do you want the ASM conduct? Be able to pick up if they are equipped with IEDs, any sort of weapon, if they are a priority enemy or not. Send notification to all Soldiers.

What actions or tasks do you take to reorient the squad and continue the mission? If personnel are no threat, keep on moving. If personnel are a threat, detain and find route to next point.

What actions or tasks do you want the ASM to take to reorient and continue the mission? Use translation from aircraft to ASM to find new route to next point once all personnel are there and continue mission.

Do you want the ASM to change its location in reference to its initial position? Yes, so you know or you are aware of starting point. 
9. During the mission you come to an area where you lose line of sight with what is ahead along the route.

Roster Number 3: E-4, MOS 11B, M240 Gunner, 2.5 years in service

As the squad leader, what actions or tasks do you do? Keep moving. Push squad out for more security and slow the pace.

What actions or tasks do the rest of the squad conduct (not the ASM)? Spread out and slow pace to maximize security.

What actions or tasks do you want the ASM conduct? Push ahead to identify line of sight, halt, scan for possible threats.

What actions or tasks do you take to reorient the squad and continue the mission? Keep pushing, maybe change route if needed.

What actions or tasks do you want the ASM to take to reorient and continue the mission? Stay ahead until squad catches up.

Do you want the ASM to change its location in reference to its initial position? No.

\section{Roster Number 5: E-4, MOS 11B, M240 Gunner, 3 years in service}

As the squad leader, what actions or tasks do you do? Slow patrol down. Have ASM go forward and identify if it's safe or not.

What actions or tasks do the rest of the squad conduct (not the ASM)? Pull security. What actions or tasks do you want the ASM conduct? Check with camera if route is safe.

What actions or tasks do you take to reorient the squad and continue the mission?

If it is clear, tell them to return to normal pace.

What actions or tasks do you want the ASM to take to reorient and continue the mission? Fall back with squad.

Do you want the ASM to change its location in reference to its initial position? Yes, it will move further ahead to check route.

\section{Roster Number 9: E-5, MOS 11B, Team Leader, 4 years in service}

As the squad leader, what actions or tasks do you do? Halt and have the squad set up a perimeter.

What actions or tasks do the rest of the squad conduct (not the ASM)? Find cover and concealment within the perimeter and scan their sectors of fire.

What actions or tasks do you want the ASM conduct? Move forward to scan ahead and get visual of the area that cannot be seen.

What actions or tasks do you take to reorient the squad and continue the mission? Take the information that the ASM has gathered and find the best route to take.

What actions or tasks do you want the ASM to take to reorient and continue the mission? Continue the mission with the direction of the squad leader.

Do you want the ASM to change its location in reference to its initial position? No. 
Roster Number 10: E-1, MOS 11B, Squad Member, 1 year in service

As the squad leader, what actions or tasks do you do? I would halt my entire squad and have my ASM continue to move forward.

What actions or tasks do the rest of the squad conduct (not the ASM)? I would have my squad halt and pull security.

What actions or tasks do you want the ASM conduct? I would have my ASM move forward and scan the route.

What actions or tasks do you take to reorient the squad and continue the mission? Once the ASM scans the route, I will have my squad pick up and move forward.

What actions or tasks do you want the ASM to take to reorient and continue the mission? I would have the ASM halt and wait for the squad to meet up with it.

Do you want the ASM to change its location in reference to its initial position? Yes, I would need the ASM to scan the upcoming route ahead.

Roster Number 15: E-5, MOS 19K, Tank gunner, 4 years in service

As the squad leader, what actions or tasks do you do? Try and get to a point where I can get a visual but not too much that I expose myself or my squad.

What actions or tasks do the rest of the squad conduct (not the ASM)? Maintain formation and get to a point where they can see up ahead.

What actions or tasks do you want the ASM conduct? Go ahead of the squad and provide a video for the squad so they're not exposing themselves.

What actions or tasks do you take to reorient the squad and continue the mission? Basically keep them in formation and continue moving forward.

What actions or tasks do you want the ASM to take to reorient and continue the mission? Move ahead and once it has confirmed no threat through video, move out with the squad.

Do you want the ASM to change its location in reference to its initial position? Yes, ahead of the squad to provide overwatch (video) to the squad.

\section{Roster Number 17: E-2, MOS 19K, Tank driver, 1 year in service}

As the squad leader, what actions or tasks do you do? Get the squad to halt quickly. Find out what's ahead.

What actions or tasks do the rest of the squad conduct (not the ASM)? No response (NR).

What actions or tasks do you want the ASM conduct? NR

What actions or tasks do you take to reorient the squad and continue the mission? NR

What actions or tasks do you want the ASM to take to reorient and continue the mission? NR

Do you want the ASM to change its location in reference to its initial position? NR 
Roster Number 20: E-5, MOS 19K, Tank commander, 10 years in service

As the squad leader, what actions or tasks do you do? Find out what is on the other side.

What actions or tasks do the rest of the squad conduct (not the ASM)? Continue to push.

What actions or tasks do you want the ASM conduct? Continue to push.

What actions or tasks do you take to reorient the squad and continue the mission?

Continue to push.

What actions or tasks do you want the ASM to take to reorient and continue the mission? Continue to push.

Do you want the ASM to change its location in reference to its initial position? Yes, continue to push.

Roster Number 21: E-3, MOS 19K, Tank driver, .5 years in service

As the squad leader, what actions or tasks do you do? Navigate around.

What actions or tasks do the rest of the squad conduct (not the ASM)? Follow squad leader.

What actions or tasks do you want the ASM conduct? Navigate around.

What actions or tasks do you take to reorient the squad and continue the mission?

Follow robot.

What actions or tasks do you want the ASM to take to reorient and continue the mission? Re-plot route.

Do you want the ASM to change its location in reference to its initial position? Yes, to navigate around obstacle blocking line of sight.

Roster Number 27: E-5, MOS 11C, squad leader, 7 years in service

As the squad leader, what actions or tasks do you do? Make sure night vision is on and working.

What actions or tasks do the rest of the squad conduct (not the ASM)? To have night vision and thermal reading at the same time.

What actions or tasks do you want the ASM conduct? Nothing.

What actions or tasks do you take to reorient the squad and continue the mission?

Call up to higher.

What actions or tasks do you want the ASM to take to reorient and continue the mission? Call up to higher via text.

Do you want the ASM to change its location in reference to its initial position? No. 
Roster Number 29: E-5, MOS 13F, Forward Observer, 4 years in service As the squad leader, what actions or tasks do you do? Call short halt. Orient on map and identify terrain features.

What actions or tasks do the rest of the squad conduct (not the ASM)? Pull security. What actions or tasks do you want the ASM conduct? Have map and terrain information on screen (FBCB2).

What actions or tasks do you take to reorient the squad and continue the mission? Continue checks and security.

What actions or tasks do you want the ASM to take to reorient and continue the mission? Continue checks.

Do you want the ASM to change its location in reference to its initial position? No.

Roster Number 32: E-5, MOS 91C, NCOIC, 7 years in service

As the squad leader, what actions or tasks do you do? Alert the teams to move closer together. Scan area slower.

What actions or tasks do the rest of the squad conduct (not the ASM)? Come closer together and scan the area better.

What actions or tasks do you want the ASM conduct? Go out ahead and collect intelligence on the land. Find a better route.

What actions or tasks do you take to reorient the squad and continue the mission? Set rally point if someone gets lost.

What actions or tasks do you want the ASM to take to reorient and continue the mission? Alert everyone to rally point and tell them to do a self report.

Do you want the ASM to change its location in reference to its initial position? No.

\section{Roster Number 33: E-5, MOS 91H, Squad leader, 3.5 years in service}

As the squad leader, what actions or tasks do you do? Stay on path. Notify Soldiers. Have all personnel alert looking for things out of the normal.

What actions or tasks do the rest of the squad conduct (not the ASM)? Stay alert and look for things out of the normal for the area you are in.

What actions or tasks do you want the ASM conduct? To see ahead and scan the area so if something that can be a threat is up the road it can send an alert to all Soldiers.

What actions or tasks do you take to reorient the squad and continue the mission? Get a good idea or reading of where you are, obtain grid reading and continue.

What actions or tasks do you want the ASM to take to reorient and continue the mission? Scan and find out exactly where we are and how we can get to point ahead of us without coming into any conflict.

Do you want the ASM to change its location in reference to its initial position? No. 
10. Please identify the following gestures (hand and arm signals) you would commonly use in controlling the squad and ASM:

\begin{tabular}{|l|c|c|}
\hline \multicolumn{1}{|c|}{ Gesture } & Yes & No \\
\hline Move Out & 10 & 2 \\
\hline Double Time & 6 & 6 \\
\hline Enemy in sight & 12 & 0 \\
\hline Take Cover & 10 & 2 \\
\hline Wedge & 12 & 0 \\
\hline Vee & 6 & 6 \\
\hline Column & 11 & 1 \\
\hline Staggered Column & 12 & 0 \\
\hline Echelon Left & 10 & 2 \\
\hline Echelon Right & 10 & 2 \\
\hline Contact Left & 10 & 2 \\
\hline Contact Right & 10 & 2 \\
\hline NBC & 11 & 1 \\
\hline Danger Area & 9 & 3 \\
\hline Freeze & 10 & 2 \\
\hline Disperse & 6 & 6 \\
\hline Assemble & 11 & 1 \\
\hline Other: Rally point & 2 & \\
\hline
\end{tabular}

11. Please identify the verbal commands you would use to control the squad and the ASM:

\begin{tabular}{|l|c|c|}
\hline \multicolumn{1}{|c|}{ Phrase } & Yes & No \\
\hline Halt & 9 & 3 \\
\hline Stop & 9 & 3 \\
\hline Move & 11 & 1 \\
\hline Run & 7 & 5 \\
\hline Duck & 6 & 6 \\
\hline Other: Contact & 1 & \\
\hline Other: NBC & 1 & \\
\hline Other: Incoming Fire & 1 & \\
\hline Other: Enemy & 1 & \\
\hline Other: Cover & 1 & \\
\hline
\end{tabular}

\section{Post-mission checks:}

\begin{tabular}{|l|c|}
\hline \multicolumn{1}{|c|}{ PREFERRED METHOD } & NUMBER \\
\hline red/amber/green lights red/amber/green lights & 4 \\
\hline text message to operator/SL & 3 \\
\hline item by item checklist display & 4 \\
\hline alert signal & 0 \\
\hline other: (describe) device to plug in and read errors. & 1 \\
\hline
\end{tabular}


The following questions deal with the amount of trust you have in the ASM. Consider those tasks you identify to be totally independent of human interaction - the ASM performs them "without supervision". Trust could be defined as the confidence you have in the ASM to conduct those tasks in a safe manner that do not present any safety or mission accomplishment factors for the squad.

Assuming the ASM capabilities are accurate and reliable:

13. What tasks would you have complete trust in that the ASM could conduct to aid in the squad's mission without your supervision?

\begin{tabular}{|l|c|}
\hline \multicolumn{1}{|c|}{ TASK WITH COMPLETE TRUST } & NUMBER \\
\hline Resupply of ammunition and equipment. & 1 \\
\hline Carrying the gear. & 1 \\
\hline Scouting/checking routes. & 5 \\
\hline Identification of targets. & 1 \\
\hline Check for IEDs. & 3 \\
\hline Location due to GPS. & 2 \\
\hline Movement in formation. & 1 \\
\hline Move to a position to give video feedback to the squad. & 1 \\
\hline Verbal commands. & 1 \\
\hline Translating foreign languages. & 1 \\
\hline Ability to navigate terrain and know what it can or cannot do. & 1 \\
\hline Internal diagnostics report. & 1 \\
\hline Contacting higher and FBCB2. & 1 \\
\hline Radio telephone operator. & 1 \\
\hline Carry the wounded. & 1 \\
\hline Pulling guard. & 1 \\
\hline Rushing the enemy. & 1 \\
\hline Sending reports & 1 \\
\hline
\end{tabular}

14. What tasks would you have some trust in that the ASM could conduct to aid in the squad's mission without your supervision?

\begin{tabular}{|l|c|}
\hline \multicolumn{1}{|c|}{ TASK WITH SOME TRUST } & NUMBER \\
\hline Casualty evacuation. & 3 \\
\hline Determining which casualty it should assist first. & 1 \\
\hline Leading movement with GPS. & 1 \\
\hline Going around obstacles. & 1 \\
\hline Moving out of an area that is taking indirect fire. & 1 \\
\hline Using voice control to execute a movement. & 1 \\
\hline Security of equipment/gear stowed. & 1 \\
\hline Engage enemy. & 2 \\
\hline Notification of enemy. & 1 \\
\hline Lasing structure within a certain distance. & 1 \\
\hline
\end{tabular}


15. What tasks would you have no trust in that the ASM could conduct to aid in the squad's mission without your supervision?

\begin{tabular}{|l|c|}
\hline \multicolumn{1}{|c|}{ TASK WITH NO TRUST } & NUMBER \\
\hline If it had fire capability, would rather control that. & 3 \\
\hline Firing back. & 1 \\
\hline Destroying enemy. & 1 \\
\hline Finding cover and concealment. & 1 \\
\hline Scanning high parts of buildings. & 1 \\
\hline Transporting wounded soldiers to a pickup point on its own. & 1 \\
\hline Making on the spot decisions. & 1 \\
\hline Provide cover fire while we move. & 1 \\
\hline I don't know. & 1 \\
\hline Grids. & 1 \\
\hline Picking up heat signatures. & 1 \\
\hline Shielding signal from enemy detection. & 1 \\
\hline Low battery or fuel. & 2 \\
\hline
\end{tabular}




\section{Appendix D. Interview Results: Junior Enlisted Soldiers}




\section{AUTONOMOUS SQUAD MEMBER INTERVIEW RESULTS}

\section{$\mathbf{N}=12$}

1. Review responses to demographics and scenario questions (look for clarification, expansion on noteworthy response, gain insight as to why, etc.)

\begin{tabular}{|l|c|}
\hline \multicolumn{1}{|c|}{ COMMENTS } & NUMBER \\
\hline $\begin{array}{l}\text { Keep ASM close to SAW gunner (tied to squad member) as he produces } \\
\text { the most casualties. }\end{array}$ & 1 \\
\hline $\begin{array}{l}\text { ASM tied to squad leader because he knows most about ASM and can take } \\
\text { control. }\end{array}$ & 1 \\
\hline ASM tied to squad leader, kept in middle, until it proves trustworthy. & 1 \\
\hline Always tied to squad member so less of distraction to others. & 1 \\
\hline ASM should move to where it is needed and assist in searches. & 2 \\
\hline ASM should be moved around based on the situation. & 1 \\
\hline With the ASM in the lead, it provides more time for the squad to react. & 1 \\
\hline $\begin{array}{l}\text { The ASM should follow the squad to protect it and be able to continue the } \\
\text { mission because it reduces the Soldiers' loads. A human should pull point } \\
\text { because of the deductive reasoning he has. }\end{array}$ & 1 \\
\hline $\begin{array}{l}\text { Forgot about high value targets (HVT) when vehicle or personnel } \\
\text { approached and used the ASM for cover and concealment. }\end{array}$ & 2 \\
\hline The ASM is not expendable and is needed in the squad. & 1 \\
\hline The ASM is expendable compared to a Soldier. & \\
\hline The ASM should continuously report its status. & \\
\hline
\end{tabular}

2. What three capabilities/functions are needed for an ASM to be useful to contributing to the success of any mission, and why? Prioritize the top three.

Number 1. Capability/function:

\begin{tabular}{|l|c|}
\hline \multicolumn{1}{|c|}{ COMMENTS } & NUMBER \\
\hline Camera to scan area. & 1 \\
\hline Video camera to confirm IEDs. & 1 \\
\hline GPS to know its own and squad's position. & 1 \\
\hline GPS to know location to call for air support quicker. & 2 \\
\hline $\begin{array}{l}\text { Moving through terrain, must maintain movement with squad, if it can't, } \\
\text { then it is useless. }\end{array}$ & 1 \\
\hline Must be able to self-navigate without consistently telling it where to go. & 1 \\
\hline Land navigation knowing where it's at and where it's going. & 1 \\
\hline Weapon system to increase lethality and lighten Soldier's load. & 1 \\
\hline Communications with higher via radio and FBCB2. & 1 \\
\hline Chemical sensors better than what the squad has. & 1 \\
\hline Lasing capability to designate targets out to 20km. & 1 \\
\hline
\end{tabular}


Number 2. Capability/function:

\begin{tabular}{|l|c|}
\hline \multicolumn{1}{|c|}{ COMMENTS } & NUMBER \\
\hline Identification of targets and scanning for the enemy. & 3 \\
\hline Sniper detection and reduce the Soldier's load. & 1 \\
\hline Camera for observation. & 2 \\
\hline $\begin{array}{l}\text { Night vision/thermal with instrumentation for 360 degree coverage. } \\
\text { Provides another set of eyes. }\end{array}$ & 1 \\
\hline GPS because it must know where it is at. & 1 \\
\hline $\begin{array}{l}\text { Defensive capability with armor so it could also be used for cover for the } \\
\text { Soldiers as well. }\end{array}$ & 1 \\
\hline Audio and visual understanding for command and control of the ASM. & 1 \\
\hline Control under any circumstances by a human using a joystick. & 1 \\
\hline $\begin{array}{l}\text { Sending reports, pre-programmed formats and changes in formats lessens } \\
\text { the burden on the squad leader. }\end{array}$ & 1 \\
\hline
\end{tabular}

Number 3. Capability/function:

\begin{tabular}{|l|c|}
\hline \multicolumn{1}{|c|}{ COMMENTS } & NUMBER \\
\hline IED detection. & 1 \\
\hline Understanding voice commands. & 1 \\
\hline $\begin{array}{l}\text { Visual recording that can aid in after action reviews (AAR) and confirm } \\
\text { what you saw or missed. }\end{array}$ & 1 \\
\hline GPS to know the location at all times. & 1 \\
\hline $\begin{array}{l}\text { Loudspeaker for use in urban areas to communicate with civilians on the } \\
\text { battlefield (COB). }\end{array}$ & 1 \\
\hline $\begin{array}{l}\text { Communicate failure or malfunction in order to fix the problem before a } \\
\text { total system failure occurs. }\end{array}$ & 4 \\
\hline Load carrying to reduce the Soldier's load. & 1 \\
\hline Weapon system to provide cover fire by the ASM operator. & 1 \\
\hline Weapon system to provide more lethality. & \\
\hline
\end{tabular}

3. What three capabilities/functions are "nice to have" for an ASM to be useful to contributing to the success of any mission, and why? Prioritize the top three.

Number 1. Capability/function:

\begin{tabular}{|l|c|}
\hline \multicolumn{1}{|c|}{ COMMENTS } & NUMBER \\
\hline Capability to transport supplies and equipment. & 3 \\
\hline Must be armored to maintain movement capability. & 1 \\
\hline A generator to charge batteries. & 3 \\
\hline $\begin{array}{l}\text { Weapon system so that it can fight back automatically and increase } \\
\text { lethality and provide self-defense. }\end{array}$ & 1 \\
\hline Thermals with better night vision in order to detect hot spots. & 1 \\
\hline Be able to pull guard to replace a squad member. & 1 \\
\hline Radar system to provide for counter-battery fire. & 1 \\
\hline $\begin{array}{l}\text { Be able to disarm an IED in order to save time and continue mission } \\
\text { instead of having to wait for explosive ordinance detachment. }\end{array}$ & 1 \\
\hline
\end{tabular}


Number 2. Capability/function:

\begin{tabular}{|l|c|}
\hline \multicolumn{1}{|c|}{ COMMENTS } & NUMBER \\
\hline Identify direction of fires. & 1 \\
\hline Carry first aid supplies and evacuate casualties. & 2 \\
\hline $\begin{array}{l}\text { Load additional weapons and ammunition. Load spare machine gun } \\
\text { barrels. }\end{array}$ & 1 \\
\hline A water tank dispenser with nozzle in lieu of using water cans. & 1 \\
\hline $\begin{array}{l}\text { Distribute ammunition to others where it is needed by self-navigating to } \\
\text { their locations. }\end{array}$ & 1 \\
\hline FBCB2 in order to maintain contact with higher. & 1 \\
\hline A blue force tracker so the squad leader has accountability at all times. & 1 \\
\hline Advanced optics to see at farther distances. & 1 \\
\hline A vehicle scanner to support traffic control point (TCP) tasks. & 1 \\
\hline $\begin{array}{l}\text { Identification of ground and air vehicles to conduct fire mission after } \\
\text { locking on target. }\end{array}$ & 1 \\
\hline A satellite radio to listen to to break the monotony. & 1 \\
\hline
\end{tabular}

Number 3. Capability/function:

\begin{tabular}{|l|c|}
\hline \multicolumn{1}{|c|}{ COMMENTS } & NUMBER \\
\hline Weapon system. & 1 \\
\hline Signal capability. & 1 \\
\hline Carry detainee kits, zip cuffs, finger printing kits. Have facial recognition. & 1 \\
\hline A water source and dispensing station similar to a water buffalo. & 1 \\
\hline $\begin{array}{l}\text { Laser range finder for range estimation. Possible attachable accessory. } \\
\text { Way to autonomously lase IEDs. }\end{array}$ & 1 \\
\hline $\begin{array}{l}\text { Defensive capability against missiles and rocket propelled grenades (RPG) } \\
\text { by detecting them and then defeating them. }\end{array}$ & 1 \\
\hline Capability to transport litters. Casualty evacuation aid. & 2 \\
\hline External power source for recharging batteries. & 2 \\
\hline $\begin{array}{l}\text { Communications to send reports automatically to prevent stopping and free } \\
\text { up squad leader from tasks. }\end{array}$ & 1 \\
\hline An extended battery life for longer operation. & 1 \\
\hline
\end{tabular}


4. If you were to conduct a different mission, other than route reconnaissance, what would need to be changed for/on the ASM for that type of mission?

\begin{tabular}{|l|c|}
\hline \multicolumn{1}{|c|}{ COMMENTS } & NUMBER \\
\hline Nothing. & 5 \\
\hline Protective armor. & 1 \\
\hline Self-destruct button to keep enemy from having friendly intelligence. & 1 \\
\hline Good for other missions without modifications. & 1 \\
\hline $\begin{array}{l}\text { Defuse bombs, knock down doors, clear room (see the enemy and engage), } \\
\text { and defeat or breach walls and obstacles. }\end{array}$ & 1 \\
\hline Mission dependent - a mission module tailored for each mission. & 1 \\
\hline Be able to designate targets. & 1 \\
\hline Cameras to provide versatility for observation. & 1 \\
\hline Use as remote listening post/observation post (LP/OP). & 1 \\
\hline
\end{tabular}

5. If you were to conduct a night mission what would need to be changed for/on the ASM for that type of mission?

\begin{tabular}{|l|c|}
\hline \multicolumn{1}{|c|}{ COMMENTS } & NUMBER \\
\hline Noise and light discipline. & 2 \\
\hline Infrared camera. Infrared strobe and FLIR system. & 9 \\
\hline Night vision observation and display. & 4 \\
\hline Reflective infrared identification in order to see it. & 1 \\
\hline Move it to the front of the formation. & 2 \\
\hline Real time video display. & 1 \\
\hline Camouflage. & 1 \\
\hline Non-reflecting infrared to prevent detection by the enemy. & 1 \\
\hline
\end{tabular}

6. Is the ASM a good idea? What makes it critical for mission success?

\begin{tabular}{|c|c|}
\hline Yes & No \\
\hline 11 & 1 \\
\hline
\end{tabular}

\begin{tabular}{|l|c|}
\hline \multicolumn{1}{|c|}{ COMMENTS } & NUMBER \\
\hline Locate ahead of squad for early warning. & 1 \\
\hline Long lasting battery. & 1 \\
\hline $\begin{array}{l}\text { Use as additional eyes without point man being shot. Keeps Soldier out of } \\
\text { harm's way. }\end{array}$ & 1 \\
\hline GPS. & 2 \\
\hline $\begin{array}{l}\text { Recording IED and sniper locations for use in AAR. View recording to } \\
\text { determine what was missed. }\end{array}$ & 1 \\
\hline Needs capability to send pictures and video to higher. & 1 \\
\hline Would have to use it first before assessing criticality. & 1 \\
\hline Not needed in armor unit. & \\
\hline
\end{tabular}




\begin{tabular}{|l|c|}
\hline $\begin{array}{l}\text { Carry gear and wounded Soldiers - squad would be better off with lighter } \\
\text { load. }\end{array}$ & 2 \\
\hline Carry more ammunition and heavier weapon systems. & 1 \\
\hline Could be used as cover if necessary. & 1 \\
\hline Only if it remains operational and does not need to be recovered. & 1 \\
\hline Used instead of a human in high danger areas. & 1 \\
\hline Incorporate state of the art technologies. & 1 \\
\hline Easier on squad by maintaining information. & 1 \\
\hline Maintain communications with ground commander. & 1 \\
\hline Provides enemy intelligence and route ahead of time. & 1 \\
\hline No. Not big on technology. No trust in tasks. & \\
\hline
\end{tabular}

7. What is the best way to command and control the ASM?

\begin{tabular}{|l|c|}
\hline \multicolumn{1}{|c|}{ COMMAND METHOD } & NUMBER \\
\hline verbal command & 6 \\
\hline hand and arm signal & 1 \\
\hline text message & 1 \\
\hline dedicated operator & 2 \\
\hline Other: verbal command plus dedicated operator & 1 \\
\hline Other: joystick as backup & 1 \\
\hline Other: arm and hand signal as backup & 1 \\
\hline Other: visual as a backup & 1 \\
\hline Other: download mission so it would understand it better & 1 \\
\hline Other: remotely via application on FBCB2 & NUMBER \\
\hline & 1 \\
\hline General Comments & 1 \\
\hline A display that's programmable with way points. & 1 \\
\hline A manual backup. & 1 \\
\hline Could communicate directly with a dedicated operator. & 1 \\
\hline $\begin{array}{l}\text { Verbal is good but may need visual backup because of all the } \\
\text { yelling taking place during a firefight. }\end{array}$ & $\begin{array}{l}\text { A game controller since Soldiers are very knowledgeable of } \\
\text { how to use them. }\end{array}$ \\
\hline
\end{tabular}

8. What is the best way for the ASM to acknowledge receipt of the command?

\begin{tabular}{|l|c|}
\hline \multicolumn{1}{|c|}{ COMMAND METHOD } & NUMBER \\
\hline verbal & 3 \\
\hline Visual (light, etc.) & 3 \\
\hline text message & 4 \\
\hline panel display & 0 \\
\hline Other: no signal, just execute tasks & 2 \\
\hline
\end{tabular}




\begin{tabular}{|l|c|}
\hline \multicolumn{1}{|c|}{ COMMENTS } & NUMBER \\
\hline Need earpiece when noise discipline is critical. & 1 \\
\hline Text message as backup for verbal. & 1 \\
\hline Visual as a backup. & 1 \\
\hline Text message maintains noise and light discipline. Trust it to understand. & 1 \\
\hline Visual and panel displays provide quick response. & 1 \\
\hline Text message would be easy to interpret. & 1 \\
\hline
\end{tabular}

9. What knowledge does the ASM need to have learned in order to perform required tasks and tools/sensors does it need to perform those tasks?

\begin{tabular}{|l|c|}
\hline \multicolumn{1}{|c|}{ COMMENTS } & NUMBER \\
\hline Basic drills understanding to stay out of way if moving or fire fight occurs. & 2 \\
\hline How to navigate and best use of terrain. & 2 \\
\hline What squad member is controlling it. & 1 \\
\hline Know priority for casualty aid when there are multiple casualties. & 1 \\
\hline Know how and where to seek and find cover. & 2 \\
\hline How to provide cover for Soldiers if none is available. & 1 \\
\hline Identification of friend or foe (IFF). & 1 \\
\hline $\begin{array}{l}\text { Army technical manuals, field manuals, battalion and company standing } \\
\text { operating procedures all uploaded and know the drills for each event. }\end{array}$ & 1 \\
\hline React to contact and provide cover fire in a specified direction. & 1 \\
\hline Embedded warrior skills. & 1 \\
\hline Weekly reboot and any software upgrades. & 1 \\
\hline Preventive maintenance checks and services (PMCS). & 1 \\
\hline Sensing incoming fire. & 1 \\
\hline Knowing when to engage the enemy. & 1 \\
\hline Sending text messages. & 1 \\
\hline Knowing how to report status of squad and itself. & 1 \\
\hline
\end{tabular}

10. What is the source of your personal knowledge to conduct tactical missions - how did you learn the procedures or actions to take?

\begin{tabular}{|l|c|}
\hline \multicolumn{1}{|c|}{ SOURCE } & NUMBER \\
\hline School & 4 \\
\hline OJT & 0 \\
\hline Unit Training & 1 \\
\hline Other: unit training and schools & 7 \\
\hline
\end{tabular}

11. Do you want the ASM to remind you about the next mission objective if you don't immediately remember what it is or know how to get there?

\begin{tabular}{|c|c|}
\hline Yes & No \\
\hline 11 & 1 \\
\hline
\end{tabular}




\begin{tabular}{|l|c|}
\hline \multicolumn{1}{|c|}{ COMMENTS } & NUMBER \\
\hline Should be able to be pre-programmed. & 1 \\
\hline Squad leader has many tasks and this would be an aid. & 2 \\
\hline Used as squad leader's right hand man. & 1 \\
\hline Send text message. & 1 \\
\hline Should have a panel and GPS display. & 2 \\
\hline Should have a display for updates from higher. & 1 \\
\hline Do it automatically after each event. & 1 \\
\hline Limits mistakes. & 1 \\
\hline $\begin{array}{l}\text { This is very important because the mind may become foggy and the ASM } \\
\text { can keep you on track. }\end{array}$ & 1 \\
\hline Should have a critical events log. & 1 \\
\hline Via network - leaves note and coordination line to view. & 1 \\
\hline Only if first mission is completed and it doesn't jump the gun. & 1 \\
\hline No. Don't trust it due to security. Should know it to begin with. & \\
\hline
\end{tabular}

(11. Follow-up:) Do you want the ASM to inform you of status of reaching phase lines, LD, objective, etc. on time?

\begin{tabular}{|c|c|}
\hline Yes & No \\
\hline 11 & 1 \\
\hline
\end{tabular}

\begin{tabular}{|l|c|}
\hline \multicolumn{1}{|c|}{ COMMENTS } & NUMBER \\
\hline Especially if it is ahead of the squad. & 1 \\
\hline Fastest way to inform higher. & 1 \\
\hline Maintains information on how far it is to the objective. & 3 \\
\hline $\begin{array}{l}\text { Use a text message since light is not tactical when observing noise and } \\
\text { light disciplines. }\end{array}$ & 1 \\
\hline Should be communicated by voice. & 2 \\
\hline Via an earpiece. & 2 \\
\hline Puts you in the right area without second guessing. & 1 \\
\hline Use checklist for the mission to ensure everything gets done. & 1 \\
\hline Confirms where you are suppose to be. & 1 \\
\hline No. Don’t trust it due to security. Should know it to begin with. & 1 \\
\hline
\end{tabular}

12. When you have been on patrol or operating potentially dangerous equipment, have you ever been interrupted at a bad time? If yes, what bad consequences occurred or nearly occurred as a result of that interruption?

\begin{tabular}{|c|c|}
\hline Yes & No \\
\hline 5 & 7 \\
\hline
\end{tabular}




\begin{tabular}{|l|c|}
\hline \multicolumn{1}{|c|}{ COMMENTS } & NUMBER \\
\hline $\begin{array}{l}\text { Occurred when visibility was restricted or limited by rain and dust. Night } \\
\text { vision reduces depth perception due ti its magnification. }\end{array}$ & 1 \\
\hline $\begin{array}{l}\text { Civilians on the battlefield interrupted the mission, gear breaks, or Soldier } \\
\text { injures himself. }\end{array}$ & 1 \\
\hline LRADS fell off the truck. & 1 \\
\hline Having to move casualty to safety and calling in 9-line report. & 1 \\
\hline During a convoy, one of the vehicles broke down. & 1 \\
\hline
\end{tabular}

If a bad outcome was avoided, how?

\begin{tabular}{|l|c|}
\hline \multicolumn{1}{|c|}{ COMMENTS } & NUMBER \\
\hline Everyone had to focus on their individual tasks. & 1 \\
\hline Sometimes, it's unavoidable. & 1 \\
\hline Stopped movement, replaced LRADS on turret and continued mission. & 1 \\
\hline Provide support by fire while retrieving casualty. & 1 \\
\hline Recovered the vehicle that was broke down. & 1 \\
\hline
\end{tabular}

Did a teammate or other person step in to help?

\begin{tabular}{|c|c|}
\hline Yes & No \\
\hline 5 & 0 \\
\hline
\end{tabular}

\begin{tabular}{|l|c|}
\hline \multicolumn{1}{|c|}{ COMMENTS } & NUMBER \\
\hline Ground guide dismounted and was followed by driver. & 1 \\
\hline Team members, squad leader, team leaders, and all else involved. & 1 \\
\hline Squad members all pitched in to secure LRADS. & 1 \\
\hline Medic was quick to act and aid casualty. & 1 \\
\hline The vehicle commander of the broke down vehicle. & 1 \\
\hline
\end{tabular}

13. If so, what did the other person do that was particularly helpful?

\begin{tabular}{|l|c|}
\hline \multicolumn{1}{|c|}{ COMMENTS } & NUMBER \\
\hline $\begin{array}{l}\text { The loader was used as the ground guide. He can see what the driver and } \\
\text { vehicle commander couldn't and acted as another set of eyes. }\end{array}$ & 1 \\
\hline It depended on the mission at the time. & 1 \\
\hline Helped reinstall the LRADS. & 1 \\
\hline Treated casualty. & 1 \\
\hline $\begin{array}{l}\text { A three-man crew used on vehicle to tow another vehicle while others } \\
\text { provided suppressive fire. }\end{array}$ & 1 \\
\hline
\end{tabular}




\section{EXPLORATORY QUESTIONS}

(for possible modeling of future capabilities/excursions)

14. Should the ASM have a weapons platform on it? (caliber, manual or remote controlled, autonomous vs. human interaction, basic load quantity, etc).

\begin{tabular}{|c|c|}
\hline Yes & No \\
\hline 9 & 3 \\
\hline
\end{tabular}

\begin{tabular}{|l|c|c|}
\hline \multicolumn{1}{|c|}{ CAPABILITY } & YES & NO \\
\hline Autonomous engagements & 1 & \\
\hline Human interface engagements & 7 & \\
\hline Other: Both human and autonomous & 1 & \\
\hline Manned gun control & 1 & \\
\hline Remote gun control & 8 & \\
\hline
\end{tabular}

\begin{tabular}{|c|c|}
\hline COMMENTS & NUMBER \\
\hline \multicolumn{2}{|l|}{ Caliber } \\
\hline $5.56 \mathrm{~mm}$ & 1 \\
\hline $7.62 \mathrm{~mm}$ & 4 \\
\hline .50 caliber & 3 \\
\hline Multi-caliber small arms and MK19 to lock on to general area. & 1 \\
\hline \multicolumn{2}{|l|}{ Basic Load } \\
\hline 300 rounds & 2 \\
\hline 400 rounds & 1 \\
\hline 1000 rounds & 2 \\
\hline 1200 rounds & 1 \\
\hline 1500 rounds & 1 \\
\hline 2000 plus rounds & 1 \\
\hline 3000 rounds $5.56 \mathrm{~mm}$ and 100 rounds of MK19 ammunition & 1 \\
\hline \multicolumn{2}{|l|}{ General comments } \\
\hline Remote controlled weapon system with manual (human) backup. & 1 \\
\hline Safety requires human interaction and involvement in decisions to engage. & 1 \\
\hline Man-made stuff could kill so human is important to prevent fratricide. & 1 \\
\hline Could engage targets out of range of sensors. & 1 \\
\hline Human and/or autonomous as needed. & 1 \\
\hline Autonomous engagements could prevent human exposure. & 1 \\
\hline $\begin{array}{l}\text { Laser should designate targets and ASM should be armored as well as the } \\
\text { weapon system. }\end{array}$ & 1 \\
\hline Should provide 360 degree coverage around vehicle. & 1 \\
\hline Autonomous engagement if engaged. & 1 \\
\hline If it were autonomous, it should wait for confirmation to engage first. & 1 \\
\hline
\end{tabular}


15. Should the ASM be able to be configured for CASEVAC? (How long to configure - if not permanently configured, how many Soldiers evacuated, autonomous movement to CCP, armor protection, etc.)

\begin{tabular}{|c|c|}
\hline Yes & No \\
\hline 11 & 1 \\
\hline
\end{tabular}

\begin{tabular}{|l|c|c|}
\hline \multicolumn{1}{|c|}{ CAPABILITY } & YES & NO \\
\hline Autonomous Movement & 3 & 8 \\
\hline Armored & 10 & 1 \\
\hline
\end{tabular}

\begin{tabular}{|l|c|}
\hline \multicolumn{1}{|c|}{ COMMENTS } & NUMBER \\
\hline How long to configure litter support system & 6 \\
\hline As soon as possible - minimum time requirements. & 2 \\
\hline Five minutes. & 2 \\
\hline Five to 10 minutes. & 1 \\
\hline Embedded, already in place. & 4 \\
\hline \multicolumn{2}{|c|}{} \\
\hline Number of casualties to transport & 1 \\
\hline 1 & 5 \\
\hline $1-2$ & 1 \\
\hline 2 & \\
\hline 3 & 1 \\
\hline General Comments & 4 \\
\hline Soldiers not required to carry casualties is good. & 1 \\
\hline $\begin{array}{l}\text { Need to escort ASM to return fire if necessary to protect casualty. Needs } \\
\text { human thought process for intervention. }\end{array}$ & 1 \\
\hline Up-armored to protect against 7.62 rounds. & 1 \\
\hline Medical equipment already stowed on it. & \\
\hline Armor would hinder speed. & \\
\hline
\end{tabular}

16. Should the ASM have smoke grenade dispensers or smoke generator? (preferred equipment, duration, distance of employment, wind sensing capability)

\begin{tabular}{|c|c|}
\hline Yes & No \\
\hline 8 & 4 \\
\hline
\end{tabular}

\begin{tabular}{|l|c|c|}
\hline CAPABILITY & YES & NO \\
\hline Dispenser & 7 & \\
\hline Generator & 1 & \\
\hline Wind Sensing & 7 & 1 \\
\hline
\end{tabular}




\begin{tabular}{|c|c|}
\hline COMMENTS & NUMBER \\
\hline \multicolumn{2}{|l|}{ Length of smoke Generation } \\
\hline .5-1 minute & 2 \\
\hline 5 minutes & 2 \\
\hline 5-10 minutes & 3 \\
\hline Don’t know & 1 \\
\hline \multicolumn{2}{|l|}{ Distance to Employ Screen } \\
\hline 10-15 meters & 1 \\
\hline 25 meters & 1 \\
\hline 30 meters & 3 \\
\hline 35 meters & 1 \\
\hline 50 meters & 1 \\
\hline Don’t know & 1 \\
\hline \multicolumn{2}{|l|}{ General Comments } \\
\hline Should always be controlled by human. & 1 \\
\hline Should provide 360 degree coverage. & 1 \\
\hline $\begin{array}{l}\text { Needs high speed mode of movement to get out of area quickly while } \\
\text { moving to another location. }\end{array}$ & 1 \\
\hline
\end{tabular}

17. Should the ASM have chemical detection sensors/alarms? If yes, why/for what reasons/missions? (contaminated area avoidance, attacks, etc.)

\begin{tabular}{|c|c|}
\hline Yes & No \\
\hline 12 & 0 \\
\hline
\end{tabular}

\begin{tabular}{|l|c|}
\hline \multicolumn{1}{|c|}{ COMMENTS } & NUMBER \\
\hline $\begin{array}{l}\text { Takes too long to do it manually during mission. Need knowledge prior to } \\
\text { attack ASAP. }\end{array}$ & 2 \\
\hline Relieves burden of squad member having to do it. & 1 \\
\hline $\begin{array}{l}\text { Soldier not normally monitoring continuously, only when danger may be } \\
\text { possible. }\end{array}$ & 1 \\
\hline It reduces Soldier load and provides for immediate notification. & 3 \\
\hline Real time warning and reporting. & 6 \\
\hline You can't see the threat so it should detect it. & 1 \\
\hline Battle buddies know what is happening. & 1 \\
\hline Threat is always present. & 1 \\
\hline $\begin{array}{l}\text { If ASM is ahead, alert provides more time to mask and be prepared to } \\
\text { continue the mission. }\end{array}$ & 1 \\
\hline
\end{tabular}


18. Should the ASM have target detection capability? (distance, human or vehicle, location (azimuth and distance), track targets after detection)

\begin{tabular}{|c|c|}
\hline Yes & No \\
\hline 11 & 1 \\
\hline
\end{tabular}

\begin{tabular}{|l|c|c|}
\hline \multicolumn{1}{|c|}{ CAPABILITY } & YES & NO \\
\hline Human targets & 9 & 2 \\
\hline Vehicle targets & 10 & 1 \\
\hline Azimuth to target & 11 & 0 \\
\hline Distance to target & 11 & 0 \\
\hline Track targets & 9 & 2 \\
\hline
\end{tabular}

\begin{tabular}{|l|c|}
\hline \multicolumn{1}{|c|}{ COMMENTS } & NUMBER \\
\hline 300 meters & 3 \\
\hline 400 meters & 2 \\
\hline 500 plus meters & 3 \\
\hline 1300 meters & 1 \\
\hline 7200 meters - provide counter-battery against mortars & 1 \\
\hline \multicolumn{2}{|l|}{} \\
\hline General Comments & 1 \\
\hline Should be able to detect the type of weapon being carried. & 1 \\
\hline Identify whether the vehicle has IEDs or explosives in it. & 3 \\
\hline Should scan for and detect targets while tracking. & 1 \\
\hline Only if it has a manned weapon system. & 1 \\
\hline No because it may consider a friendly an enemy. & 1 \\
\hline Should be tied in with FBCB2. & 1 \\
\hline Provide grid reference for real time population of report. & 1 \\
\hline Should also be able to detect aircraft. &
\end{tabular}

19. Should the ASM have shot detection capability? (location, distance, azimuth, caliber)

\begin{tabular}{|c|c|}
\hline Yes & No \\
\hline 12 & 0 \\
\hline
\end{tabular}

\begin{tabular}{|l|c|c|}
\hline \multicolumn{1}{|c|}{ CAPABILITY } & YES & NO \\
\hline Location of shooter & 12 & 0 \\
\hline Distance to shooter & 11 & 1 \\
\hline Azimuth to shooter & 12 & 0 \\
\hline Caliber of weapon fired & 8 & 4 \\
\hline
\end{tabular}




\begin{tabular}{|l|c|}
\hline \multicolumn{1}{|c|}{ COMMENTS } & NUMBER \\
\hline For indirect fire, should provide azimuth, distance, and kill zone. & 2 \\
\hline Should also provide information for mortar attacks. & 1 \\
\hline Conducts crater analysis for mortar and artillery rounds. & 1 \\
\hline Soldiers have to remove kit now to detect potential IED placements. & 1 \\
\hline
\end{tabular}

20. Should the ASM camera sensors be mounted on an extendable/collapsible mast? (height of operation, day/night/IR, etc.)

\begin{tabular}{|c|c|}
\hline Yes & No \\
\hline 11 & 1 \\
\hline
\end{tabular}

\begin{tabular}{|l|c|c|}
\hline \multicolumn{1}{|c|}{ SENSOR } & Yes & No \\
\hline Day/Night & 11 & 0 \\
\hline IR & 11 & 0 \\
\hline Other: pan/tilt & 8 & \\
\hline Other: zoom & 1 & \\
\hline
\end{tabular}

\begin{tabular}{|l|c|}
\hline \multicolumn{1}{|c|}{ COMMENTS } & NUMBER \\
\hline HEIGHT NEEDED & 1 \\
\hline 4 feet & 3 \\
\hline 5-6 feet & 2 \\
\hline 8 feet to look over a wall & 5 \\
\hline 10 feet & \\
\hline \multicolumn{2}{|l|}{} \\
\hline General Comments & 1 \\
\hline Should be able to see through walls. & 1 \\
\hline Should be able to look over a wall. & 1 \\
\hline Manual control of where camera is looking. & 1 \\
\hline Should not be higher than antenna. & 1 \\
\hline Should be able to see over an HMMWV. & 2 \\
\hline Should have 360 degree coverage. & 1 \\
\hline Should be able to lower it also to hide it. & 1 \\
\hline Needs bulletproof lens and protective cover. & 1 \\
\hline No. Could ASM elevate itself instead of using mast? & \\
\hline
\end{tabular}

21. Should the ASM have a loading arm or retrieval arm for loading/unloading equipment or "snagging" a casualty to move to safe area?

\begin{tabular}{|c|c|}
\hline Yes & No \\
\hline 5 & 7 \\
\hline
\end{tabular}




\begin{tabular}{|l|c|c|}
\hline \multicolumn{1}{|c|}{ TASK } & YES & NO \\
\hline Loading/unloading equipment & 5 & 0 \\
\hline Casualty Aid & 5 & 0 \\
\hline
\end{tabular}

\begin{tabular}{|l|c|}
\hline \multicolumn{1}{|c|}{ COMMENTS } & NUMBER \\
\hline $\begin{array}{l}\text { Not good to retrieve or load casualties because it may inflict additional } \\
\text { damage. }\end{array}$ & 1 \\
\hline Equipment is not that heavy and Soldiers can load it. & 1 \\
\hline Soldiers would be gentler when loading casualties than a robotic arm. & 1 \\
\hline $\begin{array}{l}\text { Would keep Soldiers from exposing themselves if ASM drug casualty out } \\
\text { of harm's way. }\end{array}$ & 1 \\
\hline Could help stabilize casualty during loading. & 1 \\
\hline Would help load casualty while under fire. & 1 \\
\hline Tasks are too short to require aid or automation. & 1 \\
\hline Squad can load it - don't trust ASM to do it. & 1 \\
\hline Loading casualty needs to be done quickly. & 1 \\
\hline
\end{tabular}

22. What should be the procedure for conveying the mission to the ASM?

\begin{tabular}{|l|c|}
\hline \multicolumn{1}{|c|}{ COMMENTS } & NUMBER \\
\hline Pre-program operations order and route. & 2 \\
\hline Deny enemy intelligence of friendlies if captured (possible "zeroize”). & 2 \\
\hline Download specific portions because of operational security reasons. & 1 \\
\hline Speech recognition/verbal command. & 2 \\
\hline Map with graphics capabilities/tablet. & 4 \\
\hline Computer keyboard for input. & 4 \\
\hline $\begin{array}{l}\text { Have ASM in operations order briefing with audio equipment to } \\
\text { understand mission. }\end{array}$ & 1 \\
\hline Text message. & 2 \\
\hline Brief operator, operator then preloads information before mission. & 1 \\
\hline Scan paper copy into ASM and then have it acknowledge receipt. & 1 \\
\hline
\end{tabular}

23. What other mission-related or task-related items are needed or should be considered that were not discussed?

\begin{tabular}{|l|c|}
\hline \multicolumn{1}{|c|}{ COMMENTS } & NUMBER \\
\hline None. & 1 \\
\hline Radio and radio mount for communications by human. & 2 \\
\hline Needs to be waterproof. & 1 \\
\hline Low visibility. & 1 \\
\hline Jam electronic signals. & 1 \\
\hline Detect mines. & 1 \\
\hline Won't get stuck in mud or snow. & 1 \\
\hline Needs really good terrain navigation similar to a 4-wheeler. & 1 \\
\hline
\end{tabular}




\begin{tabular}{|l|c|}
\hline Must be able to wipeout database or computer memory quickly. & 3 \\
\hline Blue force tracker. & 1 \\
\hline Fording capability of 3-5 feet. & 2 \\
\hline Shocks to stabilize casualties. & 1 \\
\hline Prevent high centering during navigation. & 1 \\
\hline Water filtration system. & 1 \\
\hline Prevent reverse engineering by enemy - built in incendiary grenade. & 1 \\
\hline Must be able to carry what's loaded. & 1 \\
\hline Multi-terrain capable for wherever deployed. & 2 \\
\hline Independent wheel suspension. & 1 \\
\hline Black box recorder of everything. & 1 \\
\hline Leave it in forward operating base if it can't be of any use. & 1 \\
\hline Possibly use for troop support to break contact after popping smoke. & 1 \\
\hline $\begin{array}{l}\text { Special application for traffic control point to control vehicles and keep } \\
\text { weapon system on tracked target. }\end{array}$ & 1 \\
\hline Engage targets by itself. & 1 \\
\hline Send call for fire automatically based on laser accuracy. & 1 \\
\hline
\end{tabular}

\begin{tabular}{|l|c|}
\hline $\begin{array}{l}\text { Situational awareness for company standing operating procedures and } \\
\text { missions couples with “if-then” artificial intelligence for recommendations. }\end{array}$ & 1 \\
\hline $\begin{array}{l}\text { Scan picture of high value target. Once scanned, send out and alert squad. } \\
\text { ASM should have facial recognition capability. }\end{array}$ & 1 \\
\hline $\begin{array}{l}\text { Touch screen for squad leader to identify a rally point without having to } \\
\text { give a verbal command. }\end{array}$ & 1 \\
\hline
\end{tabular}

\section{OTHER POTENTIAL CONSIDERATIONS}

24. Along the lines of other mission-related or task-related items needed:

- A. Should the ASM have a manual backup for command and control? Why?

\begin{tabular}{|c|c|}
\hline Yes & No \\
\hline 12 & 0 \\
\hline
\end{tabular}

\begin{tabular}{|l|c|}
\hline \multicolumn{1}{|c|}{ COMMENTS } & NUMBER \\
\hline To control it after a malfunction occurs. Overcome malfunctions. & 8 \\
\hline Electronics can fail. & 1 \\
\hline All technologies are faulty. & 1 \\
\hline Always good to have a manual backup. & 1 \\
\hline No robot should have total control of itself. & 1 \\
\hline
\end{tabular}

- B. Should the ASM have a battery charger integrated to charge squad's batteries?

\begin{tabular}{|c|c|}
\hline Yes & No \\
\hline 12 & 0 \\
\hline
\end{tabular}




\begin{tabular}{|l|c|}
\hline \multicolumn{1}{|c|}{ COMMENTS } & NUMBER \\
\hline Radio batteries. & 7 \\
\hline All batteries that are used by the squad. & 4 \\
\hline All batteries with appropriate adapters. & 1 \\
\hline AA batteries for night observation devices (NODs). & 3 \\
\hline If it doesn't interfere with ASM's mission. & 1 \\
\hline Conformal batteries. & 1 \\
\hline
\end{tabular}

- C. Should the ASM have run-flat tires.

\begin{tabular}{|c|c|}
\hline Yes & No \\
\hline 12 & 0 \\
\hline
\end{tabular}

\begin{tabular}{|l|c|}
\hline \multicolumn{1}{|c|}{ COMMENTS } & NUMBER \\
\hline Do not want to leave or have to abandon ASM. & 2 \\
\hline Do not tie up other sources in order to retrieve it. & 2 \\
\hline Must be able to continue the mission. & 5 \\
\hline It becomes useless if it cannot move or continue mission. & 2 \\
\hline Possibly legs vs. wheels for negotiating slopes. & 1 \\
\hline Honeycombed wheels like land-mine proof tires. & 1 \\
\hline Prefer treads to tires. & 1 \\
\hline
\end{tabular}

- D. Should the ASM have a map display that allows programming of way points/routes, CCP, phase lines, objective, etc.?

\begin{tabular}{|c|c|}
\hline Yes & No \\
\hline 11 & 1 \\
\hline
\end{tabular}

\section{COMMENTS}

To be able to change the mission or route on the fly as needed.

To plan an alternate route.

Recognize voice/speech.

Graphics package interface.

Keyboard input.

Commander could see it also without having to have it radioed to him.

Easier for troops and mission planning.

Maintains situational awareness.

Similar to FBCB2.

It would make it easier.

A display that can be covered.

Could be used to conduct mission brief.

Should be consistent with land navigation.

NUMBER

\begin{tabular}{|l|}
\hline 1 \\
\hline 1 \\
\hline 1 \\
\hline 1 \\
\hline 1 \\
\hline 1 \\
\hline 1 \\
\hline 2 \\
\hline 1 \\
\hline 1 \\
\hline 1 \\
\hline 1 \\
\hline 1 \\
\hline
\end{tabular}


- E. Should the ASM be air-transportable by helicopter?

\begin{tabular}{|c|c|}
\hline Yes & No \\
\hline 11 & 1 \\
\hline
\end{tabular}

\section{COMMENTS}

Should be able to be transported as loaded for mission.

Needs to accompany/travel with squad.

Everything should be able to be airlifted.

NUMBER 1

3

- F. Should the ASM have a run-silent mode of operation?

\begin{tabular}{|c|c|}
\hline Yes & No \\
\hline 12 & 0 \\
\hline
\end{tabular}

\begin{tabular}{|l|c|}
\hline \multicolumn{1}{|c|}{ COMMENTS } & NUMBER \\
\hline Maintains element of surprise. & 1 \\
\hline Won't give away squad's position. & 3 \\
\hline Maintains noise and light discipline. & 6 \\
\hline Stealth mode prevents it from being detected. & 2 \\
\hline Any noise defeats the purpose of stealth. & 1 \\
\hline
\end{tabular}

- G. Should the ASM have voice recognition? (all squad members vs. selected)

\begin{tabular}{|c|c|}
\hline Yes & No \\
\hline 9 & 3 \\
\hline
\end{tabular}

\begin{tabular}{|c|c|}
\hline ALL & SELECTED \\
\hline 5 & 4 \\
\hline
\end{tabular}

\section{COMMENTS}

Chain of command in succession from squad leader to team leaders to squad members.

Prioritize and maintain the chain of command succession because combat noises may confuse it if it is distorted or there is yelling going on.

Squad leaders and team leaders.

Squad members with security clearances.

Recognize the NCOs and officers.

Identify speaker for security to take command and control from.

Needs passcode for security and authorization to command it.

Everyone does not need control.

No. Simplicity is best.

No. Touchy technology.

\begin{tabular}{|c|}
\hline NUMBER \\
\hline 2 \\
\hline 1 \\
\hline 2 \\
\hline 1 \\
\hline 1 \\
\hline 1 \\
\hline 1 \\
\hline 1 \\
\hline 1 \\
\hline 1 \\
\hline
\end{tabular}


- H. Should the ASM have multilingual voice recognition? (translation capability)

\begin{tabular}{|c|c|}
\hline Yes & No \\
\hline 5 & 7 \\
\hline
\end{tabular}

\section{COMMENTS}

Only for translation so enemy cannot command it. Enemy might use it to control ASM against friendlies.

Could be used to translate but must keep it from being commanded and controlled by indigenous personnel.

Translate through an earpiece and record what is being said.

Possibly interface with FBCB2.

Monitored at all times by operator.

Eases burden of learning another language.

NUMBER 1

1

1

1

1

2


INTENTIONALLY LEFT BLANK. 


\section{Appendix E. Demographics: Senior Noncommissioned Officers}




\section{AUTONOMOUS SQUAD MEMBER DEMOGRAPHICS (SENIOR NCOS)}

$\mathbf{N}=6$

1. Age: 29.3 Years

2. Sex: 6 male

3. Rank:

\begin{tabular}{|c|c|}
\hline RANK & QUANTITY \\
\hline E-5(P) & 1 \\
\hline E-6 & 5 \\
\hline
\end{tabular}

4. MOS:

\begin{tabular}{|c|c|}
\hline MOS & QUANTITY \\
\hline $11 \mathrm{~B}$ & 6 \\
\hline
\end{tabular}

5. Years in service: 9.5 years

6. Deployments: Have you been deployed? 6 Yes

If yes, where and how many times to each location.

\begin{tabular}{|l|c|}
\hline \multicolumn{1}{|c|}{ LOCATION } & NUMBER \\
\hline Afghanistan & 3 \\
\hline Iraq & 4 \\
\hline Kuwait & 4 \\
\hline
\end{tabular}

7. Present duty position:

\begin{tabular}{|l|c|}
\hline DUTY POSITION & NUMBER \\
\hline Squad leader & 3 \\
\hline Team leader & 1 \\
\hline Section Leader & 1 \\
\hline Staff NCO & 1 \\
\hline
\end{tabular}


8. Have you had experience with robots during tactical operations, either directly (operation) or indirectly (in support and aware of what the robot did)?

$\underline{4}$ Yes (If yes, answer all the following) $\quad \underline{2}$ No (If No, go to question 12)

- $\underline{4}$ Afghanistan $\underline{2}$ Iraq _ other:

- Type of unit assigned: $\underline{4}$ Infantry

9. What was the robot used for?

- Explore and Detonate IEDs (2)

- Surveillance

- Reconnaissance

10. Which of the following contributed to successful robot missions (check all that apply):

- 1 _ Maneuverability

- _ _ _ Ability to lift objects

- $\quad$ _ 3 Sensors (cameras, acoustic, etc.)

- 1 __ Ability to negotiate any type of terrain

11. What missions are robots best suited for:

- Reconnaissance

- Explore known hazards and reconnaissance

- Overwatch

- Mounted

12. If the robot had all the capabilities you would like it to have, then what missions would it be best designed for?

- Missions:

\begin{tabular}{|l|c|}
\hline \multicolumn{1}{|c|}{ MISSION } & NUMBER \\
\hline Dismounted patrol & 1 \\
\hline Surveillance/reconnaissance & 3 \\
\hline Route clearing & 1 \\
\hline Carrying equipment & 1 \\
\hline Weapons employment & 1 \\
\hline Casualty evacuation & 1 \\
\hline Explosive ordnance disposal & 2 \\
\hline
\end{tabular}


- Capabilities:

\begin{tabular}{|l|c|}
\hline \multicolumn{1}{|c|}{ CAPABILITY } & NUMBER \\
\hline Terrain negotiation & 3 \\
\hline Camera (day and night, zoom) & 2 \\
\hline IED detection & 1 \\
\hline Load carrying & 1 \\
\hline $\begin{array}{l}\text { Forward operating base (FOB) } \\
\text { resupply }\end{array}$ & 1 \\
\hline Speed & 1 \\
\hline Lightweight & 1 \\
\hline Long battery life & 1 \\
\hline Multi-deployable (land, air, sea) & 1 \\
\hline Ballistic computation & 1 \\
\hline
\end{tabular}

- Concept of employment:

\begin{tabular}{|l|c|}
\hline \multicolumn{1}{|c|}{ EMPLOYMENT } & NUMBER \\
\hline Carry extra equipment & 1 \\
\hline Controlled with a hand unit & 1 \\
\hline Manual and self-sustainable & 2 \\
\hline Site exploitation & 1 \\
\hline No response & 1 \\
\hline
\end{tabular}

13. For future operations, what would be the best method of controlling the robot?

\begin{tabular}{|l|c|}
\hline \multicolumn{1}{|c|}{ CONTROL METHOD } & NUMBER \\
\hline Tele-operated (operator control via joystick, screen, or voice) & 5 \\
\hline $\begin{array}{l}\text { Autonomous (artificial intelligence and robot acts similar to a } \\
\text { squad member) }\end{array}$ & 1 \\
\hline
\end{tabular}




\section{Appendix F. Survey Results: Senior Noncommissioned Officers}




\section{AUTONOMOUS SQUAD MEMBER SURVEY INSTRUCTIONS}

You have been identified as the squad leader within a platoon. That platoon has been given a mission to conduct a dismounted route reconnaissance. Your squad has been designated as the lead or point squad for the mission. Your squad has been ordered to conduct a route reconnaissance along a section of road to be used for military movement. The area of operations has evidence of friendly and enemy events. There has been enemy activity in the area and your mission is to ensure that the route is clear for vehicular travel and any IEDs are reported and disposed of. You have been given photographs of certain high value targets (HVT) known to be in the area in the past 96 hours and are supposed to identify and detain these persons if encountered.

The Area of Operations (AO) is a lightly forested undulating patch of countryside with a couple of buildings and at least one paved road with occasional vehicular or pedestrian traffic.

The platoon leader has given you a company asset to aid in your mission - an autonomous squad member (ASM) (see concept and equipment photos below). The ASM has artificial intelligence, acts as a member of the squad, and conducts tasks and movement on its own based on the actions of the other squad members and its own observations from its sensor suite. The ASM is an all terrain vehicle that can navigate most terrain except for steep slopes but travels primarily on roads. It has obstacle avoidance technologies that allow it to maneuver around obstacles and non-negotiable terrain features. The ASM is equipped with multiple cameras, acoustic sensors, and lasers. It has a cargo carrying capability for squad equipment and other technologies that you will define based on the mission.

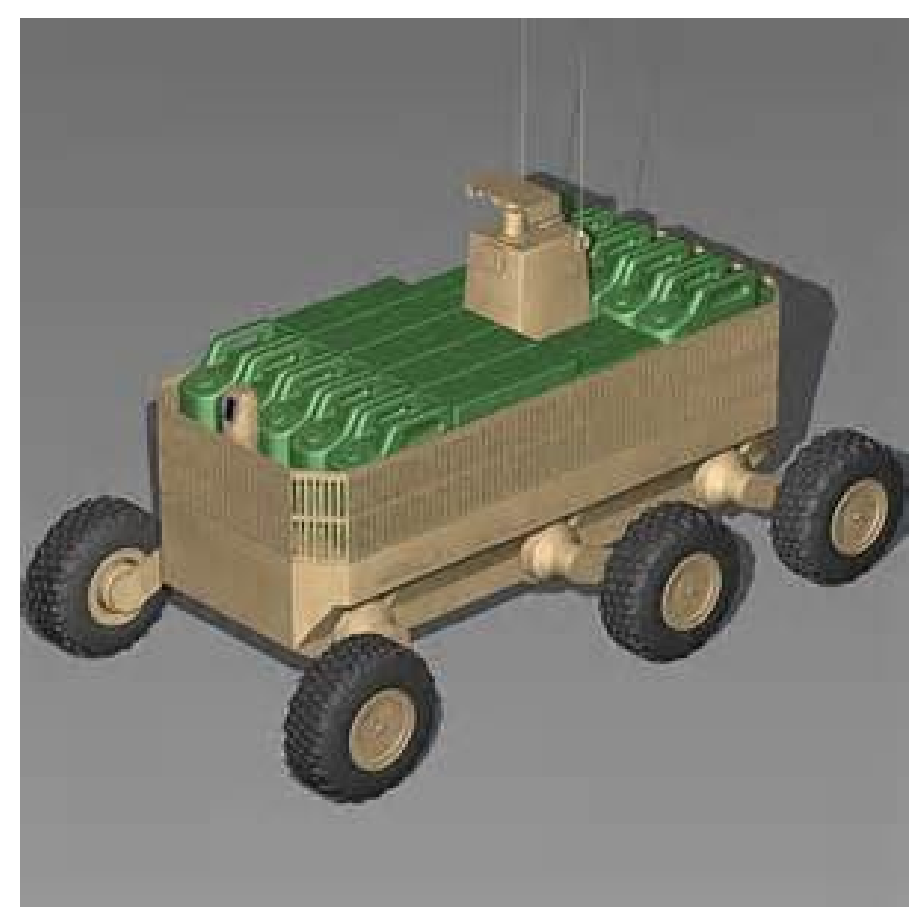




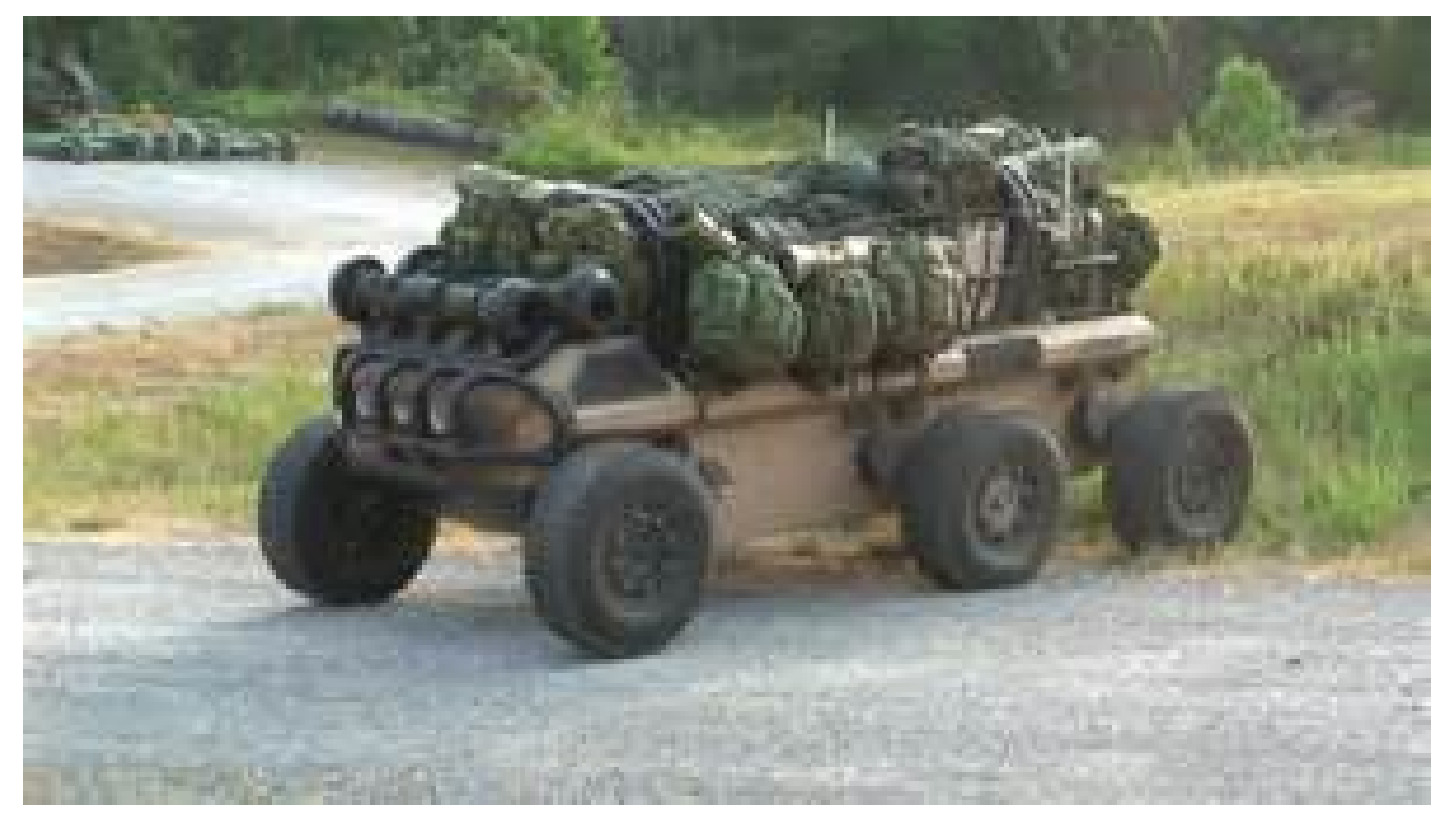

You will be asked a series of questions related to the mission and key events during it about your actions, your squad members' actions, and the actions of the ASM. These are constructed to help you determine the best ways to use and equip the ASM for successful mission performance. After completing the questionnaire, you will be interviewed.

During the mission, your squad will encounter events that will trigger some action or decisions. Your responses will aid computer modelers to develop the simulation and incorporate the actions of the squad and the ASM to determine various outcomes.

Please ask questions about anything you do not understand on the survey. 


\section{AUTONOMOUS SQUAD MEMBER SCENARIO SURVEY RESULTS (SENIOR NCOS)}

\section{$\mathbf{N}=6$}

\section{Pre-mission checks:}

What is the preferred method for the ASM to indicate that all systems (power, drive train, tires, etc. and sensors) are operational?

\begin{tabular}{|l|c|}
\hline \multicolumn{1}{|c|}{ PREFERRED METHOD } & NUMBER \\
\hline red/amber/green lights & 2 \\
\hline text message to operator/SL & 2 \\
\hline item by item checklist display & 1 \\
\hline alert signal & 0 \\
\hline $\begin{array}{l}\text { other: (describe) Should be a combination of lights and status bar with } \\
\text { an itemized list with short and long versions of the list. }\end{array}$ & 1 \\
\hline
\end{tabular}

What equipment, weapons, ammunition etc. would you want to be able to load on the ASM initially that would be available to the squad during the mission?

\begin{tabular}{|l|c|}
\hline \multicolumn{1}{|c|}{ ITEMS TO BE LOADED } & NUMBER \\
\hline Weapons (small arms or heavy weapons) & 5 \\
\hline Ammunition & 5 \\
\hline Meals ready to eat (MRE) & 2 \\
\hline Water & 2 \\
\hline Grenades & 2 \\
\hline Less than lethal devices and equipment. & 1 \\
\hline Detonation material (C-4) & 1 \\
\hline 60 mm mortar tube and rounds & 1 \\
\hline
\end{tabular}

\section{Execution of mission:}

Where in the formation do you want the ASM located?

\begin{tabular}{|l|c|}
\hline \multicolumn{1}{|c|}{ ASM LOCATION } & NUMBER \\
\hline Front & 2 \\
\hline Rear & 3 \\
\hline Middle & 0 \\
\hline Tied to SL & 1 \\
\hline Tied to squad member & 0 \\
\hline
\end{tabular}


What actions and/or tasks do you want the ASM to conduct upon reaching the SP?

\begin{tabular}{|l|c|}
\hline \multicolumn{1}{|c|}{ ACTIONS AND/OR TASKS } & NUMBER \\
\hline $\begin{array}{l}\text { Pre-combat checks to ensure enough ammunition, food, and water are } \\
\text { loaded. }\end{array}$ & 1 \\
\hline Preventative maintenance, checks, and services (PMCS). & 1 \\
\hline Continuous assessment of terrain. & 1 \\
\hline Weapons check. & 1 \\
\hline Designate targets. & 1 \\
\hline $\begin{array}{l}\text { Continuous assessment of the location of adjacent friendly units/Soldiers } \\
\text { like a blue force tracker (BFT). }\end{array}$ & 1 \\
\hline $\begin{array}{l}\text { Provide digital representation of anything on the battlefield and place it } \\
\text { at the squad leader's disposal via a graphics user interface device. }\end{array}$ & 1 \\
\hline Move with the squad. & 1 \\
\hline Upload all way points in the ASM. & 1 \\
\hline Conduct route reconnaissance 50 meters in front of the squad. & 1 \\
\hline Communications check for connectivity. & 1 \\
\hline $\begin{array}{l}\text { All sensors need to report status to operator in real time as well as all } \\
\text { camera feeds provided in real time. }\end{array}$ & 1 \\
\hline Carry load. & \\
\hline
\end{tabular}

During subsequent movement, what actions and/or tasks do you want the ASM to conduct?

\begin{tabular}{|l|c|}
\hline \multicolumn{1}{|c|}{ ACTIONS AND/OR TASKS } & NUMBER \\
\hline Scouting forward. & 1 \\
\hline Follow specific route 50 meters in front of the squad. & 1 \\
\hline Scanning for danger. & 1 \\
\hline Route clearance. & 1 \\
\hline Battle mapping. & 1 \\
\hline Weapons deployment via a tele-communicated control system. & 1 \\
\hline Move with the squad - don't want it thinking too much. & 1 \\
\hline Medical evacuation. & 1 \\
\hline Keep communication up. & 1 \\
\hline Carry the load. & 1 \\
\hline Provide security. & 1 \\
\hline $\begin{array}{l}\text { All sensors need to report status to operator in real time as well as all } \\
\text { camera feeds provided in real time. }\end{array}$ & 1 \\
\hline Video recording of mission & 1 \\
\hline
\end{tabular}


3. During the mission, you come under a mortar attack.

Roster Number 201: E-6, MOS 11B, Section leader, 9 years in service

As the squad leader, what actions or tasks do you do? 3 D’s. Move back to safe location. Plan for counter attack.

What actions or tasks do the rest of the squad conduct (not the ASM)? Same as the squad leader plus pull security.

What actions or tasks do you want the ASM conduct? Give a good location for mortar attack.

What actions or tasks do you take to reorient the squad and continue the mission? Based on the information provided by the ASM, consolidate squad and prepare for squad attack.

What actions or tasks do you want the ASM to take to reorient and continue the mission? Shift to front of formation.

Do you want the ASM to change its location in reference to its initial position? Yes.

Contact is imminent so if ASM is in front, it could be used for cover.

\section{Roster Number 202: E-5 (P), MOS 11B, Team Leader, 5 years in service}

As the squad leader, what actions or tasks do you do? Determine a distance and direction for movement. Begin movement. Re-assess and continue movement as required. Contact higher and begin counter-artillery measures.

What actions or tasks do the rest of the squad conduct (not the ASM)? Follow instructions during movement. Maintain security and personnel accountability.

What actions or tasks do you want the ASM conduct? Stay out of the way - \#1 priority. Assess the environment for the possible location of the enemy mortars via acoustic sensors. Determine the nearest place with overhead cover. Automatically contact higher with a digital report.

What actions or tasks do you take to reorient the squad and continue the mission? Determine a distance and direction for movement. Begin movement. Re-assess and continue movement as required. Contact higher and begin counter-artillery measures. What actions or tasks do you want the ASM to take to reorient and continue the mission? Stay out of the way - \#1 priority. Assess the environment for the possible location of the enemy mortars via acoustic sensors. Determine the nearest place with overhead cover. Automatically contact higher with a digital report.

Do you want the ASM to change its location in reference to its initial position? Maybe. This would depend on the situation. The ASM would have to know many variables of the precise situation at hand, just as a Soldier does.

\section{Roster Number 203: E-6, MOS 11B, Squad Leader, 9 years in service} As the squad leader, what actions or tasks do you do? Provide proper linkup direction and distance. Look for wounded while moving.

What actions or tasks do the rest of the squad conduct (not the ASM)? Conduct the appropriate battle drill for indirect fire and move quickly to the designated linkup or rally point.

What actions or tasks do you want the ASM conduct? Follow the squad. What actions or tasks do you take to reorient the squad and continue the mission? Reorganize after the attack. Plan the route back to wherever we were headed. 
What actions or tasks do you want the ASM to take to reorient and continue the mission? Follow the squad.

Do you want the ASM to change its location in reference to its initial position? No.

Roster Number 204: E-6, MOS 11B, Squad Leader, 11 year in service As the squad leader, what actions or tasks do you do? Give distance and direction to move.

What actions or tasks do the rest of the squad conduct (not the ASM)? Move to rally point.

What actions or tasks do you want the ASM conduct? Find where the mortars came from.

What actions or tasks do you take to reorient the squad and continue the mission? Accountability, consolidation, and reorganization.

What actions or tasks do you want the ASM to take to reorient and continue the mission? Take out the threat.

Do you want the ASM to change its location in reference to its initial position? No.

Roster Number 205: E-6, MOS 11B, Squad Leader, 5 years in service

As the squad leader, what actions or tasks do you do? Command everyone to seek cover followed by announcing a rally point for everyone to get to rapidly.

What actions or tasks do the rest of the squad conduct (not the ASM)? Seek cover and repeat the distance and direction to the rally point ensuring that everyone understands.

What actions or tasks do you want the ASM conduct? It would have to be able to navigate to the rally point by either voice command or be synchronized to other technologies by pushing a location on a map.

What actions or tasks do you take to reorient the squad and continue the mission?

Pull 360 degree security at rally point and receive reports from team leaders.

What actions or tasks do you want the ASM to take to reorient and continue the mission? Have MEDEVAC capabilities to possibly drag a Sked litter behind.

Do you want the ASM to change its location in reference to its initial position? Yes.

Because if it is now carrying a casualty, it needs to be in a secure area in the formation.

\section{Roster Number 206: E-6, MOS 11B, Staff NCO, 17.5 years in service}

As the squad leader, what actions or tasks do you do? Assess the situation. Plot a new course or tell the ASM to follow alternate route to objective. ASM continues to provide live situational awareness.

What actions or tasks do the rest of the squad conduct (not the ASM)? Assess the situation and move to our objective on an alternate course. (May not be the same as the ASM.)

What actions or tasks do you want the ASM conduct? Continue with its route reconnaissance.

What actions or tasks do you take to reorient the squad and continue the mission?

Tell my team leader running point a new azimuth to follow. Identify the grid we have to move to. 
What actions or tasks do you want the ASM to take to reorient and continue the mission? I want it to do what I tell it to do as described above.

Do you want the ASM to change its location in reference to its initial position? Yes.

If hit, I want it to travel on an alternate route to the objective providing a live feed.

4. During the mission, you receive sniper fire.

\section{Roster Number 201: E-6, MOS 11B, Section leader, 9 years in service}

As the squad leader, what actions or tasks do you do? Take cover, prepare countersniper mission or call for fire.

What actions or tasks do the rest of the squad conduct (not the ASM)? Take cover and pull security.

What actions or tasks do you want the ASM conduct? Give grid to sniper location and produce call for fire information.

What actions or tasks do you take to reorient the squad and continue the mission? Get reports from team leaders and move out.

What actions or tasks do you want the ASM to take to reorient and continue the mission? Move to front and scan for potential targets.

Do you want the ASM to change its location in reference to its initial position? Yes.

Shift to front to provide cover and better visuals.

\section{Roster Number 202: E-5 (P), MOS 11B, Team Leader, 5 years in service}

As the squad leader, what actions or tasks do you do? Seek cover immediately. Contact higher. Break contact or begin counter-sniper operations.

What actions or tasks do the rest of the squad conduct (not the ASM)? Seek cover and scan the environment if possible based on the situation at hand. Wait for further instructions.

What actions or tasks do you want the ASM conduct? If possible, identify the position of the sniper via acoustic sensors - based on its known position and the relative distance of the possible origin of the shots fired.

What actions or tasks do you take to reorient the squad and continue the mission? If possible, identify the position of the sniper with an up-armored vehicle and eliminate the threat. Otherwise, there are many variable scenarios.

What actions or tasks do you want the ASM to take to reorient and continue the mission? If possible, identify the position of the sniper via acoustic sensors - based on its known position and the relative distance of the possible origin of the shots fired.

Do you want the ASM to change its location in reference to its initial position? Yes. It should assess its environment and seek cover and concealment. 
Roster Number 203: E-6, MOS 11B, Squad Leader, 9 years in service

As the squad leader, what actions or tasks do you do? Get down behind cover and instruct Soldiers to do the same until the sniper is located.

What actions or tasks do the rest of the squad conduct (not the ASM)? The same as I do.

What actions or tasks do you want the ASM conduct? Stay put or maybe to draw fire.

What actions or tasks do you take to reorient the squad and continue the mission?

Reconsolidate and reorganize. Move to the appropriate area.

What actions or tasks do you want the ASM to take to reorient and continue the mission? Follow the squad.

Do you want the ASM to change its location in reference to its initial position? No.

\section{Roster Number 204: E-6, MOS 11B, Squad Leader, 11 year in service}

As the squad leader, what actions or tasks do you do? Find cover and concealment.

What actions or tasks do the rest of the squad conduct (not the ASM)? Find cover and concealment.

What actions or tasks do you want the ASM conduct? Conduct reconnaissance by fire.

What actions or tasks do you take to reorient the squad and continue the mission?

Find where the sniper is and kill them.

What actions or tasks do you want the ASM to take to reorient and continue the mission? Take out the threat.

Do you want the ASM to change its location in reference to its initial position? Yes.

If it needs to.

Roster Number 205: E-6, MOS 11B, Squad Leader, 5 years in service

As the squad leader, what actions or tasks do you do? Seek cover and determine what direction the fire is coming from and maneuver on its location.

What actions or tasks do the rest of the squad conduct (not the ASM)? Seek cover and pull security. Report any intel.

What actions or tasks do you want the ASM conduct? Be able to determine direction via audible and report it directly to the squad leader.

What actions or tasks do you take to reorient the squad and continue the mission? Determine the best avenue of approach. Establish a support by fire element and maneuver on enemy position using proper individual movement techniques (IMT).

What actions or tasks do you want the ASM to take to reorient and continue the mission? Tether to the support by fire team leader.

Do you want the ASM to change its location in reference to its initial position? Yes. Move with support by fire team leader. 


\section{Roster Number 206: E-6, MOS 11B, Staff NCO, 17.5 years in service}

As the squad leader, what actions or tasks do you do? Try to fix the target location. Call in situation report (SITREP) to higher.

What actions or tasks do the rest of the squad conduct (not the ASM)? Fix the target, close on target location and destroy target. Ultimately, continue the mission.

What actions or tasks do you want the ASM conduct? If not with squad, continue the mission.

What actions or tasks do you take to reorient the squad and continue the mission?

Tell lead team leader to proceed to grid or orient for new distance and direction.

What actions or tasks do you want the ASM to take to reorient and continue the mission? Proceed to the next way point.

Do you want the ASM to change its location in reference to its initial position? No.

5. During the mission, you encounter an obstacle that requires movement around it.

Roster Number 201: E-6, MOS 11B, Section leader, 9 years in service

As the squad leader, what actions or tasks do you do? Send out scout team.

What actions or tasks do the rest of the squad conduct (not the ASM)? Provide security.

What actions or tasks do you want the ASM conduct? Recon route and detect any IEDs.

What actions or tasks do you take to reorient the squad and continue the mission?

Pick up and move out.

What actions or tasks do you want the ASM to take to reorient and continue the mission? Move back to rear.

Do you want the ASM to change its location in reference to its initial position? No.

\section{Roster Number 202: E-5 (P), MOS 11B, Team Leader, 5 years in service}

As the squad leader, what actions or tasks do you do? Move around the obstacle based on the tactical situation at hand.

What actions or tasks do the rest of the squad conduct (not the ASM)? Maintain security during movement.

What actions or tasks do you want the ASM conduct? Provide me a means to track the location and type of obstacle and periodically update its status (i.e., avoidable, unavoidable, etc.).

What actions or tasks do you take to reorient the squad and continue the mission? Clearly define the intended route change. Establish rally points on the route.

What actions or tasks do you want the ASM to take to reorient and continue the mission? Track the movements of the squad in real time (must be $100 \%$ encrypted). Maintain situational awareness in a 360-degree, three- dimensional battle space (i.e., camera, thermal, infrared, range finder).

Do you want the ASM to change its location in reference to its initial position? Yes. Should follow the route of the squad and remain available to push up as needed for recon purposes. 
Roster Number 203: E-6, MOS 11B, Squad Leader, 9 years in service

As the squad leader, what actions or tasks do you do? Halt and look for the best way around it.

What actions or tasks do the rest of the squad conduct (not the ASM)? Halt and pull security.

What actions or tasks do you want the ASM conduct? Halt or maybe move around the terrain and give us a better view of the surroundings.

What actions or tasks do you take to reorient the squad and continue the mission? Give the new route to the point man.

What actions or tasks do you want the ASM to take to reorient and continue the mission? Follow the squad.

Do you want the ASM to change its location in reference to its initial position? No.

\section{Roster Number 204: E-6, MOS 11B, Squad Leader, 11 year in service}

As the squad leader, what actions or tasks do you do? Move around.

What actions or tasks do the rest of the squad conduct (not the ASM)? Follow.

What actions or tasks do you want the ASM conduct? Move around obstacle once it is safe.

What actions or tasks do you take to reorient the squad and continue the mission?

Go around the obstacle and orient self on map.

What actions or tasks do you want the ASM to take to reorient and continue the mission? Move.

Do you want the ASM to change its location in reference to its initial position? No.

\section{Roster Number 205: E-6, MOS 11B, Squad Leader, 5 years in service}

As the squad leader, what actions or tasks do you do? Do a map reconnaissance and determine a new route that best supplements security and speed.

What actions or tasks do the rest of the squad conduct (not the ASM)? Continue to pull 360 degree security and report any significant intel to the team leaders.

What actions or tasks do you want the ASM conduct? If the mission is becoming compromised due to the capabilities of the ASM, then the ASM needs to be something affordable enough to just blow in place.

What actions or tasks do you take to reorient the squad and continue the mission? Inform team leaders of the obstacle and the new plan of action.

What actions or tasks do you want the ASM to take to reorient and continue the mission? The ASM should be able to overcome an obstacle by bridging gaps.

Do you want the ASM to change its location in reference to its initial position? No. 
Roster Number 206: E-6, MOS 11B, Staff NCO, 17.5 years in service

As the squad leader, what actions or tasks do you do? Report obstacle to higher. Ensure lead team leader doglegs around the obstacle.

What actions or tasks do the rest of the squad conduct (not the ASM)? Follow the team leader around the obstacle.

What actions or tasks do you want the ASM conduct? Operator will give it a new waypoint or follow behind the squad.

What actions or tasks do you take to reorient the squad and continue the mission?

Direct lead team leader to proceed to grid or orient team leader with new distance and direction.

What actions or tasks do you want the ASM to take to reorient and continue the mission? Operator push ASM 50 meters out giving a list of way points to follow to get to the objective.

Do you want the ASM to change its location in reference to its initial position? Yes. Push to waypoints given it.

6. During the mission, you detect an IED location.

Roster Number 201: E-6, MOS 11B, Section leader, 9 years in service

As the squad leader, what actions or tasks do you do? Cordon off area and call in an unidentified explosive ordinance report.

What actions or tasks do the rest of the squad conduct (not the ASM)? Provide security.

What actions or tasks do you want the ASM conduct? Exploit IED.

What actions or tasks do you take to reorient the squad and continue the mission? Conduct equipment check and move out.

What actions or tasks do you want the ASM to take to reorient and continue the mission? Conduct equipment check and move out.

Do you want the ASM to change its location in reference to its initial position? Yes. An IED is expected.

Roster Number 202: E-5 (P), MOS 11B, Team Leader, 5 years in service As the squad leader, what actions or tasks do you do? Clear, cordon, confirm, call, and check.

What actions or tasks do the rest of the squad conduct (not the ASM)? Wait for explosive ordinance detachment. Maintain the cordon.

What actions or tasks do you want the ASM conduct? It would be awesome if it could scan the material of the IED to determine its size and chemical disposition.

What actions or tasks do you take to reorient the squad and continue the mission? Clear, cordon, confirm, call, and check. Wait for explosive ordinance detachment. Maintain the cordon.

What actions or tasks do you want the ASM to take to reorient and continue the mission? It would be awesome if it could scan the material of the IED to determine its size and chemical disposition.

Do you want the ASM to change its location in reference to its initial position? No. It's a bomb, don't be walking all around and stuff. 
Roster Number 203: E-6, MOS 11B, Squad Leader, 9 years in service

As the squad leader, what actions or tasks do you do? Halt the formation. Call it up and conduct the 5 C's.

What actions or tasks do the rest of the squad conduct (not the ASM)? Halt and pull security. Conduct 5's and 25's.

What actions or tasks do you want the ASM conduct? Approach the IED to get better eyes on it.

What actions or tasks do you take to reorient the squad and continue the mission?

Move along a different route until it's cleared.

What actions or tasks do you want the ASM to take to reorient and continue the mission? Report back with proof that it's an IED.

Do you want the ASM to change its location in reference to its initial position? No.

\section{Roster Number 204: E-6, MOS 11B, Squad Leader, 11 year in service}

As the squad leader, what actions or tasks do you do? Get distance, make sure it is marked, and call it up.

What actions or tasks do the rest of the squad conduct (not the ASM)? Same as squad leader.

What actions or tasks do you want the ASM conduct? Get rid of the IED if possible. What actions or tasks do you take to reorient the squad and continue the mission? Check for secondary IED and ambush.

What actions or tasks do you want the ASM to take to reorient and continue the mission? Provide security.

Do you want the ASM to change its location in reference to its initial position? No.

\section{Roster Number 205: E-6, MOS 11B, Squad Leader, 5 years in service}

As the squad leader, what actions or tasks do you do? Halt the squad and check, confirm, cordon, and call higher.

What actions or tasks do the rest of the squad conduct (not the ASM)? Stop movement. Conduct 5's and 25's and cordon off the area at a minimum of 300 meters.

What actions or tasks do you want the ASM conduct? Jam signals, detect wires, send video feedback to the squad leader. Send a digital 9-line unexploded ordinance report.

What actions or tasks do you take to reorient the squad and continue the mission? Get accountability of personnel and equipment and continue mission.

What actions or tasks do you want the ASM to take to reorient and continue the mission? Resume its position and continue mission.

Do you want the ASM to change its location in reference to its initial position? No. 
Roster Number 206: E-6, MOS 11B, Staff NCO, 17.5 years in service

As the squad leader, what actions or tasks do you do? Get as much standoff from the device as possible. Re-route ASM or stop it. Report to higher and ask for guidance.

What actions or tasks do the rest of the squad conduct (not the ASM)? Pull security and wait for orders.

What actions or tasks do you want the ASM conduct? Pull back with squad and continue live situational awareness.

What actions or tasks do you take to reorient the squad and continue the mission? Have lead team leader proceed to grid or orient him with a new distance and direction.

What actions or tasks do you want the ASM to take to reorient and continue the mission? Operator have ASM 50 meters out in front of squad with a new set of waypoints to follow to get to the objective.

Do you want the ASM to change its location in reference to its initial position? No.

7. During the mission, you are ambushed.

Roster Number 201: E-6, MOS 11B, Section leader, 9 years in service

As the squad leader, what actions or tasks do you do? Return fire. Direct squad to proper locations to defeat ambush.

What actions or tasks do the rest of the squad conduct (not the ASM)? Return fire and eliminate the enemy.

What actions or tasks do you want the ASM conduct? Provide 3 D's and provide cover.

What actions or tasks do you take to reorient the squad and continue the mission? Get direction and move out.

What actions or tasks do you want the ASM to take to reorient and continue the mission? Conduct system checks and move out.

Do you want the ASM to change its location in reference to its initial position? Yes. Threat level is higher.

Roster Number 202: E-5 (P), MOS 11B, Team Leader, 5 years in service

As the squad leader, what actions or tasks do you do? Read the Ranger handbook and wait to die.

What actions or tasks do the rest of the squad conduct (not the ASM)? Deploy fragmentation grenades and smoke. Orient fires towards the ambush. Assault head on.

What actions or tasks do you want the ASM conduct? Get out of my way.

What actions or tasks do you take to reorient the squad and continue the mission? Scream “ambush", it's a battle drill.

What actions or tasks do you want the ASM to take to reorient and continue the mission? Get out of my way.

Do you want the ASM to change its location in reference to its initial position? No. 
Roster Number 203: E-6, MOS 11B, Squad Leader, 9 years in service

As the squad leader, what actions or tasks do you do? Get down. Return fire and move towards the enemy.

What actions or tasks do the rest of the squad conduct (not the ASM)? The same as I do.

What actions or tasks do you want the ASM conduct? Move along with us for resupply of ammunition.

What actions or tasks do you take to reorient the squad and continue the mission?

Reorganize and reconsolidate. Send up report. Look for wounded.

What actions or tasks do you want the ASM to take to reorient and continue the mission? Follow the squad.

Do you want the ASM to change its location in reference to its initial position? No.

\section{Roster Number 204: E-6, MOS 11B, Squad Leader, 11 year in service}

As the squad leader, what actions or tasks do you do? Fight through it.

What actions or tasks do the rest of the squad conduct (not the ASM)? Fight through it.

What actions or tasks do you want the ASM conduct? Kill enemy by massing of fires.

What actions or tasks do you take to reorient the squad and continue the mission? Reconsolidate and reorganize.

What actions or tasks do you want the ASM to take to reorient and continue the mission? None.

Do you want the ASM to change its location in reference to its initial position? No.

\section{Roster Number 205: E-6, MOS 11B, Squad Leader, 5 years in service}

As the squad leader, what actions or tasks do you do? Return fire, seek cover, get the squad on line, and maneuver on the enemy position.

What actions or tasks do the rest of the squad conduct (not the ASM)? Return fire, seek cover, get on line in accordance with the team leaders.

What actions or tasks do you want the ASM conduct? Send a GPS location with distance and direction to higher. Or during night operations, project a powerful light on enemy position to limit their ability to see and during day time, deploy smoke for screening.

What actions or tasks do you take to reorient the squad and continue the mission? Get accountability of equipment and personnel, continue the mission. Redistribute ammunition and water if necessary.

What actions or tasks do you want the ASM to take to reorient and continue the mission? Send a digital incident and LACE report to higher.

Do you want the ASM to change its location in reference to its initial position? No. 
Roster Number 206: E-6, MOS 11B, Staff NCO, 17.5 years in service

As the squad leader, what actions or tasks do you do? If ambush is near, turn into it and fight with the squad. Report to higher afterwards. If ambush is far, report it to higher, maneuver squad to make contact,

What actions or tasks do the rest of the squad conduct (not the ASM)? For near ambush, turn and fight. When completed, consolidate and re-organize. For far ambush, fix the target, maneuver squad to engage and destroy the target. Consolidate and reorganize after.

What actions or tasks do you want the ASM conduct? Report live feed to higher for their situational awareness. Hold in place.

What actions or tasks do you take to reorient the squad and continue the mission? Have lead team leader proceed to grid or orient him with a new distance and direction.

What actions or tasks do you want the ASM to take to reorient and continue the mission? Operator have ASM 50 meters out in front of squad with a new set of waypoints to follow to get to the objective.

Do you want the ASM to change its location in reference to its initial position? No.

8. During the mission a civilian vehicle approaches or personnel are approaching.

Roster Number 201: E-6, MOS 11B, Section leader, 9 years in service

As the squad leader, what actions or tasks do you do? Utilize training to stop vehicle or use tactical call out.

What actions or tasks do the rest of the squad conduct (not the ASM)? Provide security and establish a check point.

What actions or tasks do you want the ASM conduct? Act as road block.

What actions or tasks do you take to reorient the squad and continue the mission? Collapse check point and continue on.

What actions or tasks do you want the ASM to take to reorient and continue the mission? Collapse check point and continue on.

Do you want the ASM to change its location in reference to its initial position? No.

Roster Number 202: E-5 (P), MOS 11B, Team Leader, 5 years in service As the squad leader, what actions or tasks do you do? Maintain security. What actions or tasks do the rest of the squad conduct (not the ASM)? Maintain security.

What actions or tasks do you want the ASM conduct? Maintain security and document the activity.

What actions or tasks do you take to reorient the squad and continue the mission? Maintain security.

What actions or tasks do you want the ASM to take to reorient and continue the mission? No changes, it's a civilian vehicle.

Do you want the ASM to change its location in reference to its initial position? No. 
Roster Number 203: E-6, MOS 11B, Squad Leader, 9 years in service

As the squad leader, what actions or tasks do you do? Stop the vehicle.

What actions or tasks do the rest of the squad conduct (not the ASM)? Stop the vehicle and check it.

What actions or tasks do you want the ASM conduct? None.

What actions or tasks do you take to reorient the squad and continue the mission?

None.

What actions or tasks do you want the ASM to take to reorient and continue the mission? None.

Do you want the ASM to change its location in reference to its initial position? No.

\section{Roster Number 204: E-6, MOS 11B, Squad Leader, 11 year in service}

As the squad leader, what actions or tasks do you do? Get vehicle to stop. Search the vehicle.

What actions or tasks do the rest of the squad conduct (not the ASM)? Same as squad leader.

What actions or tasks do you want the ASM conduct? Conduct face recognition. Check for hot spots with thermal sensor.

What actions or tasks do you take to reorient the squad and continue the mission? Pull security.

What actions or tasks do you want the ASM to take to reorient and continue the mission? None.

Do you want the ASM to change its location in reference to its initial position? No.

Roster Number 205: E-6, MOS 11B, Squad Leader, 5 years in service

As the squad leader, what actions or tasks do you do? Visually try and stop.

Verbally try and stop. Shoot to disable or kill if refusing to stop.

What actions or tasks do the rest of the squad conduct (not the ASM)? Pull 360

degree security and report any significant intel to team leaders.

What actions or tasks do you want the ASM conduct? Powerful light capabilities.

Loud sound with multiple language capabilities.

What actions or tasks do you take to reorient the squad and continue the mission? No response (NR).

What actions or tasks do you want the ASM to take to reorient and continue the mission? NR.

Do you want the ASM to change its location in reference to its initial position? Yes. ASM should move to the front in order to get the attention of the vehicle/personnel approaching. 
Roster Number 206: E-6, MOS 11B, Staff NCO, 17.5 years in service

As the squad leader, what actions or tasks do you do? Report suspicious activity, tighten security, and increase situational awareness.

What actions or tasks do the rest of the squad conduct (not the ASM)? Tighten security and increase situational awareness.

What actions or tasks do you want the ASM conduct? Provide live feed for 360degree coverage and continue mission.

What actions or tasks do you take to reorient the squad and continue the mission? Have lead team leader proceed to grid or orient him with a new distance and direction.

What actions or tasks do you want the ASM to take to reorient and continue the mission? Operator have ASM 50 meters out in front of squad with a new set of waypoints to follow to get to the objective.

Do you want the ASM to change its location in reference to its initial position? No.

9. During the mission you come to an area where you lose line of sight with what is ahead along the route.

Roster Number 201: E-6, MOS 11B, Section leader, 9 years in service

As the squad leader, what actions or tasks do you do? Send out reconnaissance element.

What actions or tasks do the rest of the squad conduct (not the ASM)? Short halt. What actions or tasks do you want the ASM conduct? Recon the route.

What actions or tasks do you take to reorient the squad and continue the mission?

With intelligence from ASM, choose best route and go.

What actions or tasks do you want the ASM to take to reorient and continue the mission? Give all information to the squad leader and take position back in rear of element.

Do you want the ASM to change its location in reference to its initial position? No.

\section{Roster Number 202: E-5 (P), MOS 11B, Team Leader, 5 years in service}

As the squad leader, what actions or tasks do you do? Read a map. Deploy an intermediate security reconnaissance element.

What actions or tasks do the rest of the squad conduct (not the ASM)? Maintain security.

What actions or tasks do you want the ASM conduct? Act as the security and reconnaissance element for the squad.

What actions or tasks do you take to reorient the squad and continue the mission? Follow me.

What actions or tasks do you want the ASM to take to reorient and continue the mission? Continue as the reconnaissance element.

Do you want the ASM to change its location in reference to its initial position? Yes. Investigate the area. 
Roster Number 203: E-6, MOS 11B, Squad Leader, 9 years in service

As the squad leader, what actions or tasks do you do? Halt movement. Figure out who/what I plan to send on the recon.

What actions or tasks do the rest of the squad conduct (not the ASM)? Pull security. What actions or tasks do you want the ASM conduct? Send it on the recon.

What actions or tasks do you take to reorient the squad and continue the mission? Regroup and continue the mission.

What actions or tasks do you want the ASM to take to reorient and continue the mission? Follow the squad.

Do you want the ASM to change its location in reference to its initial position? No.

\section{Roster Number 204: E-6, MOS 11B, Squad Leader, 11 year in service}

As the squad leader, what actions or tasks do you do? Move forward or to the side for security.

What actions or tasks do the rest of the squad conduct (not the ASM)? Stay in place.

What actions or tasks do you want the ASM conduct? Conduct forward security. What actions or tasks do you take to reorient the squad and continue the mission? Pull 360 degree security.

What actions or tasks do you want the ASM to take to reorient and continue the mission? None.

Do you want the ASM to change its location in reference to its initial position? No.

Roster Number 205: E-6, MOS 11B, Squad Leader, 5 years in service

As the squad leader, what actions or tasks do you do? Do a map recon and take a small element ahead to recon the route.

What actions or tasks do the rest of the squad conduct (not the ASM)? Establish ORP operations and conduct 360 degree security while the team leaders inform their teams of the actions.

What actions or tasks do you want the ASM conduct? GPS and map imagery - also if available, synchronized with local unmanned aerial vehicle.

What actions or tasks do you take to reorient the squad and continue the mission? Brief team leaders of what is ahead and also if anything significant has changed. Report the new situation to higher.

What actions or tasks do you want the ASM to take to reorient and continue the mission? Send digital situation reports to higher.

Do you want the ASM to change its location in reference to its initial position? No. 
Roster Number 206: E-6, MOS 11B, Staff NCO, 17.5 years in service

As the squad leader, what actions or tasks do you do? Continue the mission.

What actions or tasks do the rest of the squad conduct (not the ASM)? Continue the mission.

What actions or tasks do you want the ASM conduct? Continue the mission.

What actions or tasks do you take to reorient the squad and continue the mission?

Continue the mission.

What actions or tasks do you want the ASM to take to reorient and continue the mission? Continue the mission.

Do you want the ASM to change its location in reference to its initial position? No.

10. Please identify the following gestures (hand and arm signals) you would commonly use in controlling the squad and ASM:

\begin{tabular}{|l|c|c|}
\hline \multicolumn{1}{|c|}{ Gesture } & Yes & No \\
\hline Move Out & 5 & 1 \\
\hline Double Time & 4 & 2 \\
\hline Enemy in sight & 4 & 2 \\
\hline Take Cover & 2 & 4 \\
\hline Wedge & 6 & 0 \\
\hline Vee & 4 & 2 \\
\hline Column & 5 & 1 \\
\hline Staggered Column & 6 & 0 \\
\hline Echelon Left & 3 & 3 \\
\hline Echelon Right & 3 & 3 \\
\hline Contact Left & 3 & 3 \\
\hline Contact Right & 3 & 3 \\
\hline NBC & 5 & 1 \\
\hline Danger Area & 5 & 1 \\
\hline Freeze & 5 & 1 \\
\hline Disperse & 1 & 5 \\
\hline Assemble & 1 & 5 \\
\hline
\end{tabular}


11. Please identify the verbal commands you would use to control the squad and the ASM:

\begin{tabular}{|l|c|c|}
\hline \multicolumn{1}{|c|}{ Phrase } & Yes & No \\
\hline Halt & 3 & 3 \\
\hline Stop & 2 & 4 \\
\hline Move & 3 & 3 \\
\hline Run & 3 & 3 \\
\hline Duck & 2 & 4 \\
\hline Other: Shut down & 1 & \\
\hline Other: Follow & 1 & \\
\hline Other: Destroy & 1 & \\
\hline Other: Status & 1 & \\
\hline Other: Move out & 1 & \\
\hline
\end{tabular}

\section{Post-mission checks:}

\begin{tabular}{|l|c|}
\hline \multicolumn{1}{|c|}{ PREFERRED METHOD } & NUMBER \\
\hline red/amber/green lights red/amber/green lights & 2 \\
\hline text message to operator/SL & 2 \\
\hline item by item checklist display & 1 \\
\hline alert signal & 0 \\
\hline $\begin{array}{l}\text { other: (describe) Should be a combination of lights and status bar with } \\
\text { an itemized list with short and long versions of the list. }\end{array}$ & 1 \\
\hline
\end{tabular}

The following questions deal with the amount of trust you have in the ASM. Consider those tasks you identify to be totally independent of human interaction - the ASM performs them "without supervision”. Trust could be defined as the confidence you have in the ASM to conduct those tasks in a safe manner that do not present any safety or mission accomplishment factors for the squad.

Assuming the ASM capabilities are accurate and reliable:

13. What tasks would you have complete trust in that the ASM could conduct to aid in the squad's mission without your supervision?

\begin{tabular}{|l|c|}
\hline \multicolumn{1}{|c|}{ TASK WITH COMPLETE TRUST } & NUMBER \\
\hline Carrying the gear. & 2 \\
\hline Surveillance. & 1 \\
\hline Identification of target locations. & 1 \\
\hline PMCS. & 1 \\
\hline Movement by itself. & 1 \\
\hline Casualty evacuation. & 2 \\
\hline Provide cover. & 1 \\
\hline Resupply food and ammunition in a forward operating base. & 1 \\
\hline None. & 1 \\
\hline
\end{tabular}


14. What tasks would you have some trust in that the ASM could conduct to aid in the squad's mission without your supervision?

\begin{tabular}{|l|c|}
\hline \multicolumn{1}{|c|}{ TASK WITH SOME TRUST } & NUMBER \\
\hline Following Soldiers. & 1 \\
\hline Sending pre-planned digital reports. & 1 \\
\hline Movement across terrain relative to the squad's location. & 1 \\
\hline Monitoring the environment. & 1 \\
\hline Reconnaissance of routes. & 2 \\
\hline Reconnaissance. & 1 \\
\hline Conduct a standard 9-line report. & 1 \\
\hline Call for fire. & 1 \\
\hline Use as retransmission communications platform. & 1 \\
\hline
\end{tabular}

15. What tasks would you have no trust in that the ASM could conduct to aid in the squad's mission without your supervision?

\begin{tabular}{|l|c|}
\hline \multicolumn{1}{|c|}{ TASK WITH NO TRUST } & NUMBER \\
\hline Firing back. & 3 \\
\hline Shoot on the move. & 1 \\
\hline Designation of enemy targets. & 1 \\
\hline Reconnaissance. & 1 \\
\hline Double time (high rate of speed/movement). & 1 \\
\hline Maintain sound discipline. & 1 \\
\hline Maintain position in formations. & 1 \\
\hline Completely moving and thinking on its own. & 2 \\
\hline $\begin{array}{l}\text { Acting autonomously - I don't care who wrote the code, your algorithms } \\
\text { didn't earn a Combat Infantryman's Badge (CIB). }\end{array}$ & 1 \\
\hline
\end{tabular}




\section{Appendix G. Interview Results: Senior Noncommissioned Officers}




\section{AUTONOMOUS SQUAD MEMBER INTERVIEW RESULTS (SENIOR NCOs)}

\section{$\mathbf{N}=\mathbf{6}$}

1. Review responses to demographics and scenario questions (look for clarification, expansion on noteworthy response, gain insight as to why, etc.)

\begin{tabular}{|l|c|}
\hline \multicolumn{1}{|c|}{ COMMENTS } & NUMBER \\
\hline Primarily position ASM in rear, but location is mission dependent. & 2 \\
\hline Maintain position by being tied to squad leader. Employ as seen fit to do. & 1 \\
\hline Keep ASM in front depending on mission and it is considered expendable. & 1 \\
\hline $\begin{array}{l}\text { ASM should be in front because of pressure plates and IEDs, it is } \\
\text { expendable. }\end{array}$ & 1 \\
\hline Lack trust in controlling ASM. & 1 \\
\hline No trust in ASM to act on its own without it being demonstrated first. & 1 \\
\hline Should do nothing on its own, only follow commands. & 2 \\
\hline Use it to provide cover to save a human, it's expendable. & 1 \\
\hline $\begin{array}{l}\text { Do not want to have to worry about the robot. Need to be able to destroy } \\
\text { robot if need be as in the case that the robot cannot continue the mission. }\end{array}$ & \\
\hline
\end{tabular}

2. What three capabilities/functions are needed for an ASM to be useful to contributing to the success of any mission, and why? Prioritize the top three.

Number 1. Capability/function:

\begin{tabular}{|l|c|}
\hline \multicolumn{1}{|c|}{ COMMENTS } & NUMBER \\
\hline Reduce Soldier load and increase mobility. & 1 \\
\hline Good power source if electric for sustained operations. & 1 \\
\hline $\begin{array}{l}\text { Maneuverability and ability to negotiate terrain because load must } \\
\text { accompany the squad. }\end{array}$ & 1 \\
\hline $\begin{array}{l}\text { Provide security for the whole squad by adding firing superiority } \\
\text { capability. }\end{array}$ & 1 \\
\hline Stealth operation without any noise and light production. & 1 \\
\hline Superior intelligence so it can follow directions to the end of the mission. & \\
\hline
\end{tabular}

Number 2. Capability/function:

\begin{tabular}{|l|c|}
\hline \multicolumn{1}{|c|}{ COMMENTS } & NUMBER \\
\hline Defeat IEDs to prevent human injuries and increase survivability. & 1 \\
\hline Route clearance and counter IED capabilities. & 1 \\
\hline Sensor(s) for battle tracking to “know and see” everything. & 1 \\
\hline Durability in order to be reliable enough to complete the mission. & 1 \\
\hline $\begin{array}{l}\text { Reliability and it must be self-sufficient - it can’t hinder the squad or have } \\
\text { any effect on the squad. }\end{array}$ & 1 \\
\hline $\begin{array}{l}\text { Maneuverability with adequate speed to negotiate terrain, walls, slopes etc. } \\
\text { without tipping over due to a high center of gravity. }\end{array}$ & \\
\hline
\end{tabular}


Number 3. Capability/function:

\begin{tabular}{|l|c|}
\hline \multicolumn{1}{|c|}{ COMMENTS } & NUMBER \\
\hline Identify target location and distance to target. & 1 \\
\hline Sensor or camera for reconnaissance. & 1 \\
\hline Load bearing to reduce Soldier load. & 1 \\
\hline Provide counter-fire with location and distance to source. & 1 \\
\hline $\begin{array}{l}\text { Increased lethality with ability to shoot with operator in control via a } \\
\text { handheld controller. }\end{array}$ & 1 \\
\hline $\begin{array}{l}\text { Durability to withstand the environmental elements with capability to } \\
\text { climb or negotiate terrain and obstacles. }\end{array}$ & 1 \\
\hline
\end{tabular}

1. What three capabilities/functions are "nice to have" for an ASM to be useful to contributing to the success of any mission, and why? Prioritize the top three.

Number 1. Capability/function:

\begin{tabular}{|l|c|}
\hline \multicolumn{1}{|c|}{ COMMENTS } & NUMBER \\
\hline AC outlets to power other squad items. & 1 \\
\hline Load a person autonomously. & 1 \\
\hline FBCB2. & 1 \\
\hline $\begin{array}{l}\text { Weapon ammunition compartments and medical supplies storage. } \\
\text { Digital communications to send preplanned reports that can be quickly } \\
\text { altered or changed. }\end{array}$ & 1 \\
\hline $\begin{array}{l}\text { Acoustic, shot detection, and NBC sensor packages to report real world } \\
\text { status at any time. }\end{array}$ & 1 \\
\hline
\end{tabular}

Number 2. Capability/function:

\begin{tabular}{|l|c|}
\hline \multicolumn{1}{|c|}{ COMMENTS } & NUMBER \\
\hline Litter capability. & 1 \\
\hline On board weapon system. & 1 \\
\hline Tracking device to find it and to use for other squad member locations. & 1 \\
\hline Tracker and GPS to navigate route successfully. & 1 \\
\hline $\begin{array}{l}\text { Multiple language translation capability - speak in English and robot } \\
\text { translates. }\end{array}$ & 1 \\
\hline $\begin{array}{l}\text { Recharging station for radios in order to maintain power and } \\
\text { communications. }\end{array}$ & 1 \\
\hline
\end{tabular}


Number 3. Capability/function:

\begin{tabular}{|l|c|}
\hline \multicolumn{1}{|c|}{ COMMENTS } & NUMBER \\
\hline Armor for protection and survivability. & 1 \\
\hline $\begin{array}{l}\text { Act as a virtual lieutenant - automatic communications, reports, and status } \\
\text { of squad. }\end{array}$ & 1 \\
\hline External battery or fuel cell for sustained power. & 1 \\
\hline $\begin{array}{l}\text { Alternate power source with self-maintenance to prevent having to be } \\
\text { plugged in for its own power recharging. }\end{array}$ & 1 \\
\hline Ability to recover itself and other vehicles. & 1 \\
\hline $\begin{array}{l}\text { Load carrying to reduce Soldier load. Needs to be reliable and easy to } \\
\text { maintain. }\end{array}$ & 1 \\
\hline
\end{tabular}

1. If you were to conduct a different mission, other than route reconnaissance, what would need to be changed for/on the ASM for that type of mission?

\begin{tabular}{|l|c|}
\hline \multicolumn{1}{|c|}{ COMMENTS } & NUMBER \\
\hline Nothing - should be universal for any mission. & 2 \\
\hline Nothing - should be plug and play for tailored mission support. & 1 \\
\hline Add target designation capability. & 1 \\
\hline $\begin{array}{l}\text { Weapon systems and cameras for real time feedback and target } \\
\text { engagements. }\end{array}$ & 1 \\
\hline $\begin{array}{l}\text { In rough terrain, the ASM should be able to survey the land, identify } \\
\text { obstacles, and plan a route around them while still moving to the waypoint. }\end{array}$ & 1 \\
\hline Thermal capability to detect heat signatures when in an overwatch mission. & 1 \\
\hline
\end{tabular}

5. If you were to conduct a night mission what would need to be changed for/on the ASM for that type of mission?

\begin{tabular}{|l|c|}
\hline \multicolumn{1}{|c|}{ COMMENTS } & NUMBER \\
\hline Infrared sensor and visual display. & 3 \\
\hline Infrared floodlights. & 1 \\
\hline Neon lights for ease of identifying its position. & 1 \\
\hline Ability to operate while observing noise and light discipline requirements. & 1 \\
\hline $\begin{array}{l}\text { Covert control with handheld easy and simple to use controller to eliminate } \\
\text { any yelling. }\end{array}$ & 1 \\
\hline Nothing - should already be on it. & 1 \\
\hline
\end{tabular}


6. Is the ASM a good idea? What makes it critical for mission success?

\begin{tabular}{|c|c|}
\hline Yes & No \\
\hline 1 & 5 \\
\hline
\end{tabular}

\begin{tabular}{|l|c|}
\hline \multicolumn{1}{|c|}{ COMMENTS } & NUMBER \\
\hline No - automation is not a good idea. & 1 \\
\hline No - cannot do anything on its own without being told to do it. & 1 \\
\hline No - I don't trust it because you can't get feedback as with a human. & 1 \\
\hline $\begin{array}{l}\text { No - not trustworthy. It could potentially cause problems, breakdown, and } \\
\text { not be safe. It is another thing to worry about and takes the operator out of } \\
\text { the fight while controlling the robot. ASM needs to be a battalion asset } \\
\text { with handler so it doesn't take a squad member out of the fight. }\end{array}$ & 1 \\
\hline Yes - it is an OK idea. & 1 \\
\hline
\end{tabular}

7. What is the best way to command and control the ASM?

\begin{tabular}{|l|c|}
\hline \multicolumn{1}{|c|}{ COMMAND METHOD } & NUMBER \\
\hline dedicated operator & 5 \\
\hline Other: verbal command plus dedicated operator & 1 \\
\hline General Comments & NUMBER \\
\hline $\begin{array}{l}\text { An instrumented glove would be better than a camera for } \\
\text { control. }\end{array}$ & 1 \\
\hline $\begin{array}{l}\text { It should be untethered with safety kill switches as a backup } \\
\text { in case it starts to do crazy things on its own. }\end{array}$ & 1 \\
\hline
\end{tabular}

8. What is the best way for the ASM to acknowledge receipt of the command?

\begin{tabular}{|l|c|}
\hline \multicolumn{1}{|c|}{ COMMAND METHOD } & NUMBER \\
\hline text message & 2 \\
\hline Other: & 4 \\
\hline
\end{tabular}

\begin{tabular}{|l|c|}
\hline \multicolumn{1}{|c|}{ COMMENTS } & NUMBER \\
\hline $\begin{array}{l}\text { Other }- \text { it depends on the environment. A screen display for the designated } \\
\text { operator that must be night vision device sensitive (compatible). }\end{array}$ & 1 \\
\hline Other - mission dependent. Day could be verbal but night requires stealth. & 1 \\
\hline Other - just do it. & 2 \\
\hline
\end{tabular}


9. What knowledge does the ASM need to have learned in order to perform required tasks and tools/sensors does it need to perform those tasks?

\begin{tabular}{|l|c|}
\hline \multicolumn{1}{|c|}{ COMMENTS } & NUMBER \\
\hline Unit standing operating procedures (SOP). & 1 \\
\hline Battle drills with automatic responses based on the particular battle drill. & 1 \\
\hline $\begin{array}{l}\text { Basic team and squad formations, what distances to maintain in formation } \\
\text { based on terrain. }\end{array}$ & 2 \\
\hline $\begin{array}{l}\text { Basic soldiering skills. How to follow an operations order and execute } \\
\text { commands. It needs to harvest its own energy. }\end{array}$ & 1 \\
\hline Needs to know when Soldier is in the prone position. & 1 \\
\hline $\begin{array}{l}\text { Needs to keep a safe distance from other Soldiers via Blue Force Tracker } \\
\text { (BFT). }\end{array}$ & 1 \\
\hline $\begin{array}{l}\text { Needs to be able to send and receive digital reports, situation reports, etc. } \\
\text { and when to ask for help. }\end{array}$ & 1 \\
\hline Deploy rounds under human control. & \\
\hline
\end{tabular}

10. What is the source of your personal knowledge to conduct tactical missions - how did you learn the procedures or actions to take?

\begin{tabular}{|l|c|}
\hline \multicolumn{1}{|c|}{ SOURCE } & NUMBER \\
\hline School & 1 \\
\hline OJT & 3 \\
\hline Unit Training & 1 \\
\hline Other: school and OJT & 1 \\
\hline Other: combat. & 1 \\
\hline
\end{tabular}

11. Do you want the ASM to remind you about the next mission objective if you don't immediately remember what it is or know how to get there?

\begin{tabular}{|c|c|}
\hline Yes & No \\
\hline 4 & 2 \\
\hline
\end{tabular}

\begin{tabular}{|l|c|}
\hline \multicolumn{1}{|c|}{ COMMENTS } & NUMBER \\
\hline After bullets are fired, everything can change. & 1 \\
\hline In the heat of the battle it could be an aid to the squad leader. & 1 \\
\hline
\end{tabular}

(11. Follow-up) Do you want the ASM to inform you of status of reaching phase lines, LD, objective, etc. on time?

\begin{tabular}{|c|c|}
\hline Yes & No \\
\hline 6 & 0 \\
\hline
\end{tabular}




\begin{tabular}{|l|c|}
\hline \multicolumn{1}{|c|}{ COMMENTS } & NUMBER \\
\hline Phase lines - yes, objectives - no. & 1 \\
\hline Should be a text message notification to the operator. & 1 \\
\hline
\end{tabular}

12. When you have been on patrol or operating potentially dangerous equipment, have you ever been interrupted at a bad time? If yes, what bad consequences occurred or nearly occurred as a result of that interruption?

\begin{tabular}{|c|c|}
\hline Yes & No \\
\hline 2 & 4 \\
\hline
\end{tabular}

\begin{tabular}{|l|c|}
\hline \multicolumn{1}{|c|}{ COMMENTS } & NUMBER \\
\hline $\begin{array}{l}\text { Kids and civilian leaders can distract the mission - they will want to touch } \\
\text { the robot, throw rocks, and try to steal items off the equipment. }\end{array}$ & 1 \\
\hline Getting hit on a mission in a fire-fight. & 1 \\
\hline
\end{tabular}

If a bad outcome was avoided, how?

\begin{tabular}{|l|c|}
\hline \multicolumn{1}{|c|}{ COMMENTS } & NUMBER \\
\hline $\begin{array}{l}\text { Telling the leaders to clear out. Dogs can be a real problem because they } \\
\text { are not controlled by anyone. But dogs are likely to bark at the robot. } \\
\text { Killing the dog solves the problem. }\end{array}$ & 1 \\
\hline Fought through it. & 1 \\
\hline
\end{tabular}

Did a teammate or other person step in to help?

\begin{tabular}{|c|c|}
\hline Yes & No \\
\hline 2 & 0 \\
\hline
\end{tabular}

\begin{tabular}{|l|c|}
\hline \multicolumn{1}{|c|}{ COMMENTS } & NUMBER \\
\hline $\begin{array}{l}\text { Other Soldiers depending on the situation. Sometimes being nice to the } \\
\text { civilians unless they are trying to steal another Soldier's gear. }\end{array}$ & 1 \\
\hline Entire squad was involved. & 1 \\
\hline
\end{tabular}

13. If so, what did the other person do that was particularly helpful?

\begin{tabular}{|l|c|}
\hline \multicolumn{1}{|c|}{ COMMENTS } & NUMBER \\
\hline Help control the situation. & 1 \\
\hline Provide suppressive fire, attacked the enemy, and secured the location. & 1 \\
\hline
\end{tabular}




\section{EXPLORATORY QUESTIONS}

(for possible modeling of future capabilities/excursions)

14. Should the ASM have a weapons platform on it? (caliber, manual or remote controlled, autonomous vs. human interaction, basic load quantity, etc).

\begin{tabular}{|c|c|}
\hline Yes & No \\
\hline 5 & 1 \\
\hline
\end{tabular}

\begin{tabular}{|l|c|c|}
\hline \multicolumn{1}{|c|}{ CAPABILITY } & YES & NO \\
\hline Autonomous engagements & 1 & \\
\hline Human interface engagements & 4 & \\
\hline Manned gun control & 2 & \\
\hline Remote gun control & 1 & \\
\hline Both - manual and remote control. & 1 & \\
\hline
\end{tabular}

\begin{tabular}{|l|c|}
\hline \multicolumn{1}{|c|}{ COMMENTS } & NUMBER \\
\hline Caliber & 1 \\
\hline $7.62 \mathrm{~mm}$ & 2 \\
\hline $.50 \mathrm{caliber}$ & 1 \\
\hline $25 \mathrm{~mm}$ & 1 \\
\hline Multi-caliber small arms. & 1 \\
\hline \multicolumn{2}{|c|}{} \\
\hline Basic Load & 1 \\
\hline 2000 rounds & 1 \\
\hline 50000 rounds for all weapon systems combined & 1 \\
\hline 2000 M249 rounds, 2400 M240 and .50 cal rounds. & 1 \\
\hline Depends on the mission and what the ASM can load/store on it. \\
\hline $\begin{array}{l}\text { Weapon system basic load according to the technical manual for the } \\
\text { system. }\end{array}$ \\
\hline \multicolumn{2}{|c|}{} \\
\hline General comments & 1 \\
\hline $\begin{array}{l}\text { The ASM should find and track targets but not shoot on its own. Could } \\
\text { pull a trailer for extra ammunition. }\end{array}$ & 1 \\
\hline $\begin{array}{l}\text { Autonomous engagements with a required fail-safe device for crew served } \\
\text { weapons. }\end{array}$ & \\
\hline
\end{tabular}


15. Should the ASM be able to be configured for CASEVAC? (How long to configure - if not permanently configured, how many Soldiers evacuated, autonomous movement to CCP, armor protection, etc.)

\begin{tabular}{|c|c|}
\hline Yes & No \\
\hline 6 & 0 \\
\hline
\end{tabular}

\begin{tabular}{|l|c|c|}
\hline \multicolumn{1}{|c|}{ CAPABILITY } & YES & NO \\
\hline Autonomous Movement & 3 & 3 \\
\hline Armored & 5 & 1 \\
\hline
\end{tabular}

\begin{tabular}{|l|c|}
\hline \multicolumn{1}{|c|}{ COMMENTS } & NUMBER \\
\hline How long to configure litter support system & 1 \\
\hline Less than 60 seconds. & 3 \\
\hline Less than 90 seconds. & 2 \\
\hline Less than 5 minutes. & 1 \\
\hline \multicolumn{2}{|c|}{} \\
\hline Number of casualties to transport & 3 \\
\hline 1 & 1 \\
\hline 2 & 1 \\
\hline $2-3$ & \\
\hline 5 & 2 \\
\hline General Comments & 1 \\
\hline Should be escorted if transporting casualties. & 1 \\
\hline Prefer to be able to reconfigure it for at least one. & 1 \\
\hline Tow the SKED litter rather than putting a Soldier on/in the ASM. \\
\hline If armored, it would be harder to destroy ASM if needed to do so. \\
\hline
\end{tabular}

16. Should the ASM have smoke grenade dispensers or smoke generator? (preferred equipment, duration, distance of employment, wind sensing capability)

\begin{tabular}{|c|c|}
\hline Yes & No \\
\hline 6 & 0 \\
\hline
\end{tabular}

\begin{tabular}{|l|c|c|}
\hline CAPABILITY & YES & NO \\
\hline Dispenser & 2 & \\
\hline Generator & 4 & \\
\hline Wind Sensing & 4 & 2 \\
\hline
\end{tabular}

\begin{tabular}{|l|l|} 
COMMENTS & NUMBER \\
\hline
\end{tabular}

\section{Length of smoke Generation}

\begin{tabular}{|l|l|}
\hline 5 minutes & 1 \\
\hline $5-10$ minutes & 1 \\
\hline ASM should be able to determine this on its own. & 1 \\
\hline
\end{tabular}




\begin{tabular}{|l|c|}
\hline Should be able to control the on/off function of the smoke. & 2 \\
\hline $\begin{array}{l}\text { Depends on how long it takes to move to the next covered and concealed } \\
\text { position. }\end{array}$ & 1 \\
\hline & 2 \\
\hline Distance to Employ Screen & 4 \\
\hline 35 meters & \\
\hline 50 meters & 1 \\
\hline General Comments & 1 \\
\hline Needs to provide 180-degree coverage for squad and ASM. & \\
\hline This capability should not be autonomous. &
\end{tabular}

17. Should the ASM have chemical detection sensors/alarms? If yes, why/for what reasons/missions? (contaminated area avoidance, attacks, etc.)

\begin{tabular}{|c|c|}
\hline Yes & No \\
\hline 5 & 1 \\
\hline
\end{tabular}

\begin{tabular}{|l|c|}
\hline \multicolumn{1}{|c|}{ COMMENTS } & NUMBER \\
\hline Would reduce Soldier tasks. & 2 \\
\hline $\begin{array}{l}\text { It could report status if it were forward of squad and provide real time } \\
\text { report while accompanying the squad. }\end{array}$ & 1 \\
\hline Great asset to have. & 1 \\
\hline Provide real time alerts. & 1 \\
\hline $\begin{array}{l}\text { It is a rare event but why not. Soldiers have detection tape for that } \\
\text { purpose. }\end{array}$ & 1 \\
\hline
\end{tabular}


18. Should the ASM have target detection capability? (distance, human or vehicle, location (azimuth and distance), track targets after detection)

\begin{tabular}{|c|c|}
\hline Yes & No \\
\hline 5 & 1 \\
\hline
\end{tabular}

\begin{tabular}{|l|c|c|}
\hline \multicolumn{1}{|c|}{ CAPABILITY } & YES & NO \\
\hline Human targets & 5 & 0 \\
\hline Vehicle targets & 5 & 0 \\
\hline Azimuth to target & 5 & 0 \\
\hline Distance to target & 5 & 0 \\
\hline Track targets & 5 & 0 \\
\hline
\end{tabular}

\begin{tabular}{|l|c|}
\hline \multicolumn{1}{|c|}{ COMMENTS } & NUMBER \\
\hline 800 meters & 1 \\
\hline $800-1000$ meters & 1 \\
\hline 1000 meters & 1 \\
\hline 1500 meters & 1 \\
\hline 2000 meters & 1 \\
\hline \multicolumn{2}{|c|}{} \\
\hline General Comments & 1 \\
\hline It should not track any targets out of range of the weapon systems. & 1 \\
\hline It should have facial recognition. & 1 \\
\hline It should have real time imagery. & 1 \\
\hline No - should not be used for weapons because of false reads, etc. & \\
\hline
\end{tabular}

19. Should the ASM have shot detection capability? (location, distance, azimuth, caliber)

\begin{tabular}{|c|c|}
\hline Yes & No \\
\hline 6 & 0 \\
\hline
\end{tabular}

\begin{tabular}{|l|c|c|}
\hline \multicolumn{1}{|c|}{ CAPABILITY } & YES & NO \\
\hline Location of shooter & 6 & 0 \\
\hline Distance to shooter & 6 & 0 \\
\hline Azimuth to shooter & 6 & 0 \\
\hline Caliber of weapon fired & 6 & 0 \\
\hline
\end{tabular}

\section{COMMENTS}

Sensor system needs to very reliable.

Should be on all the time and send alerts when something is detected.

Should provide an option for engagement of what was detected.

NUMBER

\begin{tabular}{l|}
1 \\
1 \\
\hline
\end{tabular}


20. Should the ASM camera sensors be mounted on an extendable/collapsible mast? (height of operation, day/night/IR, etc.)

\begin{tabular}{|c|c|}
\hline Yes & No \\
\hline 5 & 1 \\
\hline
\end{tabular}

\begin{tabular}{|l|c|c|}
\hline \multicolumn{1}{|c|}{ SENSOR } & Yes & No \\
\hline Day/Night & 5 & 0 \\
\hline IR & 5 & 0 \\
\hline
\end{tabular}

\begin{tabular}{|c|c|}
\hline COMMENTS & NUMBER \\
\hline \multicolumn{2}{|l|}{ HEIGHT NEEDED } \\
\hline 6 feet & 1 \\
\hline 10 feet & 1 \\
\hline 16 feet & 2 \\
\hline 20 feet & 1 \\
\hline \multicolumn{2}{|l|}{ General Comments } \\
\hline Needs to have facial recognition capability. & 1 \\
\hline Needs a less than lethal engagement system (e.g., dazzler). & 1 \\
\hline
\end{tabular}

21. Should the ASM have a loading arm or retrieval arm for loading/unloading equipment or "snagging" a casualty to move to safe area?

\begin{tabular}{|c|c|}
\hline Yes & No \\
\hline 1 & 5 \\
\hline
\end{tabular}

\begin{tabular}{|l|c|c|}
\hline \multicolumn{1}{|c|}{ TASK } & YES & NO \\
\hline Loading/unloading equipment & 1 & 5 \\
\hline Casualty Aid & 0 & 6 \\
\hline
\end{tabular}

\begin{tabular}{|l|c|}
\hline \multicolumn{1}{|c|}{ COMMENTS } & NUMBER \\
\hline The problem would be in how to control it. & 1 \\
\hline This would be a time consuming task for the ASM. & 1 \\
\hline Not careful enough to handle a wounded person. & 1 \\
\hline
\end{tabular}


22. What should be the procedure for conveying the mission to the ASM?

\begin{tabular}{|l|c|}
\hline \multicolumn{1}{|c|}{ COMMENTS } & NUMBER \\
\hline Use of blue force tracker. Keyboard for input. & 4 \\
\hline Via an operator by voice (requires voice recognition) or a text message. & 1 \\
\hline $\begin{array}{l}\text { Pre-mission checklist in tablet form with different mission sets. It should } \\
\text { have basic battle drills knowledge. It should know the differences between } \\
\text { regular and combat patrols. }\end{array}$ & 1 \\
\hline
\end{tabular}

23. What other mission-related or task-related items are needed or should be considered that were not discussed?

\begin{tabular}{|l|c|}
\hline \multicolumn{1}{|c|}{ COMMENTS } & NUMBER \\
\hline Water purification system. & 1 \\
\hline Needs to be 100\% reliable at all times. & 1 \\
\hline Both a wheeled and tracked operation. & 1 \\
\hline Be able to ford 4-5 feet of water. & 1 \\
\hline Medical supplies. & 1 \\
\hline $\begin{array}{l}\text { FOB security - run resupply on its own but act and engage targets upon a } \\
\text { detection. }\end{array}$ & 1 \\
\hline Other equipment such as ladders etc. & 1 \\
\hline Extrication tools to aid other Soldiers trapped in a vehicle. & 1 \\
\hline Breaching equipment. & 1 \\
\hline It should understand sectors of fire. & 1 \\
\hline Report and contamination from overhead rockets. & 1 \\
\hline It should be independent and maintain itself. & \\
\hline
\end{tabular}




\section{OTHER POTENTIAL CONSIDERATIONS}

24. Along the lines of other mission-related or task-related items needed:

- A. Should the ASM have a manual backup for command and control? Why?

\begin{tabular}{|c|c|}
\hline Yes & No \\
\hline 6 & 0 \\
\hline
\end{tabular}

\begin{tabular}{|l|c|}
\hline \multicolumn{1}{|c|}{ COMMENTS } & NUMBER \\
\hline Needs to be fail safe. & 2 \\
\hline Anything needs a backup. & 2 \\
\hline It could break. & 1 \\
\hline Should only be controlled manually. & 1 \\
\hline
\end{tabular}

- B. Should the ASM have a battery charger integrated to charge squad's batteries?

\begin{tabular}{|c|c|}
\hline Yes & No \\
\hline 6 & 0 \\
\hline
\end{tabular}

\begin{tabular}{|l|c|}
\hline \multicolumn{1}{|c|}{ COMMENTS } & NUMBER \\
\hline Universal battery charger. & 1 \\
\hline All squad batteries. & 3 \\
\hline Radio batteries. & 1 \\
\hline As long as it does not hinder ASM mission. & 1 \\
\hline
\end{tabular}

- C. Should the ASM have run-flat tires.

\begin{tabular}{|c|c|}
\hline Yes & No \\
\hline 6 & 0 \\
\hline
\end{tabular}

\begin{tabular}{|l|c|}
\hline \multicolumn{1}{|c|}{ COMMENTS } & NUMBER \\
\hline Needs good maneuverability and should not have to be recovered. & 2 \\
\hline Needs to be part of mission on continuing basis. & 2 \\
\hline Also needs a pressurization/depressurized system capability. & 1 \\
\hline
\end{tabular}

- D. Should the ASM have a map display that allows programming of way points/routes, CCP, phase lines, objective, etc.?

\begin{tabular}{|c|c|}
\hline Yes & No \\
\hline 5 & 1 \\
\hline
\end{tabular}


- E. Should the ASM be air-transportable by helicopter?

\begin{tabular}{|c|c|}
\hline Yes & No \\
\hline 6 & 0 \\
\hline
\end{tabular}

\begin{tabular}{|l|c|}
\hline \multicolumn{1}{|c|}{ COMMENTS } & NUMBER \\
\hline Needs to be as portable as the squad. & 1 \\
\hline Needed for mission if it is to be an asset - accompanies squad. & 3 \\
\hline Should also provide recovery options by helicopter. & 2 \\
\hline Helicopters are not going to come out to rescue a robot. & 1 \\
\hline Needs to be easy to transport. & 1 \\
\hline
\end{tabular}

- F. Should the ASM have a run-silent mode of operation?

\begin{tabular}{|c|c|}
\hline Yes & No \\
\hline 6 & 0 \\
\hline
\end{tabular}

\section{COMMENTS}

NUMBER

Tactical situation may dictate noise and light discipline measures are needed.

It should always be silent as the only mode of operation.

- G. Should the ASM have voice recognition? (all squad members vs. selected)

\begin{tabular}{|c|c|}
\hline Yes & No \\
\hline 4 & 2 \\
\hline
\end{tabular}

\begin{tabular}{|c|c|}
\hline ALL & SELECTED \\
\hline 0 & 4 \\
\hline
\end{tabular}

\section{COMMENTS}

NUMBER

Needed for reconnaissance - not for its own command, but to detect enemy based on hearing and understanding language.

Should recognize squad and team leaders.

Should recognize squad leader and whoever the squad leader designates.

No - could be a security problem.

- H. Should the ASM have multilingual voice recognition? (translation capability)

\begin{tabular}{|c|c|}
\hline Yes & No \\
\hline 2 & 4 \\
\hline
\end{tabular}

\section{COMMENTS}

NUMBER

It could provide intelligence on what the locals are conversing about. 
INTENTIONALLY LEFT BLANK. 


\section{List of Symbols, Abbreviations, and Acronyms}

\begin{tabular}{ll}
\hline ASM & autonomous squad member \\
IED & improved explosive device \\
IR & infrared \\
MOS & military occupational specialties \\
NBC & nuclear, biological, and chemical \\
NCO & noncommissioned officer \\
OJT & on-the-job training \\
SL & squad leader \\
SP & starting point
\end{tabular}




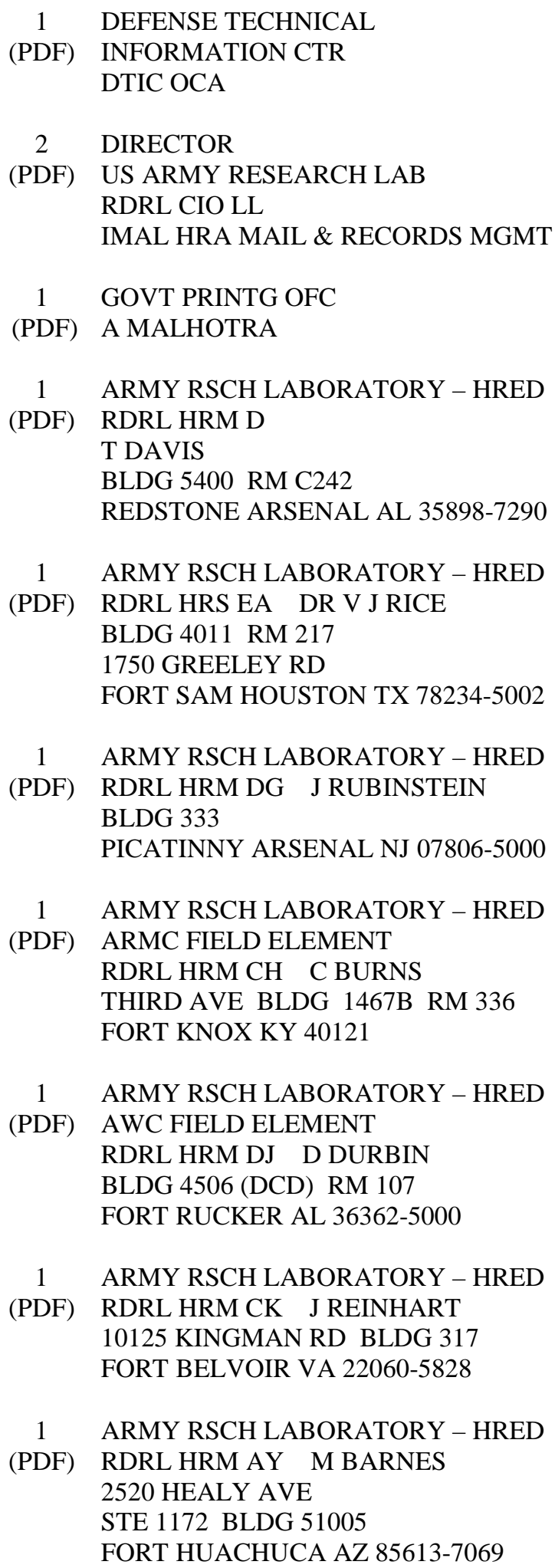

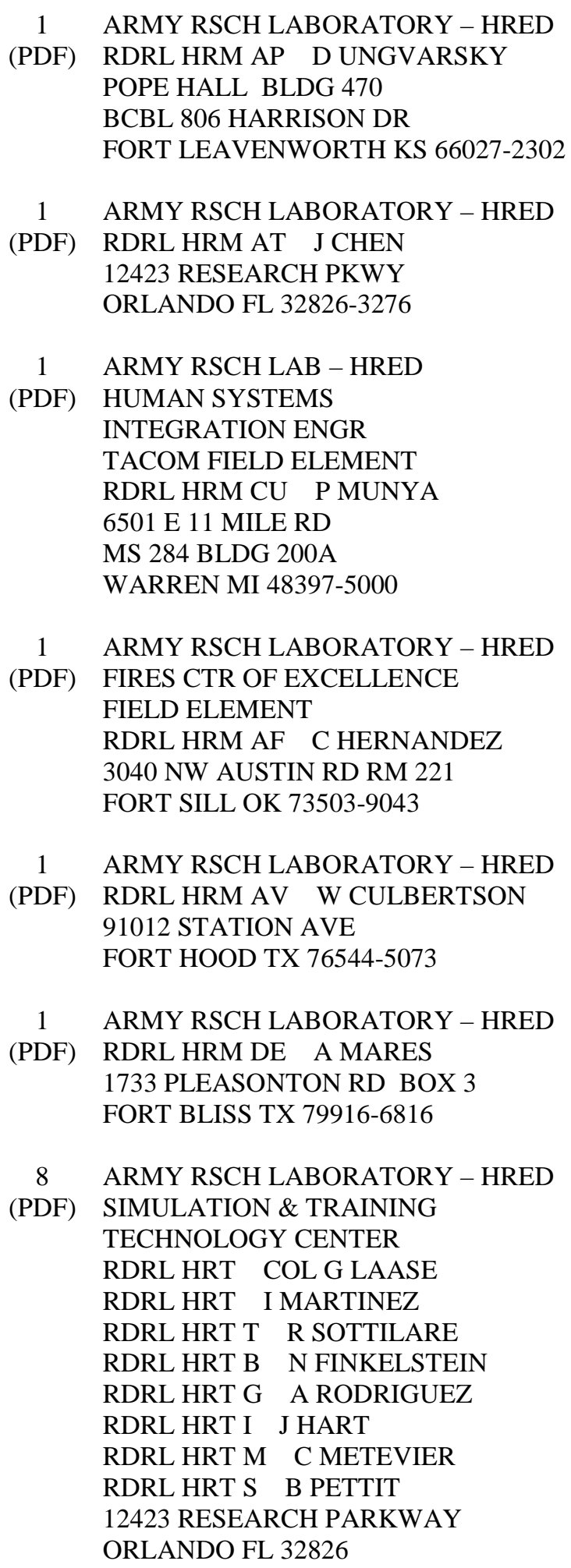




$\begin{array}{cl}11 & \text { ARMY RSCH LABORATORY - HRED } \\ \text { (PDF) } & \text { HQ USASOC } \\ & \text { RDRL HRM CN R SPENCER } \\ & \text { BLDG E2929 DESERT STORM DRIVE } \\ & \text { FORT BRAGG NC } 28310 \\ 1 & \\ \text { (PDF) } & \text { ARMY G1 } \\ & \text { DAPE MR B KNAPP } \\ & \text { WASHINGTON DC 20310-0300 } \\ & \\ \text { ABERDEEN PROVING GROUND } \\ \text { 12 } \\ \text { DIR USARL } \\ \text { RDRL HR } \\ \text { L ALLENDER } \\ \text { P FRANASZCZUK } \\ \text { RDRL HRM } \\ \text { P SAVAGE-KNEPSHIELD } \\ \text { RDRL HRM AL } \\ \text { C PAULILLO } \\ \text { RDRL HRM DW } \\ \text { L ELLIOTT } \\ \text { RDRL HRM B } \\ \text { J GRYNOVICKI } \\ \text { RDRL HRM C } \\ \text { L GARRETT } \\ \text { RDRL HRS } \\ \text { J LOCKETT } \\ \text { RDRL HRS B } \\ \text { M LAFIANDRA } \\ \text { RDRL HRS C } \\ \text { K MCDOWELL } \\ \text { RDRL HRS D } \\ \text { A SCHARINE } \\ \text { RDRL HRS E } \\ \text { D HEADLEY } \\ \end{array}$


INTENTIONALLY LEFT BLANK. 